\title{
Patterns of connectivity and isolation in marine populations
}

\section{Pelayo Salinas de León}

\author{
A thesis submitted to \\ Victoria University of Wellington \\ in fulfillment of the requirements for the degree of \\ Doctor of Philosophy in Marine Biology
}

2010

VICTORIA UNIVERSITY OF WELLINGTON

Te Whare Wānanga o te Ūpoko o te Ika a Māui

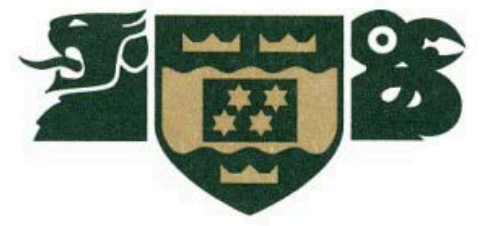


Dedicated to Isabel Castro Moreno:

te echaré de menos abuela. 
This thesis was conducted under the supervision of:

Dr James J Bell (Primary supervisor)

Victoria University of Wellington

Wellington, New Zealand

and

Dr David J Smith

University of Essex

Essex, United Kingdon 


\section{Acknowledgements}

Ever since I was a little boy I wanted to become a Jedi in marine biology and now, approaching the end of a long road there are many people that are in some part, responsible for the creation of this thesis.

The two people that I am most grateful to are my parents: Alicia and Antonio (aka the Salinas de Leon foundation). Without their love, support and encouragement I would never have got this far: Os quiero!

Another person that I am deeply grateful is my mentor and friend James. I am deeply grateful for his constant guidance and help and also the great times we spent during field work in Indonesia and New Zealand. His constant support during the past three years has been priceless! I am also indebted to Claire and Buffy for their love and hospitality. Love you long time!

Albita: You have been a guiding light and constant support during these past years and I will always remember your love and support during our time in New Zealand and Indonesia. Te quiero!

During my $\mathrm{PhD}$ life I have shared great experiences and made great friends for life including my beloved flatmate and genuine seal clubber from South Park, Novia Scotia: Tyler Kent Eddy. Our great Milford Track partners, the marrino Mexicans: Benja el joto and esponjita Ale. The Mapuche-Pichipes: Erasmo Edmondo, Mari Tekilawoman, Claudio el Cabezon, Enrique el Insecto, Alejandro el Pulpito, Cizar el Africano, Dani Daniela, Queco Rompecamisetas and Mama Andrea; The squareheads Felipa Ken, Kartoffel Katrin, Katja 1-0, Crying Jan, Pinche Cesc Fabregas and Marica Mareike; The only frenchie, Petit-Cochon Mati; The English lot: Gareth el pelirriojo, Sonia Saborabo Anna banana and Abi Spaghetti; The Kiwi Brus: Out of focus Will, Marica Mike and Pinche Bruce; The Gringo frijolero pinche fluke. To all of you: thanks for some of the best moments of my life!

Over the past years in New Zealand I have enjoyed the delightful Kiwi hospitality, discovered the most amazing place on earth and made many Kiwi friends. Of special mention are Mama Sue and Miguelito for their Sunday roast and all their love and help and my good friend Sindy for his continous mechanical help with Curreta and his friendship. 
During this thesis I have spent long periods of time conducting fieldwork in Indonesia, where I have enjoyed amazing moments and met great people! I am grateful to my second supervisor Dr David J Smith and Operation Wallacea for their guidance and support. Thanks to my friends Arif; Jufri; Ludy; Magliani and all the kitchen ladies; Adrian, Asri and all the Alam staff; Ilu; Adde and all the boat guys. I miss you all! I am very grateful to all Opwall staff, especially John, Phil, Pippa and Mr Mafia Acho. Thanks to the Opwall Science team for all the great moments: Ian, Joce, Sebcong, Matt, Joel, Leanne, Gabby, Sonia, Bridget, Jade, Abi, Bencong, and all the helping volunteers, especially Charlie and Stephen.

Many people have provided assistance in New Zealand. I am grateful to all the VUW technical staff, specially to Snout, John Van der Sman, Neville, and.... James Allen, nooot! Many thanks to Mike Aviss, Andrew Baxter and the Long Island Marine Reserve committee for their assistance. I am greatly grateful to the larvae army of monkeys for their assistance: Laura, Candice and Amanda!

Special thanks to Pinche Mary for her good humour, friendship and help over my time at SBS! I am also grateful to Patricia, Sandra, Paul and the other SBS staff. Thanks to Nicola and Sue for the great times during the field trips and for saving me from the appendicitis!

I am deeply grateful to all the funding agencies that have made this research possible: the Salinas de Leon foundation, VUW PhD Scholarship, Operation Wallacea, VUW Faculty Grant, Ian Swingland Scholarship, CMEER travel grant, NZ Educated Study Abroad Scholarship, NZMSS First conference overseas funding and 3M New Zealand.

Finally, thanks to Andres Iniesta for some unforgettable moments! 


\section{General abstract}

There is ongoing debate about the levels of connectivity among marine populations and despite its importance, there is limited information on the levels of population connectivity in most geographic locations. This lack of information severely limits our ability to adequately manage the marine environment including the design and implementation of Marine Reserve (MRs) networks. The specific objectives of this thesis were to: 1) Develop polymorphic microsatellite loci for my model species, the intertidal gastropod Austrolittorina cincta; 2) Conduct population genetic studies across A.cincta populations within the Cook strait region to asses the levels of connectivity within the regional marine reserve network; 3) Determine the levels of A. cincta larval movement and settlement from an isolated source; and 4) Asses the effect of the larval abundance on settlement rates. This thesis includes laboratory studies; population genetic studies; and field surveys within New Zealand and in the Wakatobi National Park, Indonesia. Eight novel polymorphic microsatellite loci were developed for $A$. cincta and five of these loci were used to investigate population connectivity across seven populations within the Cook Strait region, including four marine reserves. In the population genetics study, in contrast to what was expected, I recorded low, but significant genetic differentiation between most population pairs within the Cook Strait region, over a minimum and maximum spatial scale of 55 to $300 \mathrm{~km}$, including several of the MRs. In a large-scale field settlement survey on the Kapiti coast combined with the use of microsatellite markers I investigated A. cincta larval movement and settlement and found that most larvae settle within $5 \mathrm{~km}$, although some larvae might travel up to $50 \mathrm{~km}$. Finally, the coral settlement studies in the Wakatobi National Park revealed lower coral settlement rates at sites with low 
adult coral cover, suggesting an effect of the the amount of local available larvae on coral settlement rates.

While it has been suggested that marine populations are demographically open, with larvae connecting populations separated over large spatial scales, this thesis shows that populations might not be as open as previously considered and localized dispersal and self-recruitment processes might be a frequent feature in marine populations. This thesis provides valuable information to managers about marine reserve networks and the importance of adequate environmental protection to ensure future viable populations. 


\section{Table of Contents}

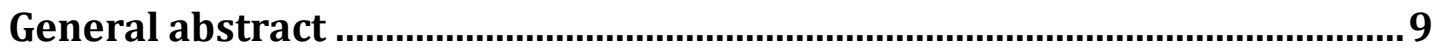

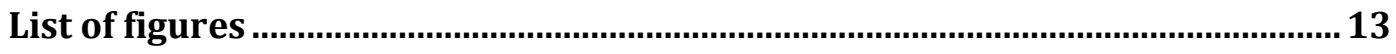

Chapter 1. General introduction ............................................................. 17

1.1. Measuring dispersal.................................................................................... 18

1.2. Use of microsatellite markers to study Marine Reserves connectivity in

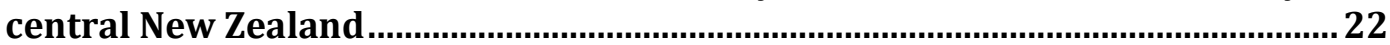

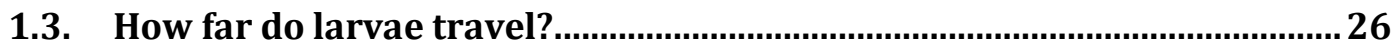

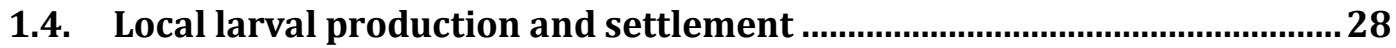

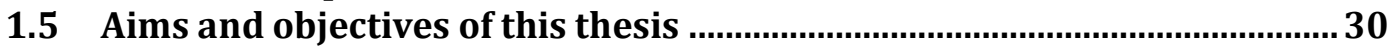

Chapter 2. Isolation and characterization of polymorphic microsatellite for the New Zealand endemic brown periwinkle Austrolittorina cincta

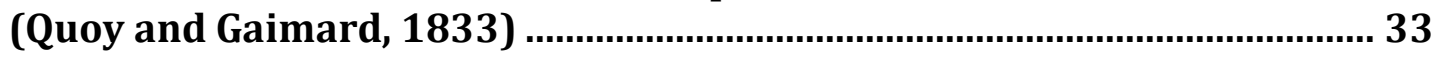

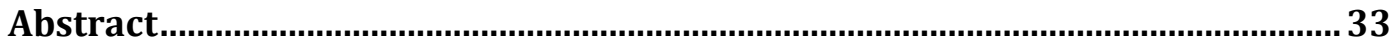

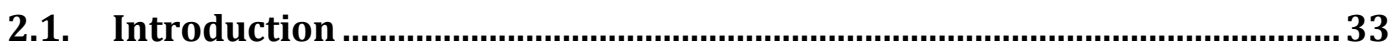

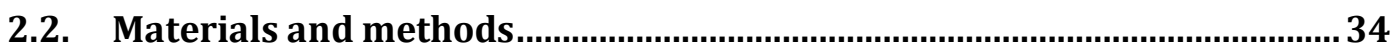

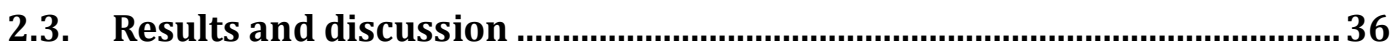

Chapter 3. Genetic connectivity between marine reserves in central New

Zealand: testing the regional network .......................................................... 38

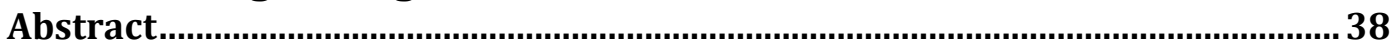

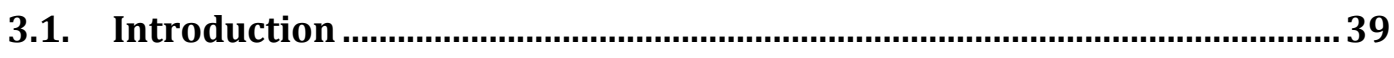

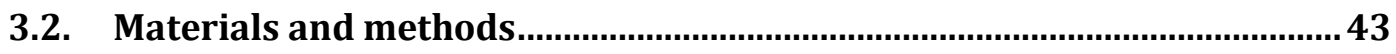

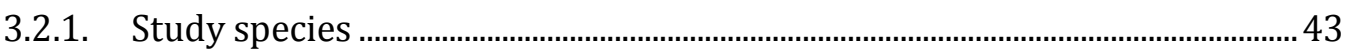

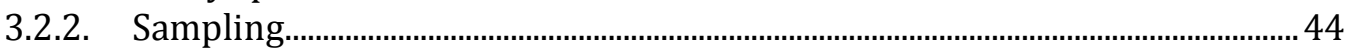

3.2.3. DNA extraction and PCR amplification ................................................................. 46

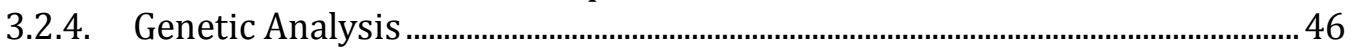

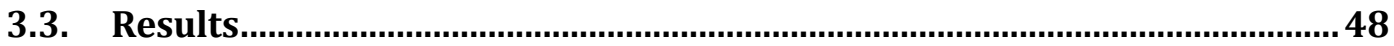

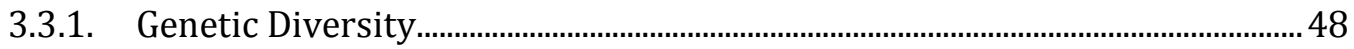

3.3.2. Genetic differentiation between populations..................................................... 49

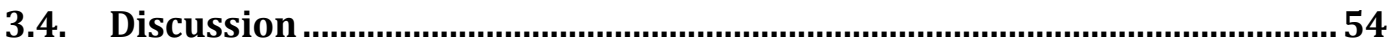

3.4.1. Between-population structure ......................................................................... 54

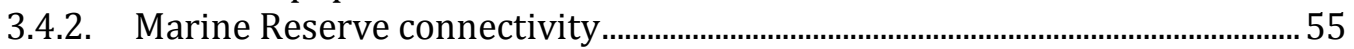

3.4.3. Marine Reserve management implications ...........................................................56

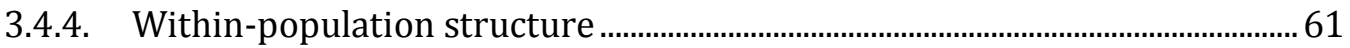

3.4.5. Validity of the results and future studies.............................................................. 62

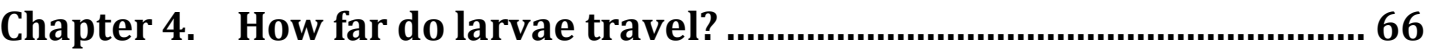

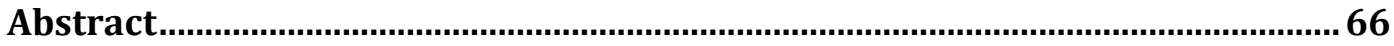

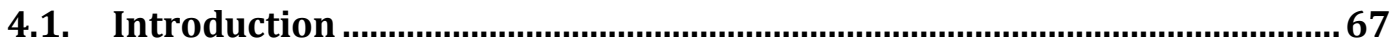

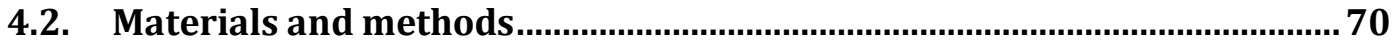

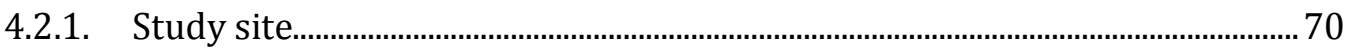

4.2.2. Settlement to Artificial Islands............................................................................ 71

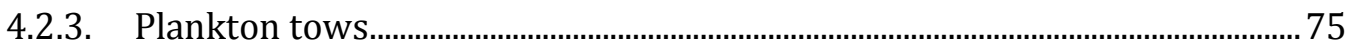

4.2.4. Molecular analysis ...............................................................................................

4.2.5. Data analysis ...............................................................................................

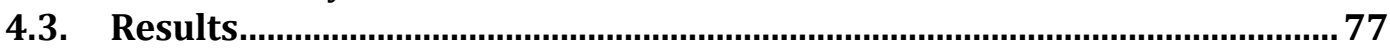

4.3.1. Settlement to Artificial Islands .......................................................................... 77 


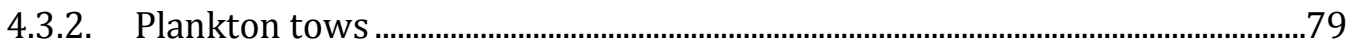

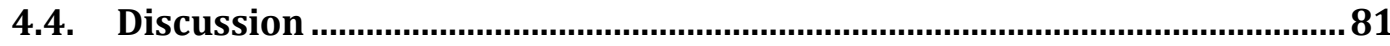

4.4.1. Localized dispersal vs long distance dispersal .....................................................84

Chapter 5. The effect of locally available larvae upon coral settlement rates: a preliminary comparison of methods to monitor settlement..........86

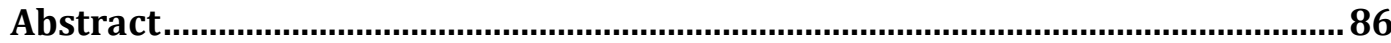

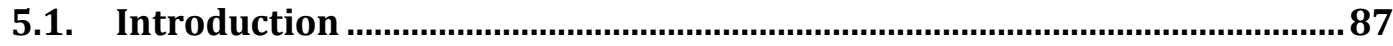

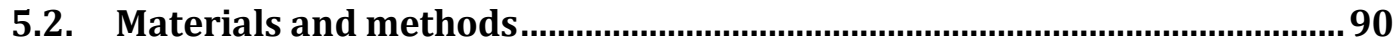

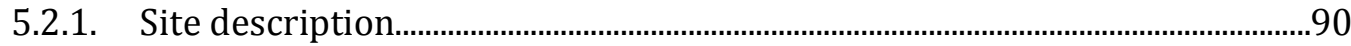

5.2.2. Sampling ..............................................................................................................91

5.2.2.1. Settlement to permanent cleared quadrats......................................................91

5.2.2.2. Settlement to panels ..............................................................................................92

5.2.3. Statistical analysis................................................................................................ 94

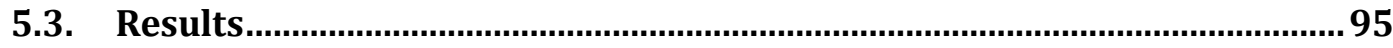

5.3.1. Settlement to cleared reef areas............................................................................95

5.3.2. Settlement to panels ……………..........................................................................97

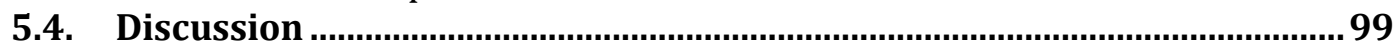

5.4.1. Settlement to permanent cleared areas .............................................................99

5.4.2. Effect of panel side, orientation and material on coral settlement.............100

5.4.3. Coral settlement in the WNMP compared with other localities ...................101

Chapter 6. The effect of locally available larvae upon coral settlement rates: temporal and spatial variability ....................................................... 103

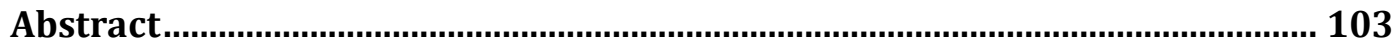

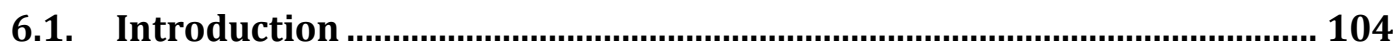

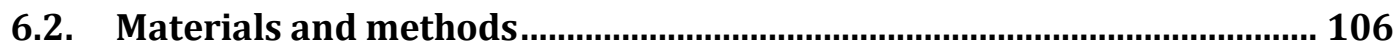

6.2.1. Study sites ..............................................................................................................106

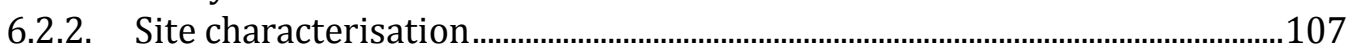

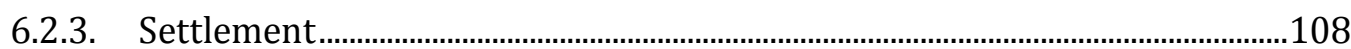

6.2.4. Settlement to natural reef cleared areas .............................................................109

6.2.5. Juvenile coral abundance and diversity .............................................................109

6.2.6. Statistical analysis.................................................................................................109

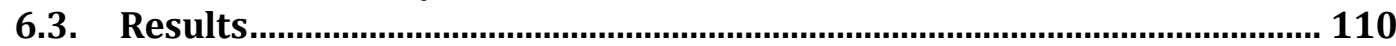

6.3.1. Site biological and physical characteristics...................................................110

6.3.2. Settlement......................................................................................................112

6.3.2.1. Yearly settlement ...........................................................................................112

6.3.2.2. Seasonal settlement .........................................................................................113

6.3.3. Settlement to cleared reef areas...........................................................................115

6.3.4. Juvenile coral abundance and diversity ...........................................................116

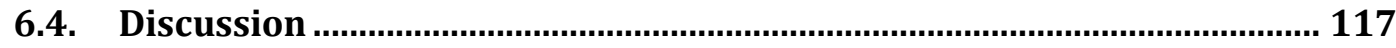

6.4.1. Variation between sites …………………......................................................117

6.4.2. Inter-annual and seasonal variation .................................................................120

6.4.3. Settlement in the Wakatobi Marine Park .........................................................122

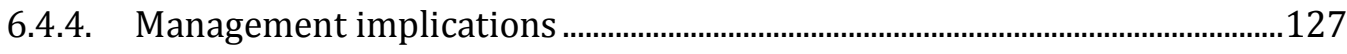

Chapter 7. General discussion .............................................................. 128

7.1. Genetic tools to investigate population connectivity: past, present and

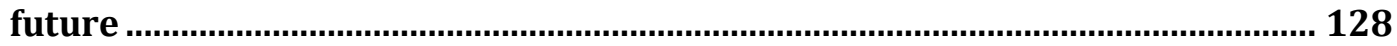

7.2. Long distance vs. localized dispersal......................................................... 132

7.3. The importance of connectivity for effective management..................... 133

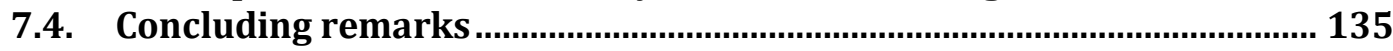

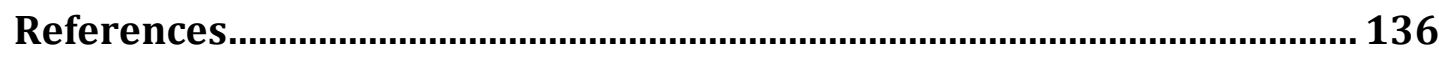




\section{List of figures}

\section{Chapter 3}

Fig. 1 Map of seven Austrolittorina cincta sampling loations (4 Marine Reserve (MR) location; 3 non MR locations) in central New Zealand for microsatellite analysis. Map also shows major NZ oceanic currents; 31 marine reserve locations and proposed phylogepgraphic breaks (after Apte and Gardner, 2002) between the North and South islands.

Fig. 2 Austrolittorina cincta isolation by distance within central New Zealand populations. Population pairwise genetic differentation plotted against minimum oceanic distance bewteen populations.

Fig. 3 Similarity dendrogram (clustering using Canberra distance and complete linkage) constructed using Drawtree in the PHYLIP software package (redrawn to scale) based on a distance matrix calculated from assignment indices for populations.

Fig. 4 Allele discovery curves for A.cincta on Wanganui (upper) and Long Island (lower) populations. These curves represent the total number of alleles captured at $2 \mathrm{~N}$ (two times the number of individuals for the diploid microsatellite markers) for all five microsatellite loci combined.

\section{Chapter 4}

Fig. 5 Satellite image (@ Google Earth) of the Kapiti - Wanganui coast on the southwest of New Zealand' North Island with a schematic representation of the five (S1 - S5) sampling stations where artificial islands were deployed to investigate larval movement of the intertial gastropod Austrolittorina cincta from Kapiti Island.

Fig. 6 Schematic representation of an artificial island designed to provide an artificial substrate for larvae of the intertidal gastropod Austrolittorina cincta to settle on.

Fig. 7 (A) Artificial Island (AI) with settlement panels attached ready for deployment (B) Deployed AI with Kapiti Island on the background .74

Fig. 8 Gastropod settlers $( \pm$ SE) per settlement panel $(15 \times 8 \mathrm{~cm}$ Scotch-Brite scouring pads) at five different sampling stations deployed around Kapiti Island, NZ. .78

Fig. 9 Microsatellite loci D104 PCR products loaded on a $3 \%$ agarose gel stained with Ethidium Bromide. Lanes 1 - 8 represent different gastropod settlers, lane 9 is positive control, lane 10 a negative control and lane 14 is a $1000 \mathrm{~kb}$ ladder. Symbol represents positive A. cincta ID.

Fig. 10 Austrolittorina cincta settlers $( \pm \mathrm{SE})$ per settlement panel $(15 \mathrm{x} 8 \mathrm{~cm}$ ScotchBrite scouring pads) on two replicate artificial islands (AI) at five different sampling stations (S1 - S5) deployed around Kapiti Island, NZ.

Fig. 11 Gastropod larvae $( \pm \mathrm{SE})$ per $\mathrm{m}^{3}$ of filtered seawater on three different plankton tows conducted at five different sampling stations (S1 - S5) around Kapiti Island, NZ 


\section{Chapter 5}

Fig. 12 Sampling sites within the Wakatobi National Park in SE Sulawesi, Indonesia. Sites B3 and B4 are located within the Hoga Island reef system, Sites S1 and S2 were located within the Sampela reef system and are adjacent to a Bajau village (represented on the map by three white houses).

Fig. 13 A) Diver clearing quadrats for coral settlement study; B) Recently cleared quadrat.

Fig. 14 Diagram of the different settlement panels and method of deployment used to monitor scleractinian coral settlement across four different sites in the Wakatobi National Marine Park in South-East Sulawesi, Indonesia.

Fig. 15 Mean ( \pm Standard Error) number of coral settlers (per $100 \mathrm{~cm}^{2}$ ) per taxonomic group on settlement plates made of different materials (concrete and terracotta) and deployed at two different orientations (vertical and horizontal) across four different sites in the Wakatobi National Marine Park, SE Sulawesi, Indonesia.

Fig. 16 Mean ( \pm Standard Error) number of coral settlers (per $100 \mathrm{~cm}^{2}$ ) on settlement plates made of two materials (concrete and terracotta) averaged across four sites (B3 and B4 at Hoga reefs; S1 and S2 at Kaledupa reefs) in the Wakatobi National Marine Park, SE Sulawesi, Indonesia Note: panel material data is presented for data pooled from vertical and horizontal surfaces.

\section{Chapter 6}

Fig. 17 Mean percentage coverage $( \pm \mathrm{SE}$ ) of the major benthic groups (a) and coral families (b) at four different sites (B3 and B4 at Hoga reef; S1 and S2 at Sampela reef) in the Wakatobi National Park, SE Sulawesi, Indonesia. (*) indicates significant differences between sites (Kruskal Wallis, $\mathrm{p}<0.05$ ). HC: Hard coral, BA: Bare, RU: Rubble, CCA: Coralline Algae, SA: Sand, SPO: Sponge, ASC: Ascidian, ALG: Algae, OT: Other.

Fig. 18 Mean $\left( \pm\right.$ SE) number of coral spat (per $100 \mathrm{~cm}^{2}$ ) on settlement plates (a) and cleared reef areas (b) deployed during 2008 and 2009 across four different sites (B3 and B4 at Hoga reef; S1 and S2 at Sampela reef) in the Wakatobi National Park, SE Sulawesi, Indonesia.

Fig. 19 Left Axis: Mean ( \pm SE) number of coral settlers (per $100 \mathrm{~cm}^{2}$ ) on settlement plates during the three different submersion periods at four sites (B3 and B4 at Hoga reef; S1 and S2 at Sampela reef) in the Wakatobi National Marine Park, SE Sulawesi, Indonesia. Right axis: mean monthly sea temperature (averaged across two sites).

Fig. 20 Mean $\left( \pm \mathrm{SE}\right.$ ) number of coral settlers (per $100 \mathrm{~cm}^{2}$ ) per taxonomic group on settlement plates during the three different submersion periods across four different sites (B3 and B4 at Hoga reef; S1 and S2 at Sampela reef) in the Wakatobi National Marine Park, SE Sulawesi, Indonesia.

Fig. 21 Mean ( \pm SE) number of coral juveniles (per $0.5 \mathrm{~m}^{2}$ ) for each taxonomic group across four different sites (B3 and B4 at Hoga reef; S1 and S2 at Sampela reef) in the Wakatobi National Marine Park, SE Sulawesi, Indonesia. 


\section{List of Tables}

\section{Chapter 2}

Table 1 Summary description of 8 microsatellite loci for Austrolittorina cincta. 37

\section{Chapter 3}

Table 2 Summary description across 5 microsatellite loci for A. cincta at 7 populations.

Table 3 Matrix of pairwise comparisons of population genetic differentiation using $\mathrm{F}_{\mathrm{ST}}$

Table 4 Summary of analysis of molecular variance (AMOVA) among population samples.

Table 5 Assignment test results for individuals from each population. of seven

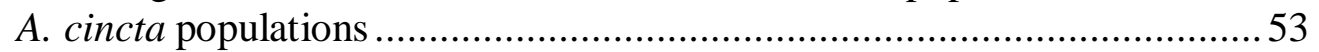

Table 6 Minimum oceanic distance between Marine Reserves within New Zealand north, south and Stewart Islands.

\section{Chapter 4}

Table 7 Summary of results of microsatellite analysis on gastropod larvae collected on 15 plankton tows at 5 sampling stations around Kapiti Island. 81

\section{Chapter 5}

Table 8 Summary of PERMANOVA results comparing the factors: reefs, sites nested within reef, materials and their interactions for hard coral settlement in the Wakatobi National Marine Park, Indonesia.

Table 9 Summary of PERMANOVA results comparing the factors: panel materials, panel orientation, reef, sites and their interactions, for hard coral settlement in the Wakatobi National Marine Park. Indonesia. 98

\section{Chapter 6}

Table 10 Site characterization table across four different sites in the Wakatobi National Marine Park, SE Sulawesi, Indonesia.

Table 11 Summary of PERMANOVA results comparing the factors: year and site, and their interactions, for hard coral settlement to terracotta settlement panels in the Wakatobi National Marine Park, Indonesia.

Table 12 Summary of PERMANOVA results comparing the factors: season and site, and their interactions for hard coral settlement to terracotta settlement panels in the Wakatobi National Marine Park, Indonesia.

Table 13 Summary of PERMANOVA results comparing the factors: year and site, and their interactions for hard coral recruitment to cleared reef areas in the Wakatobi National Marine Park, Indonesia.

Table 14 Summary ot coral setlement studies using artificial settlement substrate125 


\section{Chapter 1. General introduction}

Most coastal marine species have a life-history stage with high potential for dispersal (Cowen et al. 2000). Such dispersal can take place in their pelagic larval stage, in which larvae may be transported by oceanic currents (Roberts 1997); in their juvenile stage where individuals can migrate to different nursery areas (Gillanders et al. 2003); or as adults, where organisms may travel long distances in search of new resources (Weng et al. 2007) or breeding grounds (Rooker et al. 2007). For non-brooding, benthic species, most dispersal usually occurs during the pelagic larval stage, although it may be possible for juveniles and/or adults of both brooding and non-brooding species to travel long distances by other means such as rafting, drifting, or dislodgment (Thiel \& Gutow 2005, Levin 2006).

Given this high potential for dispersal, especially during the larval stage, marine populations have been traditionally considered as 'open populations', with continuous exchange of larvae between different populations over wide spatial scales. This traditional view was summarised in the review by Caley et al. (1996) in which he argued that for most benthic invertebrates and demersal fishes, local offspring production had little or no direct role in setting local population size because larval recruitment from elsewhere provides a substantial input of new individuals.

This traditional view has been recently challenged by a number of researchers who have reported far less dispersal than previously predicted for many species, suggesting that a large proportion of larvae may be retained in the local parental habitat (Cowen et al. 2000, Mora \& Sale 2002, Swearer et al. 2002, Warner \& Cowen 2002, Paris \& Cowen 2004, Cowen et al. 2006) leading several authors to concluded that marine populations may be less open than previously thought (Levin 
2006). These new studies have been possible because of the availability of new techniques, together with the recognition of the significance of many biological (e.g. larval behaviour and mortality) and physical (e.g. oceanographic retention features such as eddies) factors to larval exchange (Becker et al. 2007).

Understanding the level of larval exchange among populations of marine organisms is important for their effective management and understanding species ecology (Cowen et al. 2000, Sponaugle et al. 2002). Understanding larval dispersal can provide scientists and managers with valuable information to: understand complex population dynamics of commercially important species (Caley et al. 1996); determine the optimal design and location of Marine Protected Areas (MPAs) (Palumbi 2004); investigate the spread and colonization of non-indigenous species (Neubert \& Caswell 2000); and study the consequences of climate change upon species’ distributions (Harley et al. 2006). Despite the importance of quantifying the levels of larval exchange between different populations, it has been difficult to measure due to the small size and high mortality of larvae, combined with the large size and complexity of the oceans (Levin 2006, Becker et al. 2007). Measuring larval dispersal is considered to be one of the great remaining challenges for marine scientists (Mora \& Sale 2002, Sala et al. 2002, Warner \& Cowen 2002, Palumbi 2003, Jones et al. 2005).

\subsection{Measuring dispersal}

Empirical studies of larval movement between populations are very difficult to conduct and consequently are limited to only a few examples (see Palumbi 2001). Different approaches have been taken to indirectly estimate larval movement and include a wide range of techniques that are summarised below. 
Mathematical models have been widely used to study larval movements (Roberts 1997, Cowen et al. 2000, Siegel et al. 2003, Cowen et al. 2006). Early models considered larvae to be inert particles dispersed by currents (Roberts 1997), without considering the effect that different biological or physical factors may have in larval dispersal or larval behaviour. The latest models incorporate important biological (e.g. mortality and/or behaviour, such as vertical migration) and more detailed oceanographic data. A recent biophysical model by Cowen et al. (2006) used flow trajectories from a high-resolution oceanic model using 5 years of real wind data for the Caribbean to study the larval movement of several reef fish species. This model also included several biological parameters such as pelagic larval duration (PLD), larval vertical migration and adult spawning strategies. The availability of benthic habitat for settlement and an estimation of the settlement rates required to replenish the local populations were also included in the model. Cowen et al. (2006) showed that for the wider Caribbean region typical larval dispersal distances providing ecologically significant numbers of settlers were on the scale of 50 to 100 $\mathrm{km}$, with a high rate of self-recruitment (averaging $21 \%$ but as high as $55 \%$ for some regions), but also recruitment from adjacent areas.

The use of natural or artificial markers is another widely used technique to study larval movements. Some of these marking techniques are limited to specific taxonomic groups because the larval structure that is marked in the individual needs to be retained by the settled individual. Natural markers are signals present in larvae that have been exposed to particular water chemistry. These markers include structural attributes, such as larvae size; stable isotopic signatures, such as ${ }^{13} \mathrm{C},{ }^{15} \mathrm{~N}$ or ${ }^{18} \mathrm{O}$; and trace elemental fingerprinting, such as Manganese (Mn), Copper (Cu), Zinc (Zn) or Barium (Ba); (Swearer et al. 1999, Becker et al. 2007). Swearer et al (1999) 
used elemental fingerprinting signatures to study larval dispersal within an island population of reef fish. They used otoliths (bony structures within the ear of teleost fishes) as recorders of growth history and trace element environmental signatures because they are present since the larvae were released and a new layer of material is deposited daily. Newer layers incorporate trace elements present in the surrounding waters so the authors hypothesised that larvae developing within coastal systems would have higher levels of trace metals in their tissues, considering coastal waters have higher concentration of these trace metals compared to larvae developing in the open ocean. Swearer et al. (1999) reported that the reefs around their study island received a mixture of locally retained (mostly in the leeward reefs) and dispersing larvae (windward sites). Considering that nearly $70 \%$ of the recruits settled within the leeward sites, they suggested that a high proportion of the recruitment to the island is from locally retained larvae.

Artificial markers have also been used to label different structures, such as otoliths (Jones et al. 1999) and shells (Moran \& Marko 2005), and include fluorescent dyes like calcein (Moran \& Marko 2005), elemental tags or radiolabels (Levin 2006). The problem associated with this methodology is the difficulty of recapturing marked larvae given the huge dilution rates of larvae in the ocean. Almany et al. (2007) used Barium isotopes to mark larvae of two coral reef fish species with short ( 2 weeks) and long ( $>40$ month) PLD by tagging mothers who transferred stable isotope signatures to their offspring before hatching and dispersal. One year later, newly recruited fish otoliths were examined to determine the presence of the stable isotope signature. Almany et al. (2007) reported that $60 \%$ of juveniles of both species returned to their natal reefs and $40 \%$ of the juveniles came from reefs at least $10 \mathrm{~km}$ away. 
Molecular markers have been widely used to study marine population connectivity (Doherty et al. 1995, Barber et al. 2002a, Hellberg et al. 2002, Palumbi 2003, Taylor \& Hellberg 2003, Bell \& Okamura 2005, Sotka \& Palumbi 2006, Underwood et al. 2007, Bell 2008a). These markers can be used to indirectly estimate larval dispersal by comparing the genetic structure between different populations. Populations may differ in the presence of alternate forms (alleles) at the same loci, in the frequency of these alleles and in associations between alleles at different loci (Hellberg 2007). Many different types of molecular markers have been used to estimate levels of connectivity between different populations including mitochondrial DNA (Barber et al. 2002b); Randomly Amplified Polymorphic DNA markers (RAPDs) (Wood \& Gardner 2007); Allozymes (Karl \& Avise 1992) and microsatellites (Bell 2008b). For example, Taylor \& Hellberg (2003) used mitochondrial markers to evaluate population differentiation across Caribbean populations of the cleaner goby Elacatinus evelynae. Even though this species has a long-lived (3 weeks) PLD, populations of this species showed strong genetic differentiation, even between populations separated by only $23 \mathrm{~km}$, suggesting high dispersal potential, but low actual dispersal. In another study, Barber et al. (2002a) investigated patterns of genetic diversity using mitochondrial markers in two populations of Mantis shrimp, Haptosquilla pulchella and Haptosquilla glyptocercus, on the islands of Krakatau and Rakata in Indonesia. Krakatau had strong volcanic eruptions in 1883 that destroyed the coral reefs surrounding the island. Barber et al. (2002a) reported surprisingly high levels of genetic diversity in the populations on these islands suggesting multiple colonisation events from sources at least $40 \mathrm{~km}$ away. These authors reported that successful connectivity and recruitment for these species occurred over intermediate temporal (c.a. 100yr) and 
spatial scales (50-100 km). In addition to this, previous work on same species by Barber et al. (2000) showed sharp genetic breaks on evolutionary time-scales and over larger spatial scales (200-400 km) suggesting limited dispersal over distances larger than $100 \mathrm{~km}$.

Experiments using newly available substrata on which larvae can settle have also been used to indirectly study patterns of larval dispersal by studying recruitment rates into this newly available substrate (Sammarco \& Andrews 1989, Harriott 1992, Dethier et al. 2003). Studying recruitment rates to isolated habitats can also provide useful information on the dispersal potential of organisms. Dethier et al. (2003) compared the abundance of benthic species on an artificial jetty structure surrounded by dissimilar habitat with natural rocky habitats in the north west coast of the USA. Even though the jetty was at least $40 \mathrm{~km}$ from source populations, most species present in the near natural populations, including both species with long PLD and brooding species, recruited and managed to survive in this isolated habitat. Only a few species were absent, compared to natural communities, suggesting strong connectivity patterns for different dispersal strategies.

\subsection{Use of microsatellite markers to study Marine Reserves connectivity in central New Zealand}

Modern molecular techniques are a reliable tool to study the degree of connectivity between marine populations. Among the different molecular markers available, microsatellites or SSTRs (Simple Sequence Tandem Repeats) are one of the more reliable and commonly used genetic markers. Microsatellites are speciesspecific, generally polymorphic loci mainly present in non-coding regions of nuclear DNA that consist of repeats of one to six base pairs in length (Queller et al. 1993). 
Variation in the number of these repeats can be used to determine differences in population genetic structure; higher genetic differentiation is expected to occur between populations that share fewer larvae over multiple generations. Microsatellite markers have been successfully used in many marine species to assess the level of connectivity between their populations (Reusch 2002, Bell \& Okamura 2005, Purcell et al. 2006, Carreras-Carbonell et al. 2007, Bell 2008a, Ridgway et al. 2008, Blanquer \& Uriz 2010). For example, Carreras-Carbonell (2007) used ten highly polymorphic microsatellite loci to study self-recruitment in the Mediterranean triplefin Tripterygion delaisi. These authors reported that even though this species has a 3 weeks larval duration, approximately $66 \%$ of the recruits settled in their natal population. In another study Bell \& Okamura (2005) used microsatellite markers in the dog whelk Nucella lapillus to determine levels of connectivity between populations within Lough Hyne Marine Nature Reserve, a sea lough connected by tidal fluxes to the open ocean by a narrow channel, and populations on the local adjacent coast (2-3 km away) and more distance populations (100-1000s km). They reported low levels of genetic exchange, evidence for inbreeding and reduced genetic diversity within the marine reserve population, compared with the adjacent open coast populations; they also found genetic isolation between distant populations (100-1000 Km) suggesting limited larval exchange.

Several recent studies have used microsatellite markers to assess the connectivity between MPAs and nearby areas (Bell \& Okamura 2005, Bell 2008a, Ridgway et al. 2008, Planes et al. 2009). MPAs or Marine reserves (MRs) are an important management tool that has been being widely used to protect marine ecosystems that are at risk from anthropogenic disturbance and overexploitation of marine resources (Lubchenco et al. 2003). The number of newly established MRs has 
increased dramatically in recent years, but they still only represent a small overall proportion of the marine environment (Langlois \& Ballantine 2005). There is growing scientific evidence that indicates that MRs are a successful tool in protecting specific species, habitats or diversity hotspots, and/or increase fisheries yields (Palumbi 2001, Langlois et al. 2006, Ballantine \& Langlois 2008). However, there is also some evidence to suggest that MRs may not always meet their goals, such as poor enhancement of lobster stocks at the Poor Knights Islands MR following establishment on the MR (Booth et al. 2000), although generally MPA effects are positive and there are many examples worldwide, in both tropical and temperate marine ecosystems, where MRs have been successful in achieving their conservation targets and objectives (see Halpern 2003).

The potential for larvae to be exported from MRs to adjacent areas may help sustain populations outside reserve boundaries and enhance fisheries (Palumbi 2001). Evidence to demonstrate that larval exchange occurs between reserves and their surrounding areas has received little attention in the design of MRs but it may be very important (Bell 2008a). Lack of larval exchange between MRs and the surrounding populations could challenge the long-term survival of the populations inhabiting the reserve, because these populations might be potentially isolated, limiting the levels of external recruitment into the population (Palumbi 2001, Palumbi 2003, Bell \& Okamura 2005, Bell 2008a). Many MRs designated worldwide are potentially isolated habitats including islands, closed embayments, sea loughs or fiords because their 'discrete' boundaries and isolation make them easier to manage, but in most cases, connectivity has been taken for granted (Bell 2008a). Ensuring larval movement between protected and non-populations are essential to ensure the long-term success and sustainability of the reserve. Catastrophic events, 
such as oil spills or bleaching events, although rare, could wipe out a reserve's entire population and if not connected to other populations, then external sources of larvae will not be able to recover the reserve's populations (Allison et al. 2003, Wagner et al. 2007, Game et al. 2008).

One way that has been proposed to ensure that populations within marine reserves are self-sustaining is through the creation of MR/MPA networks, in which larval exchange between different reserves will support each reserve population (Palumbi 2004, Cowen et al. 2006). There has been considerable debate with respect to how MRs in these networks should be spaced (Palumbi 2001, Allison et al. 2003, Palumbi 2003, 2004, Wagner et al. 2007, Game et al. 2008). We might expect that the closer two reserves are placed; the more likely reserves will be connected by larval exchange. However, the closer two reserves are placed together the more likely they will be affected by the same catastrophic event (Allison et al. 2003, Wagner et al. 2007, Game et al. 2008).

New Zealand is one of the world leaders in marine protection with 33 marine reserves representing $7.6 \%$ of the territorial waters. However, connectivity between MRs has not been a priority in past designation processes. Physical barriers such as distance, environmental gradients or current flow patterns, together with biological factors, such as reproductive mode or PLD, may limit connectivity of different organisms between these reserves (Bell 2008a). The Cook Strait has very strong tidal currents up to $250 \mathrm{~cm} \mathrm{~s}^{-1}$ (Stanton et al. 2001). Previous genetics studies using mtDNA have reported population subdivisions between the north and south islands for the greenshell mussel Perna canaliculus and the seastar Patiriella regularis (Apte \& Gardner 2002, Waters \& Roy 2004, Ayers \& Waters 2005). These studies reported a barrier to gene flow at $42^{\circ}$ South, possibly due to the strong tidal flows and 
turbulent mixing of water in the Cook Strait and the intense upwelling on both the east and west coast (Apte \& Gardner 2002). Although Goldstein et al. (2006) also observed a genetic break in central New Zealand using mitochondrial markers for three species of limpets (Cellana ornate, Cellana radians and Cellana flava), they concluded that an older divergence time between the islands happened around 200,000-300,000 years ago. They also remarked on the importance of clearly defining the Cook Strait area to ensure studies can be compared, as previous studies used different definitions for Cook strait area and recommended the use of faster evolving genetic markers (i.e. microsatellites) in order to identify contemporary dispersal barriers.

There are six marine reserves within the Cook Strait region including Kapiti Island, Taputeranga, Long Island, Horoirangi, Tonga Island and Westhaven-Te Tai Tapu and the nearest marine reserves to these to the north or south are separated by over $250 \mathrm{~km}$. It is thus important to understand the levels of connectivity between different Marine Reserves in central New Zealand in order to make effective conservation and management decisions, and inform future marine reserve designation and ensure connectivity.

\subsection{How far do larvae travel?}

Although this question is very important for understanding many aspects of marine ecology including the development of MPA networks, there is still little information about dispersal distances for most marine organisms and direct observations of larval dispersal distances are restricted to only a few examples, and mainly for larvae from species with very low dispersal potential (Palumbi 2003). One of the few available studies was conducted by Olson (1985), where the larval movement of the tropical ascidian Didemnum molle was recorded around Lizard 
Island on the Great Barrier Reef. Individual larvae produced in an isolated patch of reef were followed by means of scuba until the larvae settled. Olson reported that the ascidian larvae were only capable of dispersing in the magnitude of hundreds of meters before settling and higher dispersal rates were only achieved at higher wind strengths.

Most of the available data on larval dispersal distances are estimates from indirect measurements of larval movement. These have been derived from several sources such as studies documenting the spread of invasive species; the use of natural or artificial markers to follow larval movement; experimental studies using settlement at increasing distances from an isolated source; or by characterising the genetic structure of adult populations (Palumbi 2003, Levin 2006).

There have been a number of studies investigating the levels of larval recruitment at increasing distances from isolated populations of adults (reviewed by Shanks et al. 2003). For example Sammarco and Andrews (1989) set up a large-scale study to determine whether reefs of the central GBR were mainly self-seeding. Several recruitment stations were deployed within increasing distances up to $5 \mathrm{~km}$ from the perimeter of an isolated reef surrounded by sand banks. They found that most larvae settled within $300 \mathrm{~m}$ of the reef and that corals with an obligate planktonic larval development period recruited in higher numbers in the outermost panels, suggesting higher dispersal potential. In contrast, obligate brooder densities was much higher directly on the reef.

Genetic isolation by distance models have been widely used to estimate larval dispersal for a wide range of organisms. Hellberg (1994) reported that the ahermatypic coral Balanophyllia elegans travelled less than $0.5 \mathrm{~km}$ before settling, usually within the vicinity of their parental colony. In a similar manner Johnson \& 
Black (1998) estimated, using allozymes, that $25 \mathrm{~km}$ was the mean dispersal distance for the littorinid gastropod Littorina cingulata. Molecular techniques have been also used to identify newly settled larvae or juveniles of inconspicuous organisms difficult to identify in their early stages, such as mussels and oysters (Lopez-Pinon et al. 2002, Phillips et al. 2008). There is also the potential for species-specific molecular markers to be used to detect the presence of larvae in the water column, although to my knowledge this approach has not been trialled, and is a focus of my research.

There are a limited number of studies that have obtained direct estimates of how far larvae travel and most of these studies have focused on organisms with very short (hours) PLD. It is thus important to try to obtain direct measures of how far larvae from other organisms with long-lived pelagic larvae travel, since these represent the majority of marine species (Levin 2006).

\subsection{Local larval production and settlement}

There is growing scientific evidence that a high proportion of larvae produced will recruit near to their parental habitat. Several studies have suggested that a high proportion of coral larvae produced recruit into their home reefs (Sammarco \& Andrews 1989, Harriott 1992, Harriott \& Banks 1995, Underwood et al. 2007, 2009). Maier et al. (2005) and more recently Underwood et al. (2007, 2009) used microsatellite markers to asses the genetic structure and patterns of larval dispersal in the brooding coral Seriatopora hystrix. These studies have revealed that a high proportion of the larvae produced recruited within their natal reef, suggesting low dispersal distances. Similar findings were reported by Hellberg (1994) in the temperate brooding coral Balanophyllia elegans, whose larvae were also recorded to settle within short distances from the parental colony. 
It is important to note that these studies were conducted in brooding species, which are believed to have lower dispersal potential compared with broadcast spawners. However, recent experiments studying larval settlement competency have revealed that although larvae from several broadcast spawners have the potential to survive in the water column for several months, larvae are competent to settle within $48 \mathrm{hr}$ after release, and therefore can settle quickly if suitable substrate is found (Graham et al. 2008). In a study by Sammarco and Andrews (1988) recruitment stations were deployed within increasing distances up to $5 \mathrm{~km}$ from the perimeter of an isolated reef surrounded by sand banks. Despite having higher potential for dispersal, the larvae of broadcasting species was found to mainly settle within $300 \mathrm{~m}$ from the reef, although individuals were recorded in more distant stations. In a similar study, but with fish, Almany et al. (2007) have shown that approximately $60 \%$ of recruited fish within the reefs of an isolated island in New Guinea were spawned at the recruitment site, for fish species with both short ( $<2$ weeks) and long (>1 month) pelagic larval durations.

Considering that a high proportion of the offspring produced may be retained within local reefs, it is likely that the condition of the reef itself and also local physical and biological factors will have an important influence on the levels of recruitments to reefs. Hughes et al. (2000) used settlement panels to study patterns of coral recruitment across the GBR. They showed that reefs with a higher proportion of fecund colonies (i.e. adult colonies) showed a stock-recruitment relationship with much higher levels of larvae produced and thus higher recruitment to artificial substrates.

Coral reefs are under threat worldwide as a result of human activities. Overfishing and the use of destructive fishing techniques, such as blast and cyanide 
fishing, increased pollution and sedimentation as a result of coastal development and mangrove removal, and rising sea levels, increased water temperature and ocean acidification attributed to global warming (Hoegh-Guldberg et al. 2007) have caused $27 \%$ of monitored reefs to be lost and it is predicted that $30-40 \%$ will be lost within the next 30 years. If self recruitment is a common feature in tropical reef systems, with limited larval dispersal between reefs, and the level of coral recruitment is heavily dependant on the proportion of adult colonies present within individual reefs, hard coral decline will directly influence the long-term survival of coral reefs at local scales. It is thus important to understand hard coral recruitment patterns with varying degrees of reef degradation in order to produce specific conservation and management plans.

\subsection{Aims and objectives of this thesis}

The first part of my $\mathrm{PhD}$ will focus on a genetic study to investigate patterns of connectivity between populations of the common NZ gastropod Austrolittorina cincta using microsatellite markers. Several populations will be characterized across New Zealand's North and South Islands, including four MRs around the Cook Strait region. I will investigate gene flow between these populations using this genetic data. These littorinid species are known to have long-lived (4-6 weeks duration) planktotrophic larvae, thus having great potential for dispersal and gene flow.

Specific objectives include:

1) The development and testing of specific microsatellite primers for these species.

2) The characterization of the genetic structure of populations for these two gastropods for seven populations, including four marine reserves. 
The second component of my $\mathrm{PhD}$ will determine how far long-lived pelagic larvae travel. Recent research implies that larvae of marine organisms travel smaller spatial scales than previously predicted. This study will provide new insights to one of the greatest challenges for marine scientists. A large-scale recruitment experiment together with a new way of utilising molecular markers will be used to try and measure how far the larvae of $A$. cincta travels from an isolated source in the west coast of New Zealand's north island

Specific objectives of this chapter are:

1. To determine the dispersal potential of a rocky shore intertidal gastropod with a long-lived pelagic larvae. Recruitment stations will be placed at increasing distances from the northward extent of rock substrate on the South west coast of the north island (northward of Kapiti), to study the potential distances that larvae can travel (and how many travel this distance) because there is a large area of unsuitable sandy habitat covering over $100 \mathrm{~km}$ to the next rocky environment. By conducting these experiments I will use recruitment rates to assess the dispersal potential of long lived-larvae

2. To determine the usefulness of the newly developed microsatellite markers to detect the presence of larvae of these two intertidal gastropods. Plankton tows will be conducted at the same locations used for the recruitment study. DNA from all organisms captured in the tow will be extracted and the newly microsatellite markers will be utilised to detect the presence of larvae within increasing distance of an isolated source and thus obtain a direct measure of how far larvae travel. 
The third component of my $\mathrm{PhD}$ will investigate the effects of locally available larvae on larval settlement rates. There is increasing evidence to suggest many marine populations, including hard corals, are largely self-seeding and thus recruitment might be heavily dependant on adult colony abundance. In this part of my $\mathrm{PhD}$ I will conduct a set of field surveys and experiments to investigate the effect of hard coral coverage upon hard coral settlement across reefs under different degrees of disturbance

This part of the project will be conducted in the Wakatobi National Marine Park in Indonesia. Specific objectives of this project will include:

1) To acquire baseline data for each of the reefs monitored to determine the level of degradation, including:

- Environmental data: water temperature, depth, salinity, turbidity; current flow strength and direction; sedimentation rates.

- Biological data: hard coral coverage, diversity and abundance; other benthic groups (i.e. ascidian, sponges) coverage, diversity and abundance.

2) To determine the effect of different tile materials, orientation and side of tile upon hard coral settlement.

3) To determine levels of hard coral settlement across reefs with different levels of live hard coral. Settlement panels will be deployed at $6 \mathrm{~m}$ in reefs under low (<15\%) and medium (35-45\%) coral coverage.

4) To determine the diversity and abundance of hard coral juveniles across the different reefs sampled and to determine the influence of environmental disturbance on recruit density and diversity. Data will be collected using SCUBA by means of underwater transects and quadrats visually counting and measuring colonies. 


\title{
Chapter 2. Isolation and characterization of
}

\author{
polymorphic microsatellite for the New Zealand \\ endemic brown periwinkle Austrolittorina cincta
}

(Quoy and Gaimard, 1833)

\begin{abstract}
Manuscript submitted for publication in Molecular ecology resources.
Salinas-de-Leon $\boldsymbol{P}$ and Bell J.J. Isolation and characterization of polymorphic microsatellite for the New Zealand endemic brown periwinkle Austrolittorina cincta (Quoy and Gaimard, 1833).

Author contribution: PS designed the study and performed the molecular work, analyzed the data and wrote the manuscript. JJB co-designed the study, edited the manuscript and obtained the funding for the study
\end{abstract}

\begin{abstract}
Eight novel microsatellite loci were isolated and characterised for the New Zealand endemic brown periwinkle Austrolittorina cincta. Genetic variation was characterised for 50 individuals from an area that is now the Taputeranga Marine Reserve (MR) on Wellington south coast, New Zealand. All loci were polymorphic and the number of alleles per locus ranged from 9 to 29. Observed and expected locus heterozygosity ranged from 0.32 to 0.92 and from 0.8 to 0.95 , respectively. Three loci had high levels of homozygosity and significant departure from HardyWeinberg equilibrium. No linkage disequilibrium was detected between any locus pairs. These markers were then used in subsequent chapters.
\end{abstract}

\subsection{Introduction}

The marine gastropod Austrolittorina cincta (Quoy and Gaimard, 1833) is a common intertidal mollusc that is endemic to New Zealand. A. cincta have limited 
adult movement and a 6 to 8 weeks planktonic larval stage, which represents this species main dispersal mechanism. It is well known that dispersal potential is not an ideal predictor of population connectivity, since the genetic structure of some population often contradicts that expected from life history strategies (Barber et al. 2002b). Microsatellite markers have been developed for many intertidal gastropods across the world (Brownlow et al. 2008; McInerney et al. 2009) and they have been repeatedly used as model species for population connectivity studies (Couceiro et al. 2007, Bell 2008a,b). Here, I characterize eight A. cincta microsatellites in order to investigate population genetic structuring and connectivity between several New Zealand statutory marine reserves within central New Zealand (Chapter 4).

\subsection{Materials and methods}

Microsatellites were isolated from A. cincta DNA libraries created by Genetic Information Services (GIS). Methods for the construction and enrichment of the DNA library are outlined in Jones et al. (2002). Four libraries were constructed by partially restricting genomic DNA with seven blunt-end cutting enzymes (RsaI, HaeIII, BsrB1, PvuII, StuI, ScaI, EcoRV). Fragments in the size range of 300-750 bp were adapted and subjected to magnetic bead capture (CPG, Inc.). Captured molecules were amplified, adapters removed by digestion with HindIII and ligated into the HindIII site of pUC19. Recombinant molecules were electroporated into Escherichia coli DH5alpha (ElectroMacTM, Invitrogen). Recombinant clones were randomly selected for sequencing and enrichment levels were expressed as the fraction of sequences that contained a microsatellite. Sequences were obtained on an ABI PRISM 377, using ABI PRISM Taq dye terminator cycle sequencing methodology. The CA library produced 17 microsatellites from 21 clones, the GA library produced 20 microsatellites from 21 clones and the TAGA library produced 
16 microsatellites from 21 clones. Polymerase Chain Reaction (PCR) primers were designed for 53 of the microsatellite-containing clones by DesignerPCR ver 1.03 (Research Genetics, Inc.).

Candidate loci were PCR amplified in 15ul reactions containing $2 \mathrm{ul} 10 \mathrm{x}$

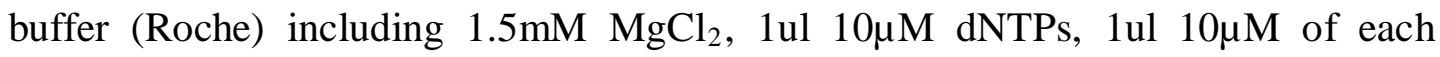
primer, 0.1ul Taq DNA polymerase (Roche) and 20ng of template DNA. Reactions were run in a MJU Research thermocycler under the following conditions: an initial denaturation step $\left(94^{\circ} \mathrm{C}\right.$ for $\left.3 \mathrm{~min}\right)$, followed by 35 cycles of $1 \mathrm{~min}$ at $94{ }^{\circ} \mathrm{C}$, annealing for $1 \mathrm{~min}$ at the locus specific temperature (see Table 1 ) and $1 \mathrm{~min}$ at 72 ${ }^{\circ} \mathrm{C}$, and a final extension at $15 \mathrm{~min}$ at $72{ }^{\circ} \mathrm{C}$. Following initial trials, 8 loci which amplified to produce high quality reproducible products were selected for population characterisation. Fifty individuals were screened for all loci from one population from the area that is now the Taputeranga Marine Reserve (MR) on the Wellington

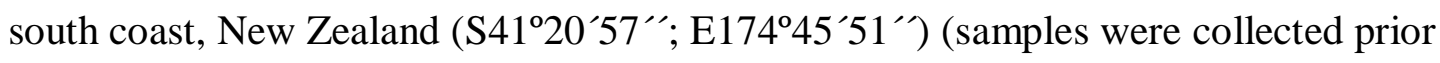
to the reserve being put in place). PCR products from loci labelled with different dyes were combined for multiplex separation on an Applied Biosystems 3130xl Genetic Analyzer, using a 500 LIZ size standard (Applied Biosystems)

Observed and expected heterozygosities, deviations form Hardy-Weinberg equilibrium (HWE) and tests for linkage disequilibrium were calculated by GENEPOP ver 4.0 (Raymond and Rousset 1995). We also used MICROCHECKER v2.2.3 (Van Oosterhout et al. 2004) with the Oosterhout algorithm to examine the influence of undetectable alleles, and to check for scoring errors and any evidence of large allele dropout 


\subsection{Results and discussion}

Table 1 summarises the characteristics of the eight loci. The number of alleles per locus ranged from 9 to 29 and the observed heterozygosity ranged from 0.35 to 0.92. Loci A122, B8 and B105 showed significant heterozygote deficiencies $(\mathrm{p}<0.001)$. The MICROCHECKER analysis suggested that these heterozygote deficiencies are likely to be due to the presence of null alleles at these three loci. No linkage disequilibrium was detected between any loci pairs.

The development of these eight highly polymorphic microsatellite loci provide useful markers to investigate patters of genetic connectivity for this common intertidal species. 
Table 1 Summary description of microsatellite loci for Austrolittorina cincta. $\mathrm{T}_{\mathrm{a}}$, annealing temperature; $\mathrm{N}_{\mathrm{A}}$ number of alleles; observed $\left(\mathrm{H}_{0}\right)$, expected $\left(\mathrm{H}_{\mathrm{e}}\right)$ heterozygosity and p value for HWE tests.

\begin{tabular}{|c|c|c|c|c|c|c|c|c|}
\hline Locus & $\begin{array}{l}\text { Genebank } \\
\text { Acc. No. }\end{array}$ & $\begin{array}{c}\text { Repeat } \\
\text { motif }\end{array}$ & Primer sequences & $\begin{array}{c}\mathbf{T}_{\mathrm{a}} \\
\left({ }^{\circ} \mathrm{C}\right)\end{array}$ & $\mathbf{N}_{\mathrm{A}}$ & $\mathbf{H}_{\mathbf{0}}$ & $\mathbf{H}_{\mathbf{e}}$ & HWE \\
\hline A8 & HQ171471 & $\begin{array}{c}\text { CA } \\
(14)\end{array}$ & $\begin{array}{l}\text { F: ACACACAAACAGGCACTGATAC } \\
\text { R: TTTTCGCTGTCAATATGTTCAC }\end{array}$ & 56 & 18 & 0.92 & 0.95 & 0.536 \\
\hline A111 & HQ171472 & $\begin{array}{l}\text { CA } \\
(34)\end{array}$ & $\begin{array}{l}\text { F: GGACAGACAGACACACATACT } \\
\text { R: CTCGTGCTTGAGAAAGTAAC }\end{array}$ & 56 & 16 & 0.88 & 0.93 & 0.268 \\
\hline A122 & HQ171473 & $\begin{array}{l}\text { CA } \\
(17)\end{array}$ & $\begin{array}{c}\text { F: AATTTTGATCCAATGAGACTCG } \\
\text { R: GTCGTTGTCTTTTGCAGGTG }\end{array}$ & 54 & 12 & 0.35 & 0.92 & $<0.05$ \\
\hline B8 & HQ171474 & $\begin{array}{l}\text { GA } \\
(25)\end{array}$ & $\begin{array}{l}\text { F: TCCGAACTCAAATTAAACATGG } \\
\text { R: GAACCCAGCTCTTGTGTTACAG }\end{array}$ & 54 & 9 & 0.38 & 0.91 & $<0.05$ \\
\hline B105 & HQ171475 & $\begin{array}{l}\text { GA } \\
(36)\end{array}$ & $\begin{array}{l}\text { F: CATCATCTGTCTTTGGGTGTTC } \\
\text { R: GAACCCAGCTCTTGTGTTACAG }\end{array}$ & 54 & 20 & 0.75 & 0.93 & $<0.05$ \\
\hline B117 & HQ171476 & $\begin{array}{l}\text { GA } \\
(11)\end{array}$ & $\begin{array}{l}\text { F: CAGGCAGACAGACACAAGG } \\
\text { R: CAGGCAGACAGACACAAGG }\end{array}$ & 56 & 15 & 0.86 & 0.90 & 0.423 \\
\hline D104 & HQ171477 & $\begin{array}{l}\text { TAGA } \\
(12)\end{array}$ & $\begin{array}{c}\text { F: ATTGATAGGATTCACGGTGTAA } \\
\text { R: GGGCATTTCACTCTGTCTG }\end{array}$ & 54 & 13 & 0.76 & 0.81 & 0.192 \\
\hline D128 & HQ171478 & $\begin{array}{l}\text { TAGA } \\
(11)\end{array}$ & $\begin{array}{c}\text { F: CCATCAGGTTTCTGTCGTC } \\
\text { R: CCGGTCTATCTTTCTACCTACC }\end{array}$ & 56 & 14 & 0.82 & 0.89 & 0.239 \\
\hline
\end{tabular}




\title{
Chapter 3. Genetic connectivity between marine reserves in central New Zealand: testing the regional network
}

\author{
Manuscript submitted for publication in Marine Biology \\ Salinas de Leon $\boldsymbol{P}$ and Bell J.J. Population connectivity in central New Zealand: \\ supporting regional-scale marine reserve network planning. \\ Author contribution: PS designed the study and performed the molecular \\ work, analyzed the data and wrote the manuscript. JJB co-designed the study, \\ edited the manuscript and obtained the funding for the project.
}

\section{Abstract}

Marine Reserves (MRs) have been widely used as a management tool for marine ecosystems. There is increasing focus to develop inter-linked networks of MRs that are connected and therefore self-supporting. An important aim of MR network creation is to ensure protected populations are connected in order to ensure population sustainability. However, in most geographic locations there is limited information on such connectivity, which limits our ability to identify sites where new MRs should be placed and whether existing MRs are connected in such networks. New Zealand currently has 33 MRs and despite their relatively wide spatial separation, connectivity has not been a priority in the past designation processes. Here I use the microsatellite markers developed in chapter 2 to examine the genetic differentiation of populations (including four MRs) of the intertidal periwinkle Austrolittorina cincta to infer levels of connectivity in the Cook Strait region in central New Zealand. This abundant species has a long-lived pelagic larvae that can potentially connect populations over large spatial scales. In constrast to what I 
expected, I recorded low, but significant genetic differentiation between most pairs of populations over a maximum spatial scale of $300 \mathrm{~km}$, including several of the MRs. My results suggest that there are processes operating to restrict gene flow between some of the reserves. My findings are relevant to the NZ Marine Protected Area policy and implementation plan, which is a bioregional approach to reserve designation that aims to create a MPA network that will complement the existing MRs by protecting other habitats. My research suggests that if the planned MPA network is to succeed, spatial scales at which reserves must be separated may need to be relatively small $(<55 \mathrm{~km})$

\subsection{Introduction}

No-take marine reserves (MRs) have been designated worldwide to protect specific species or habitats and as a fisheries management tool (Lubchenco et al. 2003). The number of newly established MRs has increased dramatically in recent years, but they still only represent a small overall proportion of the marine environment (Allison et al. 1998, Palumbi 2003, Ballantine \& Langlois 2008). For example, in New Zealand just $7.6 \%$ of the territorial waters (i.e. out to 12 nautical miles) are protected, compared to 34\% of the terrestrial environment (Department of the Environment, 2010). MRs have been shown to support larger populations, larger individuals and higher biomass than adjacent unprotected areas for many commercially fished species (Halpern 2003). MRs are also predicted to enhance populations in adjacent areas through the movement of adults outside the reserve boundaries (McClanahan \& Mangi 2000, Roberts et al. 2001, Halpern \& Warner 2002, Kelly \& MacDiarmid 2003) and also from the export of larvae from MRs (larval-export). Both these effects may help sustain populations beyond reserve boundaries (Palumbi 2001, Cudney-Bueno et al. 2009, Pelc et al. 2009). An 
increasingly important goal in coastal zone management is to create 'networks' of marine reserves or protected areas, in which populations are assumed to be connected through larval exchange or adult migration (Fernandes et al. 2005, Russ et al. 2008, Banks \& Skilleter 2010). The aim of MR networks is to ensure population sustainability, since if populations in MRs are not self-sustaining they need to be linked to other reserves for recovery from local extinctions (Allison et al. 2003, Planes et al. 2009). To date, there have been few studies that have demonstrated MR connectivity through larval exchange (Planes et al. 2009).

The traditional view that marine populations are demographically 'open' (Caley et al. 1996) has been recently challenged by evidence from diverse fields such as otolith chemistry (Jones et al. 1999, Swearer et al. 1999), oceanographic models (Roberts 1997, Cowen et al. 2000, Cowen et al. 2006) and molecular markers (Carreras-Carbonell et al. 2007, Wood \& Gardner 2007, Planes et al. 2009); these studies suggest that some proportion of larvae return to their parental population. This means that connectivity between coastal populations cannot be automatically assumed, even if species have long-lived pelagic larvae or populations are geographically close. Despite the importance of quantifying the levels of larval exchange between populations, it is difficult to measure due to the small size and high mortality of larvae, combined with the large size and complexity of the oceans (Levin 2006, Becker et al. 2007). In addition, other physical factors, such as ocean currents and water chemistry, together with the biological characteristics of larvae (including larval duration, behaviour and mortality), have a strong influence on patterns of larval dispersal and exchange (Levin 2006, Cowen \& Sponaugle 2009). If MPA networks are to be successful, a complete understanding of local and regional connectivity patterns are required. 
New Zealand currently has 33 marine reserves representing $7.6 \%$ of its territorial waters (Department of Conservation, 2010). Despite the relatively wide spatial separation of the current MRs in New Zealand, connectivity between MRs has not been considered in the past MR designation processes. Instead MRs have been proposed and designated on an ad-hoc basis. However, in 2005 the NZ Marine Protected Areas policy and implementation plan was developed with the objective of 'protecting marine biodiversity by establishing a network of MPAs that is comprehensive and representative of New Zealand's marine habitats and ecosystems' (Department of Conservation and Ministry of Fisheries, 2005). One of the MPA policy design principles is that the proposed network should be viable and that viability will depend on several factors, including connectivity between MPAs. The data that is currently available for population connectivity in NZ marine ecosystems is incomplete, particularly at region scales (100's km) and thus further work is required to understanding the linkages between NZ marine populations to adequately inform policy makers (Gardner et al. 2010). This research is focused on population connectivity on the coast of the lower North Island in New Zealand. There are six marine reserves within the Cook Strait region including two island MRs (Kapiti Island MR and Long Island MR), with the nearest MRs to the north or south being separated by over $250 \mathrm{~km}$. The localised nature of the MRs in the Cook Strait region has the potential to represent a regional-scale network, however, at present the levels of connectivity between these MRs is unknown.

In this study I used the New Zealand endemic brown periwinkle Austrolittorina cincta as a model to infer past larval exchange patterns between different populations across central New Zealand, including four MRs. A. cincta is a suitable model as it is a common gastropod, with a wide distribution around New 
Zealand that inhabits the upper intertidal area. This gastropod has limited adult movement, a planktonic larval duration (PLD) of 6 to 8 weeks, thereby being a good representative of many intertidal and sessile species (Reid \& Williams 2004). Given the 6 to 8 week PLD, larvae could potentially be transported over hundreds of kilometres. In fact, a previous genetic study in the sister species Austrolittorina antipodum using mitochondrial DNA analysis of populations across New Zealand North and South Islands did not show significant partitioning of genetic variation and a panmetic population structure (Waters et al. 2007). Despite this earlier study on a closely-related species (with similar life-history characteristics), there are a number of potential physical barriers that might influence connectivity between populations including distance, environmental gradients, and current flow patterns; and also several biological factors are also important drivers of population connectivity, particularly life-history strategy (Kyle \& Boulding 2000, Bell 2008b); these factors have been proposed as important drivers of population structuring for other NZ species (Gardner et al. 2010). Furthermore, highly polymorphic markers have often identified population structure that has not been revealed by mitochondrial DNA analysis (e.g. Lukoschek et al. 2008).

The greater Cook Strait region, the narrow gap that divides New Zealand's North and South islands, has a complex hydrography and has one of the strongest tidal currents in the world (250 $\mathrm{cms}^{-1}$; Stanton et al. 2001). Previous genetic studies using mitochondrial markers have revealed a genetic break in central New Zealand for the greenshell mussel Perna canaliculus (Apte \& Gardner 2002), the seastar Patiriella regularis (Waters \& Roy 2004) and for three species of limpets of the genus Cellana ( C. ornata, C. radians and C. flava); (Goldstien et al. 2006). These studies reported a barrier to gene flow at $42^{\circ}$ South, possibly due to the strong tidal 
flows and turbulent mixing of water in the Cook Strait and the intense upwelling on both the east and west coast (Apte \& Gardner 2002).

Considering the widespread distribution of $A$. cincta across New Zealand, its large population size and high fecundity, combined with a relatively long PLD (6-8 weeks), and that a previous mtDNA study on the sister species $A$. antipodium revealed no genetic differentiation at the whole New Zealand scale, my null hypotheses were: 1) there is no genetic population structuring for this species between New Zealand's North and South Island; 2) there is no difference in the genetic diversity of populations of this species between New Zealand's North and South Islands; and 3) there is high connectivity (therefore no genetic population structuring) between four of the Marine Reserves within the Cook Strait region.

\subsection{Materials and methods}

\subsubsection{Study species}

The brown periwinkle Austrolittorina cincta is a New Zealand endemic grazing gastropod that is abundant on the upper shores of rocky habitats throughout New Zealand. Fertilization occurs internally for this species, which is followed by a planktonic larval development stage of 6 to 8 weeks (Reid \& Williams 2004), with the potential for larvae to travel long distances carried by oceanic currents. VanderVeur (2010) studied the ecology of this species on populations on the south of NZ

North Island and revealed a very high population abundance (1600 individulas $/ \mathrm{m}^{2}$ ), relatively low adult movement rates $(18.7 \mathrm{~m} \pm 16 \mathrm{~m} /$ year $)$ and that larvae settlement peaked between February and March. 


\subsubsection{Sampling}

Between 2008 and 2010, A. cincta samples $(n=330)$ were obtained from seven different locations across New Zealand North (three locations) and South Islands (four locations), including four Marine Reserves: Wanganui (S39 56' 55";

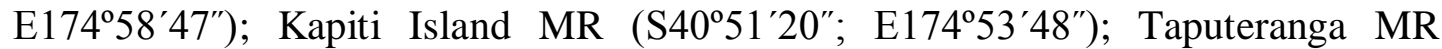

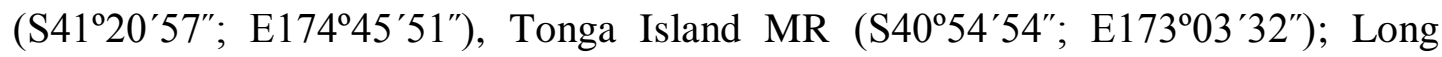

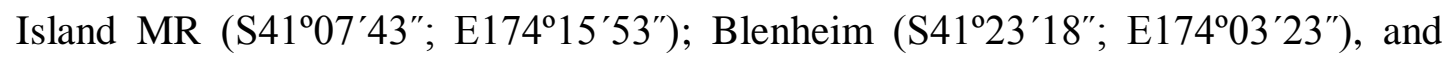
Kaikoura (S42 $26^{\prime} 50^{\prime \prime}$; E173³4'59"); (Fig. 1). Samples from Kapiti Island MR and Tonga Island MR were collected immediately next to the reserve boundary; samples from Taputeranga MR were collected before the reserve was established (in 2008); and a permit was obtained to collect samples within Long Island MR (permit number: NM-27636-MAR). Samples from Wanganui, Taputeranga MR, Tonga Island MR and Blenheim were collected from shores on the mainland of the South and North Island. Kapiti Island MR and Long Island MR samples were collected from island shores. Samples were haphazardly collected from several rocky areas at each of the sampling locations, preserved in $99 \%$ ethanol and then transported to the laboratory where they were stored at $-20^{\circ} \mathrm{C}$. 


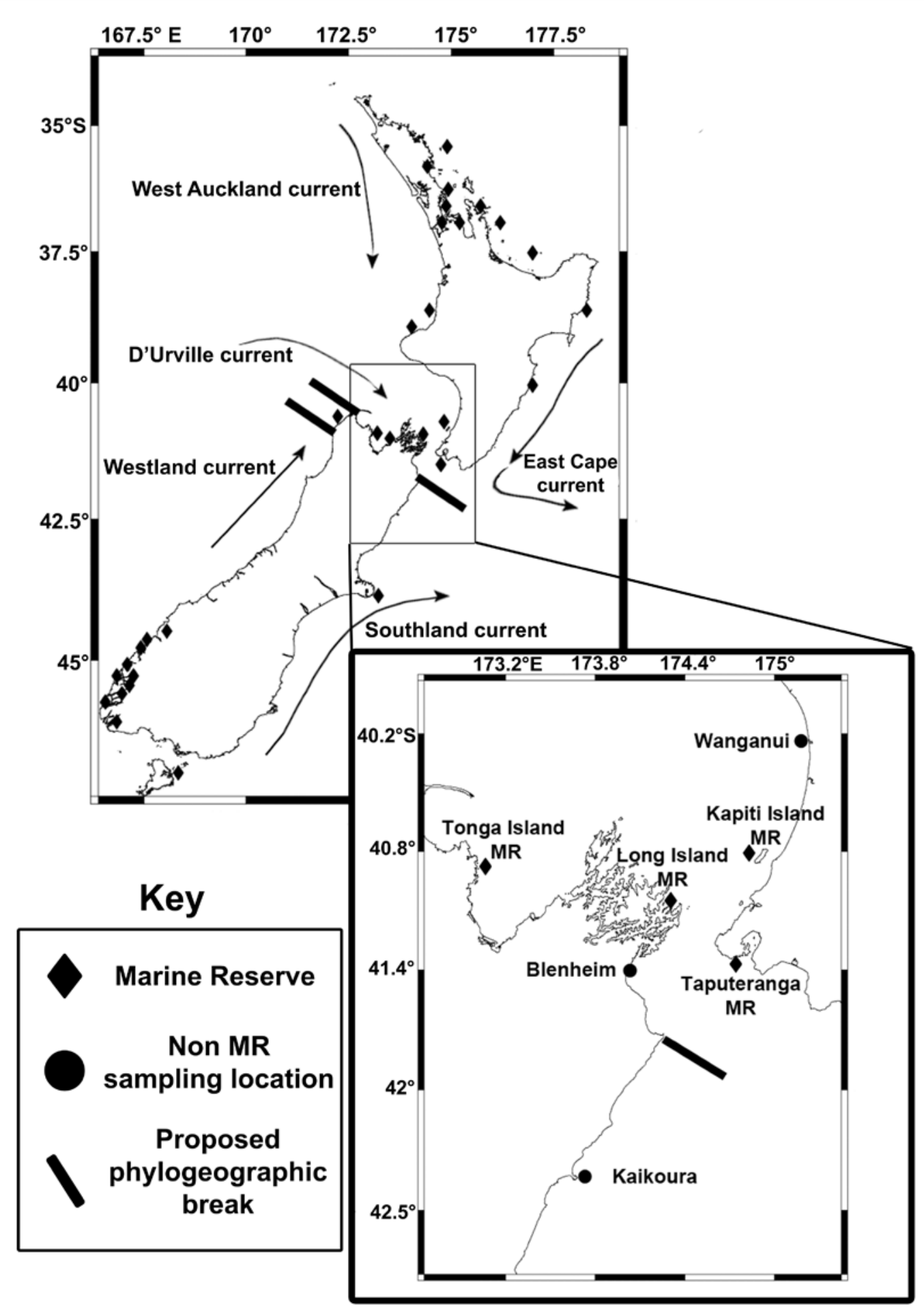

Fig. 1 Map of seven Austrolittorina cincta sampling loations (4 Marine Reserve (MR) location; 3 non MR locations) in central New Zealand for microsatellite analysis. Map also shows major NZ oceanic currents; 31 marine reserve locations and proposed phylogepgraphic breaks (after Apte and Gardner, 2002) between the North and South islands. 


\subsubsection{DNA extraction and PCR amplification}

A small piece of tissue ( $20 \mathrm{mg})$ was dissected from the foot of each $A$. cincta. Genomic DNA was extracted from these samples following the phenol:chloroform method described by Sokolov (2000), resuspended in TE buffer (10mM Tris, 0.1 EDTS, $\mathrm{pH} 8.3$ ) and stored at $-20^{\circ} \mathrm{C}$. The concentration of DNA was estimated using a Nanodrop (Thermo-Scientific). Each individual was genotyped for the five microsatellite markers (A8, A111, B117, D104, and D128) developed in chapter 2 (Genbank access codes: HQ171471, HQ171472, HQ171476, HQ171477, HQ171478).

Polymerase chain reactions (PCR) were conducted on a MJ Research thermocycler in 15 ul reaction volumes containing 2 ul 10x buffer (Roche) including $1.5 \mathrm{mM} \mathrm{MgCl}_{2}, 1$ ul $10 \mu \mathrm{M}$ dNTPs, 1 ul $10 \mu \mathrm{M}$ of each primer, 0.1 ul Taq polymerase (Roche) and 20 ng of template DNA. Amplifications were conducted with the following conditions: $95{ }^{\circ} \mathrm{C}$ for 5 minutes, followed by 40 cycles at $95{ }^{\circ} \mathrm{C}$ for 30 seconds, $54-56{ }^{\circ} \mathrm{C}$ for 30 seconds, $72^{\circ} \mathrm{C}$ for one minute, and a final $72{ }^{\circ} \mathrm{C}$ extension step of 30 minutes. The presence of PCR products was confirmed on a $1 \%$ agarose gel. PCR products from primers labelled with different dyes (FAM, VIC, NED and PET) were combined for multiplex separation on an Applied Biosystems 3130xl genetic analyser, using a 500 LIZ size standard (Applied Biosystems). Genotypes were scored by Genemarker v1.91. All automatic scoring was checked manually, and samples that showed a very low signal or no signal were re-amplified.

\subsubsection{Genetic Analysis}

Tests for Hardy-Weinberg equilibrium (HWE), genotypic linkage disequilibrium (LD) and population differentiation were conducted by ARLEQUIN 
v3.5 (Excoffier \& Lischer 2010) and estimation of the exact p-values was conducted using the Markov Chain method. Tests for HWE were conducted for each locuspopulation combination, and LD for all pairs of loci within and across populations. Genetic diversity was calculated for each population as the total number of alleles per locus, the expected proportion of heterozygotes, the observed numbers of heterozygotes and the inbreeding coefficient $\left(\mathrm{F}_{\mathrm{IS}}\right)$. $\mathrm{F}_{\mathrm{IS}}$ values were calculated by GENEPOP (Rousset 2008); differences between the observed heterozygosity (Ho) and expected heterozygosity $(\mathrm{He})$ under HWE are proportional to the values of the inbreeding coefficient. We also used MICROCHECKER v2.2.3 (Van Oosterhout et al. 2004) with the Oosterhout algorithm to examine the influence of undetectable alleles, and to check for scoring errors and any evidence of large allele dropout. Oneway Analysis of Variance (ANOVA) was used to compare the mean number of alleles per locus between populations.

The genetic structure of populations was determined using the infinite allele model (Kimura and Ohta 1978). Arlequin v3.5 calculated values of $F_{\text {st }}$ and was used to conduct hierarchical analysis of molecular variance (AMOVA). Significance levels were determined for the overall values and for pairwise population values after 9999 permutations. The effect of distance between populations was examined by measuring the oceanographic distance between populations and correlating this with genetic differentiation $\left(\mathrm{F}_{\mathrm{ST}} / 1-\mathrm{F}_{\mathrm{ST}}\right)$. A Mantel test was carried out by Arlequin v3.5 to determine if any correlation existed between genetic distance and the oceanographic distance between populations.

Assignment tests were performed using the online computer programme Doh (available at: http://www.biology.ualberta.ca/jbrzusto/doh.php), which is based on the calculations of Paetkau et al. (1995). This test determines the number of 
individuals that can be assigned to the population from which they were collected. The programme Doh was also used to create a matrix was of $A x, y$ which is a measure of how much more likely genotypes of individuals sampled in population $x$ are in a population than in population $y$. A similarity dendrogram was then produced from these distances using the Drawtree program from the PHYLIP software package (using complete linkage and Canberra distances). Genetic structuring in the dataset was further explored using the Bayesian clustering method STRUCTURE v2.3.3, which can assign individuals to genetic clusters without taking into account where the sample originated. The most likely number of genetic clusters (K) was calculated by running the programme without population information under the admixture model (where individuals may have mixed ancestry) and independent allele frequencies. The burn length was 100,000 steps followed by 1,000,000 Markov Chain Monte Carlo (MCMC) replications. I performed this analysis by running five independent chains for each $K$, from $K=1$ to $K=7$.

\subsection{Results}

\subsubsection{Genetic Diversity}

In total, 330 Austrolittorina cincta from seven different populations across the Cook Strait region were genotyped at five microsatellite loci. Loci were polymorphic across all populations and the mean number of alleles per locus ranged from 20.6 to 24 (Table 2). No linkage disequilibrium was observed between any loci pairs for any population comparisons. No significant differences in the mean number of alleles per locus were found between pairs of sites for each species (ANOVA, $\left.\mathrm{F}_{0,32} \mathrm{p}<0.05\right)$ and private alleles were present in all samples 
The expected heterozygosity over all loci for each population ranged from 0.75 to 0.95 , while the observed heterozygosity across all loci for each population ranged between 0.71 and 0.92 and was generally lower than the expected heterozygosity in all the samples, suggesting heterozygote deficiency. Four of the 35 population-locus combinations deviated significantly from HWE. Such significant deviations corresponded to high $\mathrm{F}_{\text {IS }}$ values, indicating a heterozygote deficiency within a small proportion of loci and populations.

\subsubsection{Genetic differentiation between populations}

The genetic differentiation over all 7 populations was low, but significant with an $\mathrm{F}_{\mathrm{ST}}=0.011(95 \% \mathrm{CI}=0.008$ to $0.014, \mathrm{p}<0.05)$. Most of the pairwise $\mathrm{F}_{\mathrm{ST}}$ comparisons for population pairs were significant (Table 3) and ranged between 0.004 and 0.016 . Long Island MR was significantly genetically different from all the other sampled populations and showed the highest mean genetic differentiation for all population pairs (Mean $\mathrm{F}_{\mathrm{ST}}=0.013 \pm 0.002 \mathrm{SD}$ ), while the Taputeranga MR showed the lowest genetic differentiation from other populations (Mean $\mathrm{F}_{\mathrm{ST}}=0.008$ \pm 0.002 SD). Between MR pairs comparisons, Taputeranga MR was genetically different from Tonga Island MR but not to Kapiti Island MR. Finally, Tonga Island MR and Kapiti MR were not significantly different. Kaikoura also showed significantly genetic differences with all the other populations and a high mean genetic differentiation from populations (Mean $\mathrm{F}_{\mathrm{ST}}=0.012 \pm 0.002 \mathrm{SD}$ ). Mantel tests of isolation by distance found no significant correlation between geographic distance and $\mathrm{F}_{\mathrm{ST}} /\left(1-\mathrm{F}_{\mathrm{ST}}\right) ;(\mathrm{p}=0.838$, Fig.2). 
Table 2 Total number of alleles per locus (a), observed heterozygosities $\left(\mathrm{H}_{\mathrm{o}}\right)$, expected heterozygosities $\left(\mathrm{H}_{\mathrm{e}}\right)$ and inbreeding coefficient $\left(\mathrm{F}_{\mathrm{IS}}\right)(\mathrm{bold}$ : significant deviations from HWE) for five microsatellite loci for $A$. cincta at 7 populations. (n) indicates individuals sampled per population

\begin{tabular}{|c|c|c|c|c|c|c|c|c|c|c|c|c|c|c|c|c|c|c|c|c|}
\hline \multirow[b]{2}{*}{ Locus } & \multicolumn{5}{|c|}{ Wanganui $(n=50)$} & \multicolumn{5}{|c|}{ Kapiti Island MR (n=45) } & \multicolumn{5}{|c|}{ Taputeranga MR (n=50) } & \multicolumn{5}{|c|}{ Tonga Island MR $(n=45)$} \\
\hline & A8 & A111 & B117 & D104 & D128 & A8 & A111 & B117 & D104 & D128 & A8 & A111 & B117 & D104 & D128 & A8 & A111 & B117 & D104 & D128 \\
\hline A & 27 & 26 & 21 & 15 & 16 & 22 & 22 & 22 & 19 & 18 & 26 & 28 & 19 & 16 & 17 & 25 & 23 & 19 & 15 & 13 \\
\hline $\mathbf{H}_{\mathbf{0}}$ & 0.9 & 0.88 & 0.84 & 0.82 & 0.8 & 0.87 & 0.87 & 0.8 & 0.8 & 0.8 & 0.92 & 0.88 & 0.86 & 0.76 & 0.82 & 0.89 & 0.87 & 0.78 & 0.71 & 0.84 \\
\hline $\mathbf{H}_{\mathbf{e}}$ & 0.94 & 0.94 & 0.91 & 0.84 & 0.88 & 0.92 & 0.93 & 0.88 & 0.87 & 0.85 & 0.95 & 0.94 & 0.9 & 0.81 & 0.89 & 0.95 & 0.92 & 0.87 & 0.75 & 0.89 \\
\hline \multirow[t]{2}{*}{$\mathbf{F}_{\text {IS }}$} & 0.09 & 0.07 & 0.11 & 0.1 & 0.07 & 0.09 & 0.07 & 0.08 & 0.07 & 0.06 & 0.03 & 0.06 & 0.05 & 0.06 & 0.07 & 0.07 & 0.06 & 0.09 & 0 & 0.05 \\
\hline & \multicolumn{5}{|c|}{ Long Island MR $(n=50)$} & \multicolumn{5}{|c|}{ Blenheim $(n=45)$} & \multicolumn{5}{|c|}{ Kaikoura $(n=45)$} & & & & & \\
\hline Locus & A8 & A111 & B117 & D104 & D128 & A8 & A111 & B117 & D104 & D128 & A8 & A111 & B117 & D104 & D128 & & & & & \\
\hline A & 27 & 26 & 24 & 18 & 20 & 22 & 20 & 22 & 10 & 21 & 29 & 22 & 25 & 16 & 17 & & & & & \\
\hline $\mathbf{H}_{\mathbf{o}}$ & 0.9 & 0.92 & 0.8 & 0.8 & 0.82 & 0.87 & 0.84 & 0.89 & 0.71 & 0.82 & 0.9 & 0.86 & 0.9 & 0.84 & 0.84 & & & & & \\
\hline $\mathbf{H}_{\mathbf{e}}$ & 0.95 & 0.91 & 0.89 & 0.88 & 0.89 & 0.93 & 0.89 & 0.9 & 0.75 & 0.9 & 0.94 & 0.93 & 0.9 & 0.85 & 0.89 & & & & & \\
\hline$F_{\text {IS }}$ & 0.05 & 0.01 & 0.05 & 0.09 & 0.16 & 0.06 & 0.005 & 0.06 & 0.009 & 0.12 & 0.1 & 0.08 & 0.01 & 0.03 & 0.09 & & & & & \\
\hline
\end{tabular}


Table 3 Austrolittorina cincta. Matrix of pairwise comparisons of population genetic differentiation using $\mathrm{F}_{\mathrm{ST}}$

\begin{tabular}{|lccccccc|}
\hline \multicolumn{1}{|c}{ Population } & WAN & $\begin{array}{c}\text { KAP } \\
\text { MR }\end{array}$ & $\begin{array}{c}\text { TAP } \\
\text { MR }\end{array}$ & $\begin{array}{c}\text { TI } \\
\text { MR }\end{array}$ & $\begin{array}{c}\text { LI } \\
\text { MR }\end{array}$ & BLE & KAI \\
\hline Wanganui & $\mathbf{X}$ & & & & & & \\
Kapiti MR & 0.008 & $\mathbf{X}$ & & & & & \\
Taputeranga MR & 0.006 & 0.008 & $\mathbf{X}$ & & & & \\
Tonga Island MR & $\mathbf{0 . 0 0 9}$ & 0.008 & $\mathbf{0 . 0 1 1}$ & $\mathbf{X}$ & & & \\
Long Island MR & $\mathbf{0 . 0 1 6}$ & $\mathbf{0 . 0 1 1}$ & $\mathbf{0 . 0 1 4}$ & $\mathbf{0 . 0 1 3}$ & $\mathbf{X}$ & & \\
Blenheim & 0.004 & $\mathbf{0 . 0 1 2}$ & 0.004 & $\mathbf{0 . 0 0 9}$ & $\mathbf{0 . 0 1}$ & $\mathbf{X}$ & \\
Kaikoura & $\mathbf{0 . 0 1 5}$ & $\mathbf{0 . 0 1 1}$ & $\mathbf{0 . 0 1 3}$ & $\mathbf{0 . 0 1 0}$ & $\mathbf{0 . 0 1 3}$ & $\mathbf{0 . 0 1 2}$ & X \\
\hline
\end{tabular}

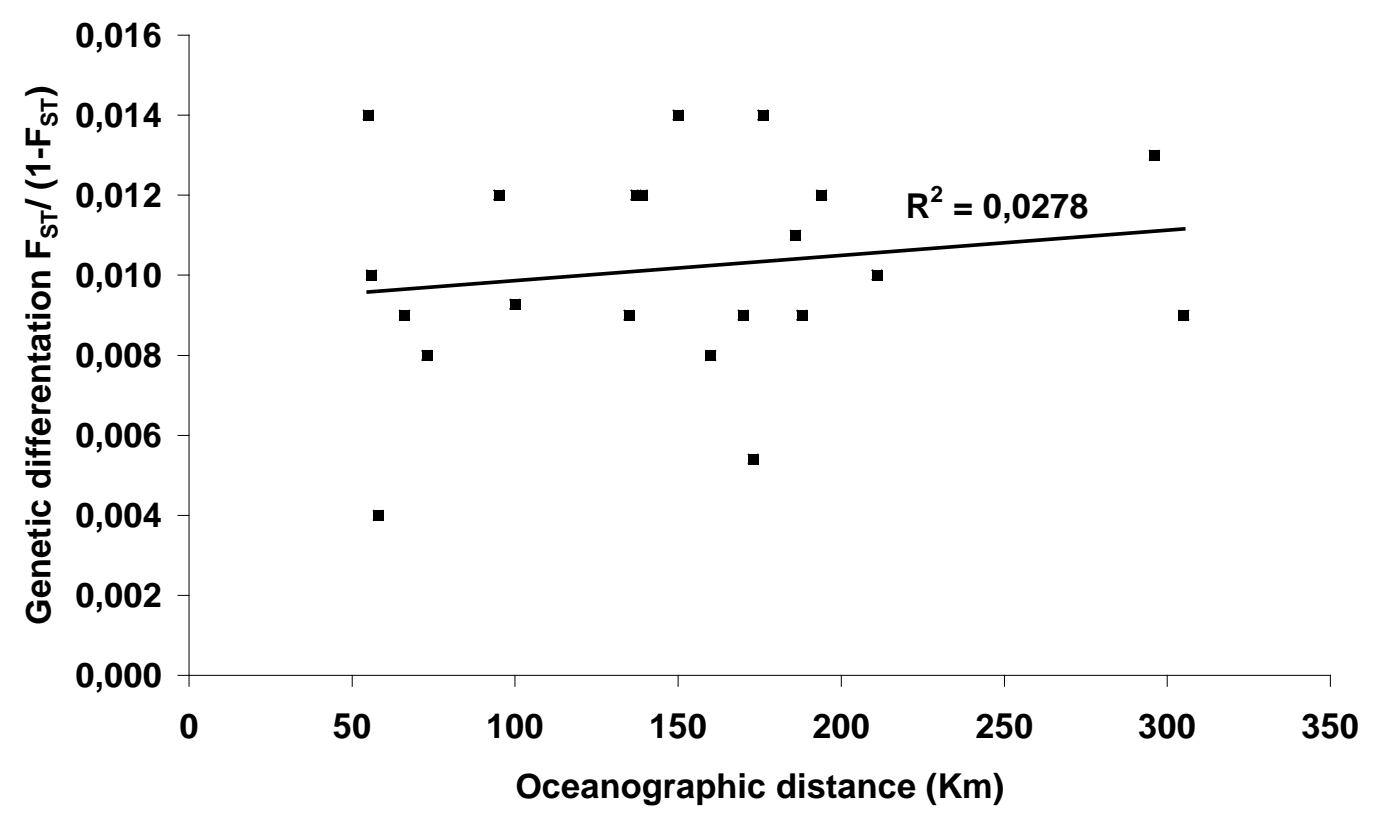

Fig. 2 Austrolittorina cincta isolation by distance within central New Zealand populations. Population pairwise genetic differentation plotted against minimum oceanic distance bewteen populations

Global AMOVA revealed that a significant proportion of the variance was attributable to genetic variation between populations (1\%, p<0.001) and 98.83\% was attributable to genetic variation within populations. When only MR populations were included in the analysis, a significant proportion of the genetic variation (0.97\%) was attributable to genetic variation between the populations and $98.9 \%$ was attributable to genetic variation within populations (Table 4). For both AMOVA, only $0.17 \%$ (all 
populaions) and $0.13 \%$ (only MRs) of the variation was explained by North and South Island groupings ( $\mathrm{p}>0.05)$.

Table 4 Summary of analysis of molecular variance (AMOVA) among populations. Degrees of freedom (df), variance components, percentage of the total variance explained by the groupings (\%) and their significance are indicated.

\begin{tabular}{|lcccc|}
\hline \multicolumn{1}{|c}{ Source of variation } & Df & $\begin{array}{c}\text { Variance } \\
\text { Component } \\
\text { s }\end{array}$ & $\begin{array}{c}\text { \% total } \\
\text { Variance }\end{array}$ & P value \\
\hline (A) North Island; South Island & 1 & 0.0039 & 0.17 & $>0.05$ \\
Among groups & 5 & 0.022 & 1.00 & $<0.001$ \\
Between samples within groups & 653 & 2.26 & 98.83 & $<0.001$ \\
Within samples & & & & \\
(B) North Island MRs; South Island MRs & 1 & 0.002 & 0.13 & $>0.05$ \\
Among groups & 2 & 0.022 & 0.97 & $<0.001$ \\
Between samples within groups & 376 & 2.273 & 98.9 & $<0.001$ \\
Within samples & & & & \\
\hline
\end{tabular}

Maximum likelihood tests examining the number of populations using an admixture model with no prior information in SRUCTURE v.2.3.3, showed that the highest probability and lowest confidence intervals were found when all samples were grouped into one cluster $(\mathrm{K}=1)$. Assignment tests revealed that the percentage of $A$. cincta individuals assigned to the population of collection varied between 20 and $46 \%$ (Table. 5) and an average of $28 \%$ of individuals were assigned to their own population. The dendrogramproduced by Drawtree based on assignment indices indicated considerable genetic differences between some populations similar to those identified from $\mathrm{F}_{\mathrm{ST}}$ (Fig. 3). 
Table 5 Assignment test results for individuals from each population. Values are the percentage of individuals from each sampling location (rows) assigned to each population (columns).

Correct assignments are indicated in bold

\begin{tabular}{|lccccccc|}
\hline & Wan & Kap & Tap & Tis & Lis & Ble & Kai \\
\hline Wanganui & $\mathbf{2 6}$ & 16 & 14 & 14 & 6 & 6 & 18 \\
Kapiti MR & 12 & $\mathbf{2 0}$ & 10 & 6 & 6 & 18 & 18 \\
Taputeranga MR & 8 & 10 & $\mathbf{4 6}$ & 16 & 8 & 8 & 4 \\
Tonga Island MR & 8 & 10 & 12 & $\mathbf{2 4}$ & 16 & 6 & 14 \\
Long Island MR & 6 & 8 & 10 & 16 & $\mathbf{3 0}$ & 10 & 20 \\
Blenheim & 6 & 10 & 6 & 12 & 14 & $\mathbf{3 0}$ & 12 \\
Kaikoura & 8 & 12 & 14 & 12 & 14 & 10 & $\mathbf{2 0}$ \\
\hline
\end{tabular}

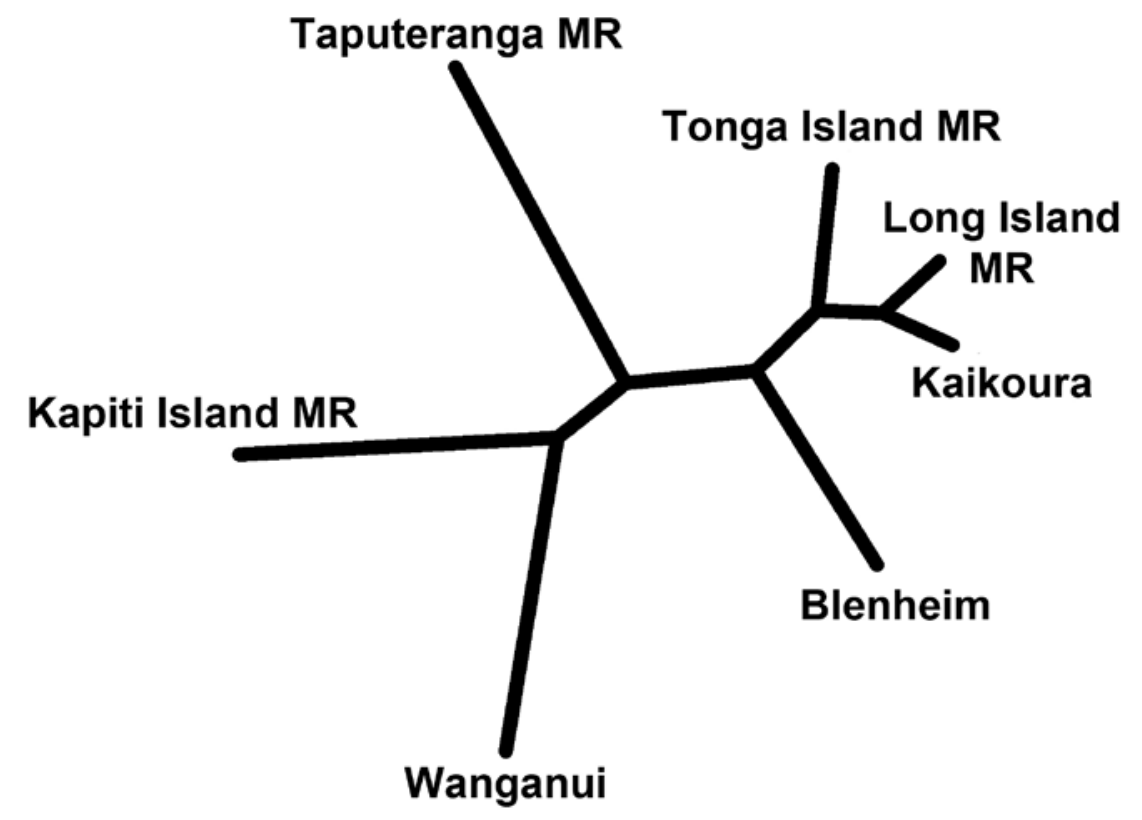

Fig. 3 Similarity dendrogram (clustering using Canberra distance and complete linkage) constructed using Drawtree in the PHYLIP software package (redrawn to scale) based on a distance matrix calculated from assignment indices for populations. 


\subsection{Discussion}

This study provides the first data on MR connectivity in central New Zealand using highly polymorphic microsatellites markers. My results showed a weak, but significant differentiation between most pairs of populations studied, suggesting the presence of barriers to larval dispersal. Out of the six possible MRs pairwise comparisons, four were significantly genetically different, suggesting the presence of barriers to gene flow between these reserves. This study highlights the importance of including connectivity measures when creating networks of MRs as connectivity cannot be inferred directly from life-history traits.

\subsubsection{Between-population structure}

The levels of genetic differentiation observed in A. cincta are similar to those identified in other marine invertebrates with planktotrophic larval development characterised with microsatellite markers (Colson \& Hughes 2004, Bell 2008a). My study showed weak, but significant differentiation between most population pairs with a significant global $F_{S T}$ of 0.011 . My results using faster evolving genetic markers contrast with those of a previous study by Waters et al. (2007) of the sister species Austrolittorina antipodium using mtDNA analysis, where no significant genetic differentiation was reported within 20 populations across its entire New Zealand range $(>2000 \mathrm{~km})$. In my study, samples of $A$. cincta were collected across different locations within the Greater Cook Strait region, a region characterised by a complex system of converging currents (Fig.1). Previous genetic studies on populations of other marine taxa around the Cook Strait region, including the greenshell mussel Perna canaliculatus (Apte \& Gardner 2002) and the cushion star Patriella regularis (Waters \& Roy 2004), have revealed that populations in the North 
of the South Island are not genetically distinct from those on the South of the North Island, suggesting a high degree of connectivity across the Cook Strait. My results partially support this high connectivity view given, as an example, the lack of significant genetic differentiation between Taputeranga MR and Blenheim populations (separated by $\sim 55 \mathrm{~km}$ ). However, in my study we also recorded significant levels of genetic differentiation between some north-south island population (e.g. Taputeranga MR - Long Island MR 55 km and Kapiti MR Blenheim $~ 100 \mathrm{~km}$ ) which suggest a more complex connectivity scenario in the Cook Strait region. In the same context, several previous genetic studies (e.g. Apte \& Gardner 2002, Waters \& Roy 2004, Ayers \& Waters 2005, Goldstien et al. 2006) conducted on populations across both New Zealand North and South Islands using mitochondrial DNA markers support the hypothesis first proposed by Apte and Gardner (2002) that upwelling south of the Cook Strait is driving the divergence of North and South Island populations at approximately $42^{\circ}$ South. In my study, only one population (Kaikoura) was situated below the proposed phylogeographical break at $\sim 42^{\circ} \mathrm{S}$ on the West coast of the South Island. The Kaikoura population showed significant genetic differentiation for all the population pairwise tests (Mean $\left.\mathrm{F}_{\mathrm{ST}}=0.012 \pm 0.002 \mathrm{SD}\right)$. Therefore my study, using faster evolving genetic markers, supports the hypothesis of a genetic break at $\sim 42^{\circ} \mathrm{S}$.

\subsubsection{Marine Reserve connectivity}

Pairwise $\mathrm{F}_{\mathrm{ST}}$ comparisons between MRs populations were not significant for two of the six MR - MR combinations suggesting relatively higher levels of connectivity through larval flow or adult migration via rafting (Table 3). Interestingly, Long Island MR showed a weak, but significant pairwise $\mathrm{F}_{\text {ST }}$ 
differentiation from the other three MRs. Long Island MR also showed the highest mean levels of population pairwise genetic differentiation (Mean $\mathrm{F}_{\mathrm{ST}}=0.013 \pm 0.002$ SD) with all other populations. This level of differentiation could be a consequence of the hydrodynamic features surrounding this island MR. Long Island MR lays at the entrance of the Queen Charlotte sound in the Marlborough sounds region (Fig.1). To my knowledge, there are no detailed hydrodynamic models for this area. However, it has been documented that complex water circulations patters arise when the strong tidal currents of the Cook Strait flow through the narrow entrances of the Queen Charlotte sound (Heath 1974). In addition to this, strong winds common in this area are channelled by the steep topography, creating local wind-driven currents and turbulence. These oceanographic patterns could create barriers to larval dispersal or enhance self-recruitment to the island. For example, Johnson and Black (2006) found that the Islands of the Abrolhos archipelago in Western Australia increase genetic subdivision and disrupt patterns of genetic connectivity of the snail Austrocochlea constricta, which has a planktonic larvae. These authors argued that complex water movements caused by the series of islands, associated reefs and intervening channels favour local retention of larvae. Similarly Bell (2008a), showed restricted gene flow between island Marine Protected Areas and their mainland for populations of the planktonic developer barnacle Semibalanus balanoides and he argued that this could be a consequence of the strong currents between the islands and the mainland.

\subsubsection{Marine Reserve management implications}

My results are relevant in the context of the recent release of the New Zealand MPA policy and implementation plan. This plan aims to create MPA networks that will complement the existing 33 MRs by protecting other habitats 
through the creation of new Marine Reserves, MPAs and other Marine Protected Areas (e.g. areas with fishing gear restrictions, marine mammal sanctuaries and areas closed to trawling). The MPA policy is based on a regional approach in which Marine Protection Planning Forums (MPPF) are to be be implemented in each of the 14 proposed New Zealand coastal biogeographic regions. Each bioregional MPPF will comprise a range of stakeholders tasked with the role of implementing the MPA network 'based on the best available information and a commitment to minimise effects of new protected areas on existing users'. Shears et al. (2008) highlighted how the past ad hoc establishment of Marine Reserves in New Zealand has resulted in a scarcity of reserves and a poor representation of individual biogeographic regions. For example, there are no reserves on the East Coast of the South Island. The MPA policy plan aims to cover those conservation gaps and to establish a viable MPA network in which MPAs are inter-connected. Although MRs have been present in NZ for over 30 years (Ballantine \& Gordon 1979) and they have been proved successful in: increasing the biomass of economically important species (Kelly et al. 2000, Willis et al. 2003, Denny et al. 2004, Pande et al. 2008); promoting ecosystem recovery through trophic cascades (Babcock et al. 1999, Shears \& Babcock 2002, 2003); and enhancing adjacent fisheries via adult movement (Kelly \& MacDiarmid 2003). However, to date there have not been any studies assessing the levels of connectivity between existing New Zealand Marine reserves.

Excluding the oceanic Auckland Islands and Kermadec Island MRs, there are 31 MRs across NZ mainland Islands, with 15 in the North Island and 16 in the South Island (Fig.1; Table. 6). The oceanographic distance between MRs ranges from 19 $\mathrm{km}$ to $\sim 300 \mathrm{~km}$, with an average distance of $72.25 \pm 12.06 \mathrm{~km}$ between MRs (Fig.1; Table. 6). The MRs sampled on this study were located around the Cook Strait 
Region and were separated by scales of 55 to $159 \mathrm{~km}$ with an average distance of $76.2 \pm 20.9 \mathrm{~km}$ between reserves. My results revealed that MRs separated for as little as $55 \mathrm{~km}$ (e.g. Taputeranga MR and Long Island MR) showed low but significant levels of genetic differentiation, suggesting the presence of barriers to larval dispersal at this scale. There are several physical barriers that could influence connectivity between marine populations including distance, environmental gradients, coastal topography or oceanographic patterns. My data did not support the presence of an isolation by distance model, suggesting that the genetic differentiation observed between some populations is driven by some other factors. The Greater Cook Strait Region hydrogaphy is complex and characterised by strong tidal mixing and high turbulence, combined with the formation of numerous eddies and upwelling areas (Apte and Gardner, 2002) and it is likely that some of these oceanographic patterns could act as a barrier for larval dispersal between populations separated over relatively short distances (i.e. $55 \mathrm{~km}$ ). For example, a phylogeogrphic study across New Zealand using a high dispersal sea star ( 9 - 10 weeks PLD) revealed a strong genetic structure, especially in Northern NZ samples (Waters \& Roy, 2004). These authors suggested the presence of eastern and western populations due to the influence of coastal currents that restrict gene flow and promote genetic differentiation between populations. This study supports the view that other NZ MR regional networks might not be as connected as previously predicted considering the strong influence of coastal hydrodynamic features.

Two of the 4 MR populations sampled in this study (i.e. Kapiti Island MR and Long Island MR) and many other NZ MRs are located in areas with high potential for isolation, including islands, closed embayments or fiords (Table 6). Several studies have revealed that the particular oceanographic features that 
characterise these areas have a profound affect on the levels of larval export from the MR compared to open coast populations (Bell \& Okamura, 2005; Bell, 2008a; McInerney et al. 2009). For example, Skold et al (2003) and Perrin et al. (2004) revealed genetic isolation of the seastar Coscinasterias muricata, a species with planktonic development, in populations inhabiting the fiordland region of the NZ South Island. These studies highlight the importance of understanding levels of regional connectivity between MRs in NZ given that in the Fiordland region alone there are 10 of the $33 \mathrm{NZ}$ marine reserves and they could be potentially isolated for other coastal areas. 
Table 6 Minimum oceanic distance between Marine Reserves within New Zealand North, South and Stewart Islands (Aukland and Kermadec Island MRs are not included). Table also includes MR description and name of nearest MR. Minimum oceanographic distance measured from Google Earth.

\begin{tabular}{|c|c|c|c|c|c|c|c|}
\hline \multicolumn{4}{|c|}{ South Island } & \multicolumn{4}{|c|}{ North Island } \\
\hline $\begin{array}{l}\text { Marine } \\
\text { Reserve }\end{array}$ & $\begin{array}{c}\text { MR } \\
\text { Description }\end{array}$ & $\begin{array}{l}\text { Nearest } \\
\text { MR }\end{array}$ & $\begin{array}{l}\text { Distance } \\
\text { (km) }\end{array}$ & $\begin{array}{l}\text { Marine } \\
\text { Reserve }\end{array}$ & $\begin{array}{c}\text { MR } \\
\text { Description }\end{array}$ & $\begin{array}{l}\text { Nearest } \\
\text { MR }\end{array}$ & $\begin{array}{c}\text { Distance } \\
\text { (km) }\end{array}$ \\
\hline Te Wharawhara & Island & $\begin{array}{c}\text { Te Tapuwae } \\
\text { O Hua }\end{array}$ & 190 & Taputeranga & Coastal / Island & Long Island - Kokomohua & 55 \\
\hline $\begin{array}{l}\text { Te Tapuwae } \\
\text { o Hua }\end{array}$ & Fiord & Taumoana & 86 & Kapiti & Island & Long Island - Kokomohua & 56 \\
\hline Taumoana & Fiord & Moana Uta & 34 & Tapuae & Coastal & Parininihi & 52 \\
\hline Moana Uta & Fiord & Taumoana & 34 & Parininihi & Coastal & Tapuae & 52 \\
\hline Taipari Roa & Fiord & $\begin{array}{l}\text { Te Awaatu } \\
\text { Channel }\end{array}$ & 21 & Poor Knights & Island & Whangarei Harbour & 70 \\
\hline Te Awaatu channel & Fiord & Kutu Parera & 20 & Whangarei Harbour & Enclosed bayment & Poor Knights & 70 \\
\hline Kutu Parera & Fiord & $\begin{array}{l}\text { Te Awaatu } \\
\text { Channel }\end{array}$ & 20 & Cape Rodney - Okakari & Coastal / Island & Long Bay - Okura & 53 \\
\hline Kahukura & Fiord & $\begin{array}{l}\text { Te Awaatu } \\
\text { Channel }\end{array}$ & 51 & Long Bay - Okura & Coastal / Estuary & Motu Manawa & 33 \\
\hline Hawea & Fiord & Te Hapua & 28 & Motu Manawa & Enclosed embayment & Long Bay - Okura & 33 \\
\hline Te Hapua & Fiord & Hawea & 28 & Te Matuku & Coastal / Estuary & Motu Manawa & 43 \\
\hline Piopiotahi & Fiord & Hawea & 45 & Te Whanganui A Hei & Coastal / Island & Tuhua & 63 \\
\hline Westhaven & $\begin{array}{c}\text { Enclosed } \\
\text { estuary }\end{array}$ & Tonga Island & 91 & Tuhua & Island & Te Whanganui A Hei & 63 \\
\hline Tonga Island & Coastal / Island & Horoirangi & 42 & Te Paepae a Aotea & Island & Tuhua & 78 \\
\hline Horoirangi & Coastal & Tonga Island & 42 & Te Tapuwae o Rongokako & Coastal & Te Angiangi & 207 \\
\hline Long Island - Kokomohua & $\begin{array}{l}\text { Island within } \\
\text { sound }\end{array}$ & Taputeranga & 55 & Te Angiangi & Coastal & Te Tapuwae o Rongokako & 207 \\
\hline Pohatu & Coastal & Taputeranga & 318 & & & & \\
\hline \multicolumn{4}{|c|}{ Mean ( \pm SE) $69 \pm 19.6$} & \multicolumn{4}{|c|}{ Mean $( \pm$ SE) $75.6 \pm 13.7$} \\
\hline \multicolumn{8}{|c|}{ Overall mean distance $( \pm$ SE) $72.25 \pm 12.06$} \\
\hline
\end{tabular}


It is important to note that we used $A$. cincta as model species to investigate connectivity because of its wide distribution and high abundance. Care should be taken when extrapolating these results to other species, since species with smaller population sizes, more restricted distributions and different life history strategies are likely to show lower levels of connectivity (Bell 2008a). For example, species with shorter larval durations (e.g. sponges); (Duran et al. 2004); direct-development reproductive strategies (e.g. molluscs); (Bell 2008b); active larval behavioural responses (e.g. fish); (Carreras-Carbonell et al. 2007); or specific habitat needs (e.g. kelp); (Alberto et al. 2010) are likely to have lower levels of connectivity.

My results suggest that if the if the planned MPA network in New Zealand is to succeed, spatial scales at which reserves must be separated may need to be relatively small $(50 \mathrm{~km})$. In addition to this, the desired MPA network might be achieved by the designation of several small MRs, given MR success appears to be independent of reserve size (Halpern 2003), separated over small scales (i.e 20 - 50 $\mathrm{km}$ ) rather that few large reserves separated over large distances.

\subsubsection{Within-population structure}

I observed an overall heterozygote deficiency in all loci from what was expected for populations that are in HWE. Heterozygote deficiency has been reported for many marine invertebrates (Zouros \& Foltz 1984), especially gastropods (Winnepenninckx \& Backeljau 1998, Sokolov et al. 2002, Brownlow et al. 2008, McInerney et al. 2009). Several factors can cause heterozygote deficiency including null alleles, the Wahlund effect, inbreeding, mutation, non-random mating or population admixture. Although the reasons behind the high levels of heterozygote deficiency in marine invertebrates still remain difficult to explain (Zouros \& Foltz 
1984, Brownlow et al. 2008), I can exclude some of these factors. MICROCHEKER tests and the lack of homozygotes for null alleles in my samples suggest null alleles are not responsible for our results. Although it can not be ruled out, it is also unlikely that the results are a consequence of the Wahlund effect, where two or more genetically differentiated populations are involuntarily sampled as one (Maggio et al. 2009), since samples were collected from adjacent rock pools. Finally, although mating among relatives, and hence inbreeding, could explain heterozygote deficiency (Bell \& Okamura 2005), the very large population numbers and long PLD of this species means this is unlikely. Non-random mating and population admixture can not be discarded and further investigation (i.e. genetic sequencing) is required to determine whether mutation in the flanking regions introduces errors in the genotyping data and therefore influences the levels of heterozygosity (Brownlow et al. 2008).

\subsubsection{Validity of the results and future studies}

Despite the significant levels of genetic diferentation between most of the population pairwise comparisons reported by the $\mathrm{F}$ statistics, it is possible that the results obtained in this study are an artifact of methods used. These confounding factors could include: inadequate sampling size, the fact that the Bayesian STRUCTURE analysis was not significant and the effect of the heterozygote deficiency reported.

The alllele discovery curves for two of the populations sampled (Fig.4) revelaed that a sample size of 45 to 50 individuals was enough to detect the genetic diversity within the populations and therefore this factor can be disregarded. 

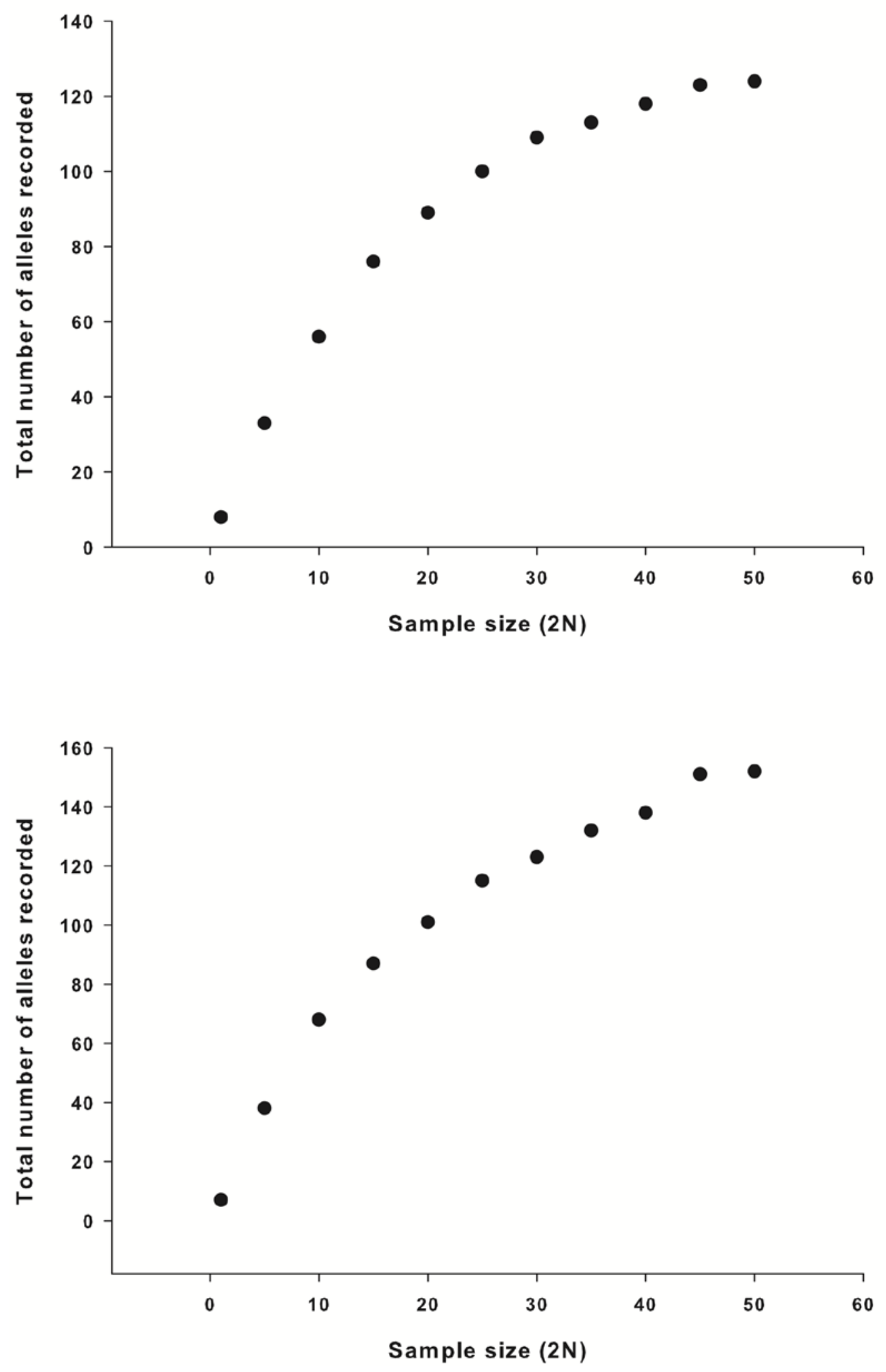

Fig. 4 Allele discovery curves for A.cincta from Wanganui (upper) and Long Island (lower) populations. These curves represent the total number of alleles captured at $2 \mathrm{~N}$ (two times the number of individuals for the diploid microsatellite markers) for all five microsatellite loci combined. 
The fact that the STRUCTURE analysis failed to detect differentation between populations might be a consequence of the limitations of this type of analysis for $F_{S T}$ values lower than 0.02 (Latch et al. 2006). Latch et al. (2006) investigated the perfomance of three different Bayesian clustering softwares (BAPS, PARTITION and STRUCTURE) at low levels of genetic differentation ( $\left.\mathrm{F}_{\mathrm{ST}}<0.1\right)$. Latch et al. reported that although both BAPS and STRUCTURE worked very well at low levels of $\mathrm{F}_{\mathrm{ST}}$ (as low as $\mathrm{F}_{\mathrm{ST}}=0.03$ ), these programs are unable to correctly identified the number of population that exist for $F_{S T}$ values lower that 0.02 . Therefore, the failure of STRUCTURE to detect differentation between the populations sampled in this study is explained by the low $\mathrm{F}_{\mathrm{ST}}$ values recorded (i.e. overal $\left.\mathrm{F}_{\mathrm{ST}}=0.011\right)$.

The most likely factor to influence the results of this atudy is the observed heterozygote deficiency. An overall heterozygote deficiency has been recorded in population genetics studies of many marine bivalves and gastropods (See Brownlow et al. 2008). Despite this widespread occurance, most studies have just hypothesised or ignored the reason behind this reported heterozygote deficiency (See Brownlow et al. 2008; Section 3.4.4). The most likely explanation for this heterozygote deficiency is the presence of null alleles. In chapter 2 , I did not use the three polymorphic loci due to the presence of null alleles as revealed by MICROCHECKER. Two recent studies (Bronlow et al. 2008 \& Lemer et al. 2011) have developed a correction method for null alleles for species with variable flanking regions (i.e. usually marine molluscs and bivalves). Both studies used the same approach of redeveloping primer sets for the loci that presented a high occurance of null alleles: Brownlow et al. used two sets of primers, while Lemer et al. used three sets of primers for each loci. After this primer redesign, the loci conformed to HWE and were adequate for population 
genetics analysis. Despite the heterozygote deficiency recorded across all loci, the five loci utilised in this study were in HWE. However, it will be interesting in a future study using microsatellite analysis for $A$. cincta to consider designing a new set of primers for the loci developed in this thesis in order to: 1) determine whether the three loci discarded in chapter 2 might be in HWE equilibrium after the primer redesign; and 2) validate the results of the population genetics study in this chapter by redesigning primers for the five loci utilised in this study to investigate if the new set of primers reveal the same patterns of genetic differentation reported by this study. 


\section{Chapter 4. How far do larvae travel?}

Author contribution: PS and JJB co-designed the study and performed the fieldwork. PJS conducted the molecular work and analyzed the data and wrote the chapter. JJB edited the chapter and obtained the funding for the project.

\section{Abstract}

In this study I aimed to directly determine how far planktonic larvae with a 6 to 8 week duration in the water column can travel. Taking advantage of the natural features of the Kapiti - Wanganui Coast on the southeast of the New Zealand North Island and my novel molecular markers from chapter 2, I designed a large-scale experiment to determine how far the larvae of the common intertidal gastropod Austrolittorina cincta travel. Satellite image analysis combined with ground truthing surveys, revealed the absence of suitable intertidal rocky shore habitat for $A$. cincta from Kapiti Island to Wanganui Jetty, located over 100 km apart. Fifteen Artificial Islands (AIs) fitted with settlement panels, used to mimic intertidal habitat, were deployed for two months at five different sampling stations around, and north of Kapiti Island. Stations were placed at different distance intervals: 50 m, 500 m, 1 km, $5 \mathrm{~km}, 15 \mathrm{~km}$ and $50 \mathrm{~km}$ and plankton tows were also conducted at each of the sampling stations. On collection of the settlement plates and plankton samples, gastropod larvae were individually isolated, and species-specific microsatellite markers were used to positively identify $A$. cincta larvae. Gastropod settler abundance varied considerably between panels and ranged from 0 to 166 settlers per panel. Most of the positively identified A.cincta settlers and larvae were recorded from the first three sampling stations $(<5 \mathrm{~km})$. However, $A$. cincta settlers and larvae 
were also recorded in low numbers at the two more distant locations (15 and $50 \mathrm{~km}$ ). My study provides one of the few direct estimates $(50 \mathrm{~km})$ of how far the larvae of species with a relatively long (6-8 weeks) pelagic larval duration travel and it provides valuable data in the context of marine reserve spacing and coastal zone management.

\subsection{Introduction}

There is an ongoing debate about the levels of connectivity between marine populations through larval exchange (Caley et al. 1996, Jones et al. 1999, Swearer et al. 1999, Cowen et al. 2000). Direct measurements of larval movement have been difficult to make due to the small size of most larvae and the comparative extremely large size of the ocean (Levin 2006). Because the larvae of many benthic marine species can stay in the plankton for days to months, the traditional view has been that larvae can be transported over large distances by oceanic currents; therefore marine populations were considered demographically 'open' (Caley et al. 1996). However, recent research has suggested that a proportion of larvae are retained within the parental habitat and therefore marine populations might be less open than previously expected (Swearer et al. 1999, Jones et al. 2005, Almany et al. 2007). For example, the use of genetic tools coupled with physical circulation models revealed that larval dispersal of Mytilid mussels typically occurs on the scale of $\sim 30 \mathrm{~km}$ on the southwest of England (Gilg et al. 2007), which is much lower than previously predicted for a species with a long lived planktonic larval stage. Measuring levels of connectivity between marine populations is essential for understanding many processes in marine ecology and it is especially relevant for the design of marine reserve networks, fisheries management and in the context of invasive species (Palumbi 2004). 
Most estimates of larval dispersal distances are based on indirect measurements and include the genetic characterization of adult populations (Hellberg et al. 2002, Hellberg 2007) or the use of natural or artificial markers to follow larval movement (Swearer et al. 1999, Thorrold et al. 2002, Almany et al. 2007, Becker et al. 2007). To date, there have been only a few studies that have measured dispersal directly and most of these studies are restricted to species with pelagic larval durations of few hours (see review by Shanks et al., 2003). For example, Olson (1984) investigated the dispersal potential of Diademnum molle, an ascidian with a tadpole larvae with a pelagic duration of $<2$ hours, revealing that the mean realised dispersal distance of this species was within the scale of 50 m. Knowlton \& Keller (1986) investigated the dispersal potential of Alpheus inmaculatus, a shrimp with a PLD of 7-14 days, by placing individual colonies of their symbiont anemone Bartholomea annulata at increasing distances from an isolated population of $A$. inmaculatus. These authors revealed that the mean realised dispersal distance of this species was in the scale of $30 \mathrm{~m}$, a very short distance considering the dispersal potential of this species. Artificial substrate in which larvae can settle has been also used to obtain estimates of larval dispersal. In a study by Tioho et al. (2001), settlement panels were placed at increasing distances from colonies of the brooding scleractinian coral Pocillopora damicornis to investigate larval movement. Adult colonies were transplanted to an area where the species did not naturally occur in order to isolate the potential sources of larvae. These authors revealed that most of the larvae settled close to the parental colony at distances $\leq 40 \mathrm{~m}$, suggesting that the planulae of brooding coral species do not travel large distances. In this study I used a similar experimental approach using artificial substrate to investigate larval movement for a species with a longer PLD. 
One of the main impediments to investigating larval movement is that the identification of marine invertebrate larvae to species-level by morphological examination is very difficult, as many diagnostic features are absent or poorly developed in early larval stages (Morgan \& Rogers 2001, Zhan et al. 2008). Several authors have used a wide range of genetic techniques to positively identify morphologically similar larvae from plankton samples and newly established settlers, including: mitochondrial markers to identify different mussel settlers (Phillips et al. 2008); restriction fragment length polymorphism (RFLPs) to identify larvae from 12 commercially important shellfish species (Zhang et al. 2004); and the use of microsatellite markers to identify scallop larvae from plankton samples (Zhan et al. 2008). Microsatellites or SSTRs (Simple Sequence Tandem Repeats) are one of the more reliable and commonly used genetic markers. Microsatellites are polymorphic loci that generally occur in the non-coding regions of nuclear DNA that consist of repeats of one to six base pairs in length (Queller et al. 1993). Because microsatellites are species-specific molecular markers, they can be used to identify a newly established settlers or a larvae of given species isolated from a plankton sample based on a single polymerase chain reaction (PCR).

In the present study, I used an experimental approach, which combined the use of artificial substrate and microsatellite molecular markers to investigate larval movement of a New Zealand endemic common intertidal gastropod. The aim of this study is to obtain a direct estimate of how far larvae with a long (6-8 weeks) PLD actually travel. 


\subsection{Materials and methods}

\subsubsection{Study site}

This experiment was designed to take advantage of the natural features of the Kapiti-Wanganui coast on the southwest coast of the New Zealand's North Island (Fig. 4). Satellite image analysis corroborated with ground truthing surveys revealed the absence of suitable intertidal rocky shore habitat for Austrolittorina cincta from Kapiti Island (KI) (S40 49'13"; E174 $\left.56^{\prime} 31^{\prime \prime}\right)$ and the coast in front of KI, all the way

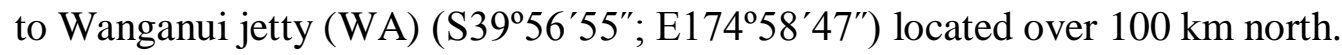

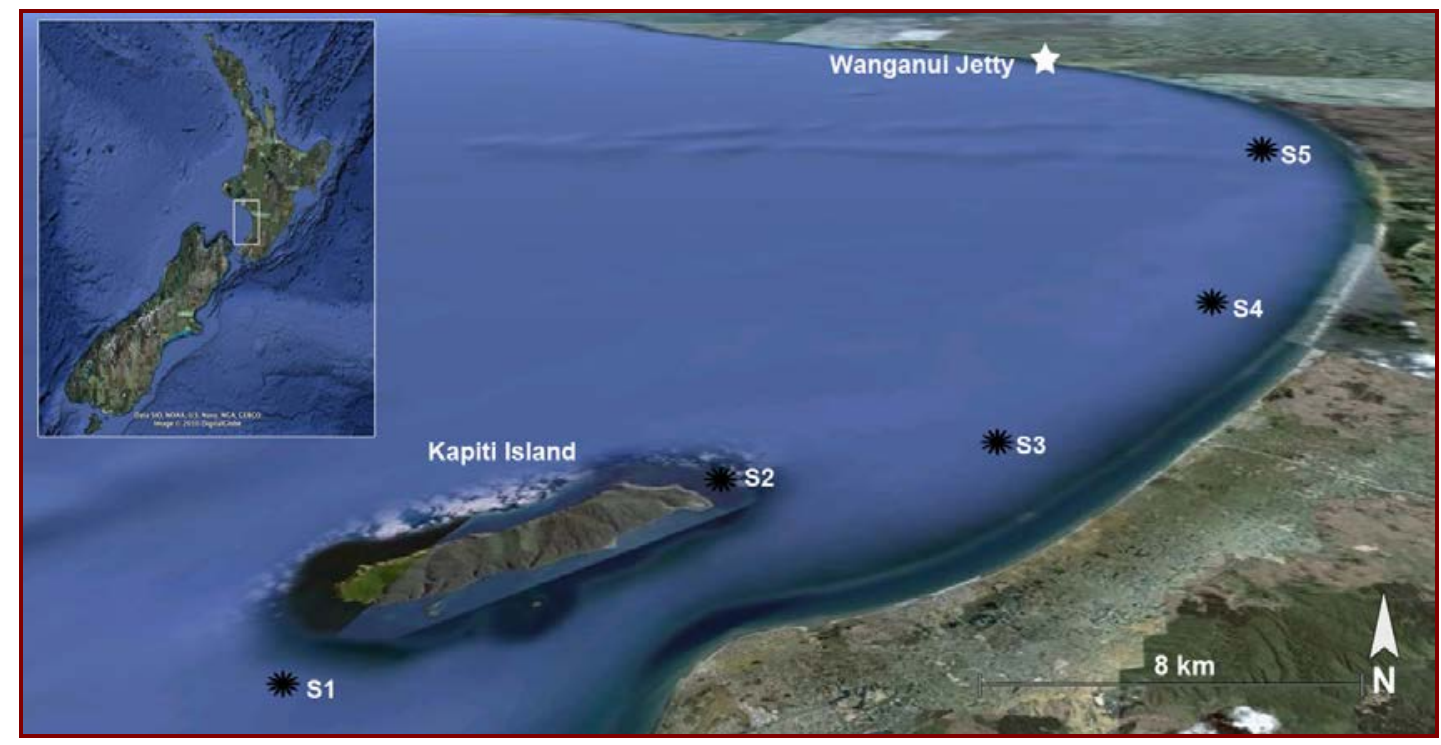

Fig. 5 Satellite image (@ Google Earth) of the Kapiti - Wanganui coast on the southwest of New Zealand' North Island with a schematic representation of the five (S1 - S5) sampling stations where artificial islands were deployed to investigate larval movement of the intertial gastropod Austrolittorina cincta from Kapiti Island.

This lack of suitable habitat for $100 \mathrm{~km}$ meant that the two populations (i.e.

KI on the South and WA on the North) were the only local sources of larvae for this species. A. cincta was selected as the model species given the availability of microsatellite markers for this species (Chapter 2) together with its relatively well known ecology. Vander-Veur (2010) studied the ecology of this species on 
populations on the south of NZ North Island and revealed a very high population abundance (1600 individulas/m2), relatively low adult movement rates (18.7 $\mathrm{m} \pm 16$ m/year) and that settlement peaked between February and March.

\subsubsection{Settlement to Artificial Islands}

Five sampling stations were selected at different distances from KI and each station consisted of three replicated artificial islands (AIs); $(n=15)$. Station 1 was located $1 \mathrm{~km}$ south of KI; station 2 was located $50 \mathrm{~m}$ north of KI; station 3 was located $5 \mathrm{~km}$ north of KI; station 4 was located $25 \mathrm{~km}$ north of KI; and station 5 was located $30 \mathrm{~km}$ north of KI (Fig. 4). Stations were marked with a GPS location for ease of relocation. As a result of logistical constraints it was not possible to conduct the experiment all the way from KI to WA (i.e. $100 \mathrm{~km}$ ). 


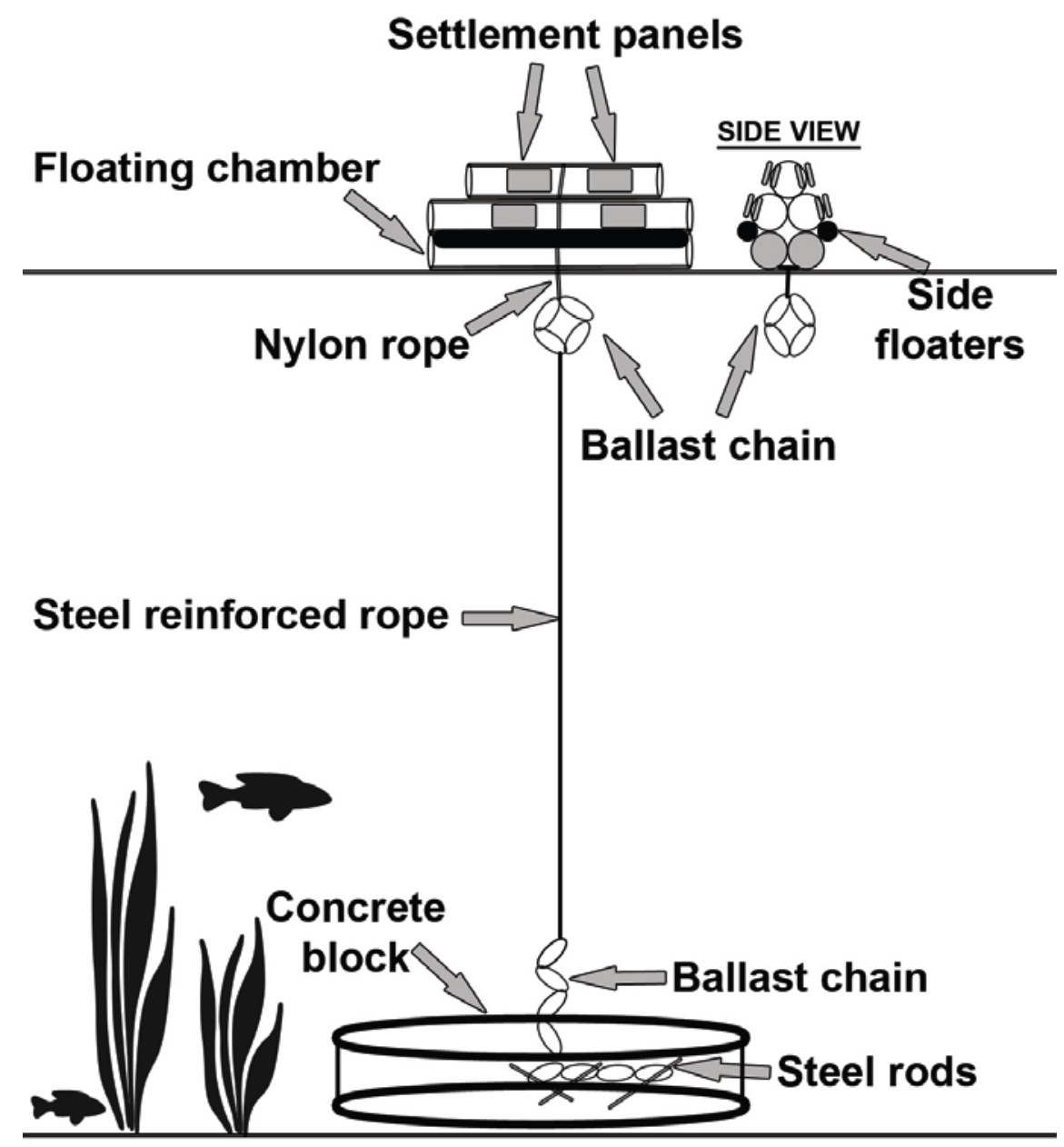

Fig. 6 Schematic representation of an artificial island designed to provide an artificial substrate for larvae of the intertidal gastropod Austrolittorina cincta to settle on.

AIs were designed to provide artificial intertidal habitat for the intertidal gastropod $A$. cincta larvae to settle on and were based on a preliminary intertidal study. Each AI was moored to a car tyre filled with concrete and deployed at around 15 m depth on the sandy seabed to try to minimise the impact of swells (Fig. 5). A 3 m chain was attached to each mooring to serve as extra anchor weight; $20 \mathrm{~cm}$ of the chain was embedded in the car tyre and three pieces of steel reinforced rods $30 \mathrm{~cm}$ in length were passed through 3 different chain links before the concrete was poured to avoid the chain being detached from the concrete mooring. A $40 \mathrm{~m}$ steel reinforced rope connected the mooring chain to the AI. Each AI consisted of 5 pieces of PVC 
pipe $60 \mathrm{~cm}$ in length: 2 pieces were sealed with PVC pipe end caps and were glued together to create an air filled flotation chamber, while the remaining three PVC pieces were glued together in a triangular shape and then glued to the air filled pieces. Two polystyrene floaters were attached to the side of the AI to provide extra buoyancy and help stabilise the AI. Five meters of nylon rope was strapped around the entire AI to ensure all the glued PVC pieces stuck together and also to attach the ballast to the AI. An initial experimental trial revealed that $2.5 \mathrm{~kg}$ of chain ballast was adequate to ensure the AI would return to its original floating position if it was tipped over by waves. A metal clip was used to join the steel reinforced rope from the mooring to the ballast chain of the AI

Sixteen settlement panels were placed on each of the three replicated AIs,: 8 on the inner side of the PVC pipes and 8 on the outer side of the PVC pipes (Fig.6). Settlement panels were 15 x 8 cm Scotch-Brite scouring pads (kindly donated by 3M New Zealand). Previous pilot studies by Vander-Veur (2010) revealed that scouring pads were the most suitable substrate to study Austrolittorinid settlement. Sets of holes were drilled through the top three PVC pipes and through the settlement panels, and panels were attached by means of cable ties through the panels and PVC pipes holes (Fig.6). 

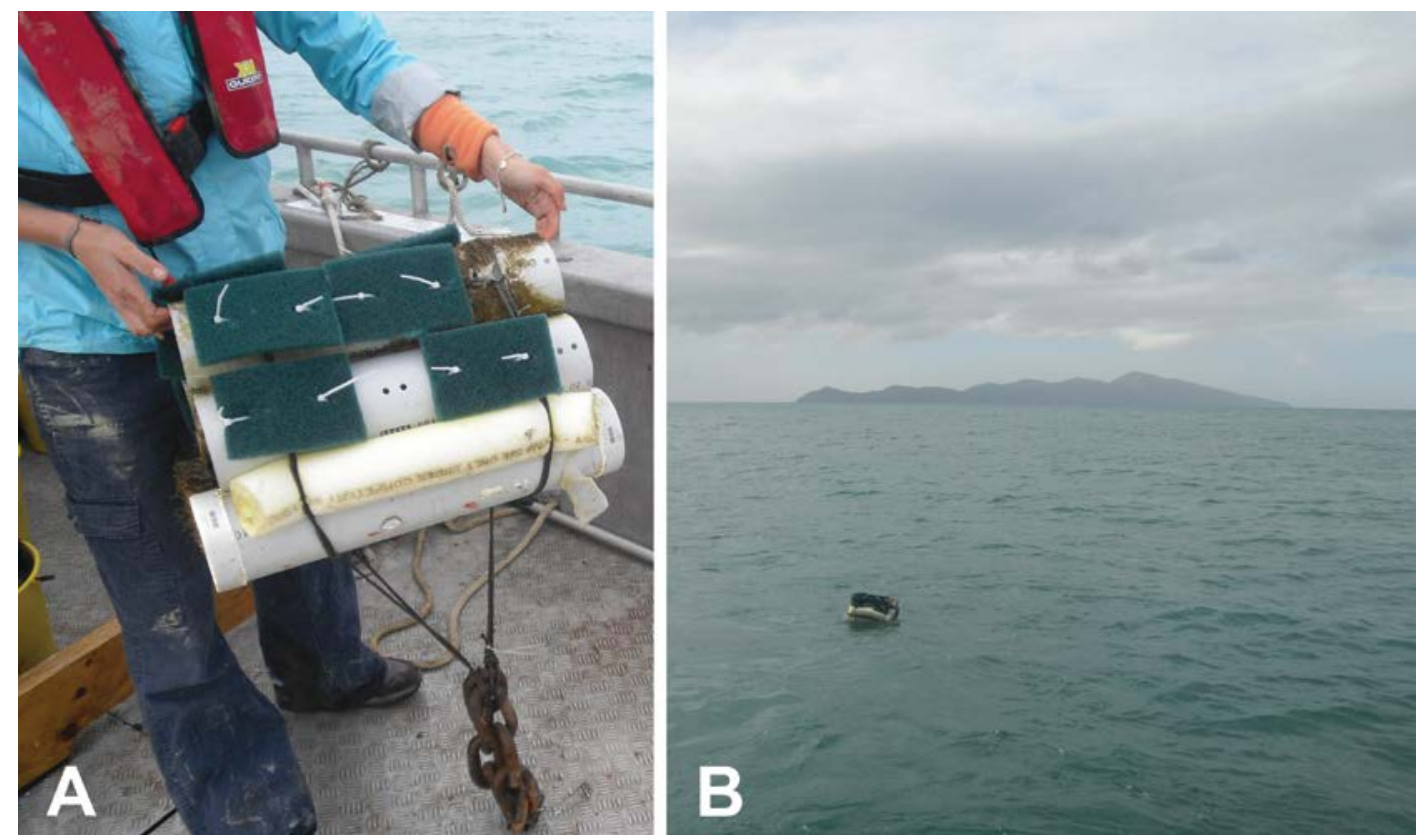

Fig. 7 (A) Artificial Island (AI) with settlement panels attached ready for deployment (B) Deployed AI with Kapiti Island on the background

AIs were deployed for a two-month period between February and March 2009. This time for deployment was based on a previous recruitment study that revealed that $A$. cincta reproduce during that period of the year (Vander-Veur, 2010). On collection, panels were labeled, preserved in 95\% ethanol and transported to the laboratory. Each panel was cut into 4 pieces, each piece was flushed with highpressure water and all settlers present on each panel were collected on a 100 microns mesh sieve located below. All the contents present on the sieve were re-suspended in $50 \mathrm{ml}$ of $95 \%$ ethanol for posterior microscope analysis. All the gastropod and bivalve larvae present on each of the samples were recorded using a dissection microscope by sorting sub-samples placed on a Bogoroff tray. Individual gastropod larvae were collected using a micropipette and placed in individual $1.5 \mathrm{ml}$ Eppendorf tubes for posterior molecular analysis. 


\subsubsection{Plankton tows}

In addition to the settlement study, plankton tows were conducted to quantify the abundance of $A$. cincta larvae in the water column. Three replicate plankton tows were conducted adjacent to each of the five sampling stations $(n=15)$. I used a circular in cross section plankton net with a $50 \mathrm{~cm}$ diameter and constructed of 100 microns mesh. Each tow was conducted by towing the net behind the boat near the water surface at a constant speed of 3 knots for 2 minutes; therefore the total length of each tow was calculated:

$3 \mathrm{knots}=5.55 \mathrm{~km} / \mathrm{h} ; 5.55 \mathrm{~km} / \mathrm{h}=1.53 \mathrm{~m} / \mathrm{s} ; 1.53 \mathrm{~m} / \mathrm{s} \times 120 \mathrm{~s}=\underline{183 \mathrm{~m}}$.

Given the $50 \mathrm{~cm}$ diameter of the plankton net, the area of the net opening is:

$\mathrm{A}=\pi \times \mathrm{r}^{2} ; \mathrm{A}=3.14 \times(0.25 \mathrm{~m})^{2} ; \mathrm{A}=\underline{0.19 \mathrm{~m}^{2}}$.

Assuming a 100\% net efficiency, each plankton tow filtered:

Total water filtered $=$ Length of tow $\mathrm{x}$ Net area; $\mathrm{T}=183 \mathrm{~m} \mathrm{x} 0.19 \mathrm{~m}^{2} ; \mathrm{T}=35.9 \mathrm{~m}^{3}$

The plankton sample was transferred to a $500 \mathrm{ml}$ jar using an opening fitted at the cod end of the net, preserved in 95\% ethanol and transported to the laboratory for posterior analysis. Plankton samples were analysed using a dissecting microscope to quantify all the gastropod and bivalve larvae present. Given the high abundance of organisms, 5 x 2 ml sub-samples were analysed from each tow using a Bogoroff tray. Individual gastropod larvae were collected using a micropipette and placed in individual $1.5 \mathrm{ml}$ Eppendorf tubes for posterior molecular analysis.

\subsubsection{Molecular analysis}

The DNA from individual isolated gastropod larvae and settlers was extracted using a Chelex extraction method. 50 ul of Chelex (BioRad) 20\% was added to each tube containing a larva, incubated for $60 \mathrm{~min}$ at $55^{\circ} \mathrm{C}$, followed by $10 \mathrm{~min}$ at $95^{\circ} \mathrm{C}$ 
and then centrifuged at maximum speed for 3 min. During trials I tested all primers developed in chapter 2. Two of the primers produced consistent product but were shown to cross amplify for the sister species A. antipodum. From the six remaining primers, D104 (HQ171477) produced consistent product and did not cross amplify with A. antipodum, therefore this was selected as the loci to be used to test the identity of the larvae/settlers identity.

Polymerase chain reactions (PCR) were conducted on a MJ Research thermocycler in 15 ul reaction volumes containing 2 ul 10x buffer (Roche) including $1.5 \mathrm{mM} \mathrm{MgCl} 2$, 1 ul $10 \mu \mathrm{M}$ dNTPs, 1 ul of $10 \mu \mathrm{M}$ of each primer, $0.1 \mathrm{ul}$ Taq DNA polymerase (Roche) and 20 ng of template DNA. Amplifications were conducted under the following conditions: $95{ }^{\circ} \mathrm{C}$ for 5 minutes, followed by 40 cycles at $95{ }^{\circ} \mathrm{C}$ for 30 seconds, $54{ }^{\circ} \mathrm{C}$ for 30 seconds, $72{ }^{\circ} \mathrm{C}$ for one minute, and a final $72{ }^{\circ} \mathrm{C}$ extension step of 30 minutes. The presence of PCR products was confirmed on a 3\% agarose gel and on each PCR cycle a positive control (i.e. using A.cincta adult DNA previously genotyped) and a negative control was (no DNA) included to avoid false positives.

\subsubsection{Data analysis}

Differences in the number of settlers on the panels and larvae in the plankton tows at the different stations were analysed by the statistical package PRIMER v6 and PERMANOVA v1.0.2. PERMANOVA is a permutation-based version of the multivariate analysis of variance (Anderson, 2001), which uses the distances between samples to partition variance and randomisations or permutations of the data to produce the p-value for the hypothesis to be tested. It is non-parametric and, 
therefore, robust to the assumption of multivariate normality making it less prone to Type I errors.

\subsection{Results}

\subsubsection{Settlement to Artificial Islands}

Out of the 15 AIs deployed, 13 were successfully recovered 2 months after deployment. In order to have the same number of AIs per station (for a balanced design), only data from 2 AIs was included in the analysis. In addition, some of the 16 panels on each of the AIs were missing, therefore only 8 panels (4 panels from the

inside and 4 panels from the outside of the PVC pipe were haphazardly chosen from those remaining) per AI were examined to ensure the same number of panels were sampled across all stations. A total of 1088 gastropod settlers were recorded in the 90 settlement panels analysed (Fig. 7). Of these, a significant $(\mathrm{p}<0.05)$ proportion (91.4\%; $n=995$ ) of the total gastropod settlers recorded were present in the first 3 AIs stations (Fig.7). 


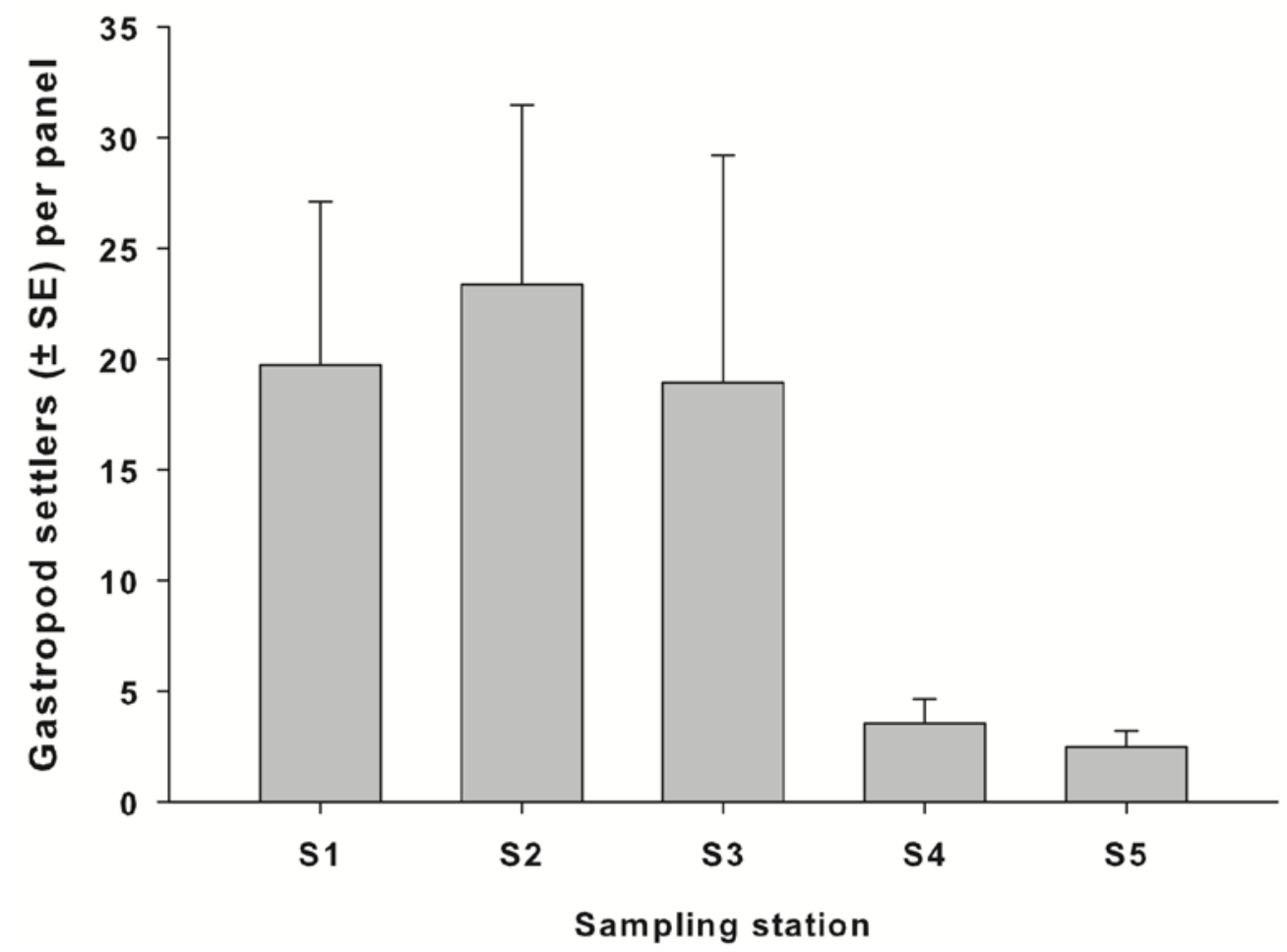

Fig. 8 Gastropod settlers ( \pm SE) per settlement panel (15 x $8 \mathrm{~cm}$ Scotch-Brite scouring pads) at five different sampling stations deployed around Kapiti Island, NZ.

Out of the 1088 gastropod settlers recorded, 433 (39.7\%) were positively identified as $A$. cincta settlers using the species-specific microsatellite marker D104 (Fig.8).

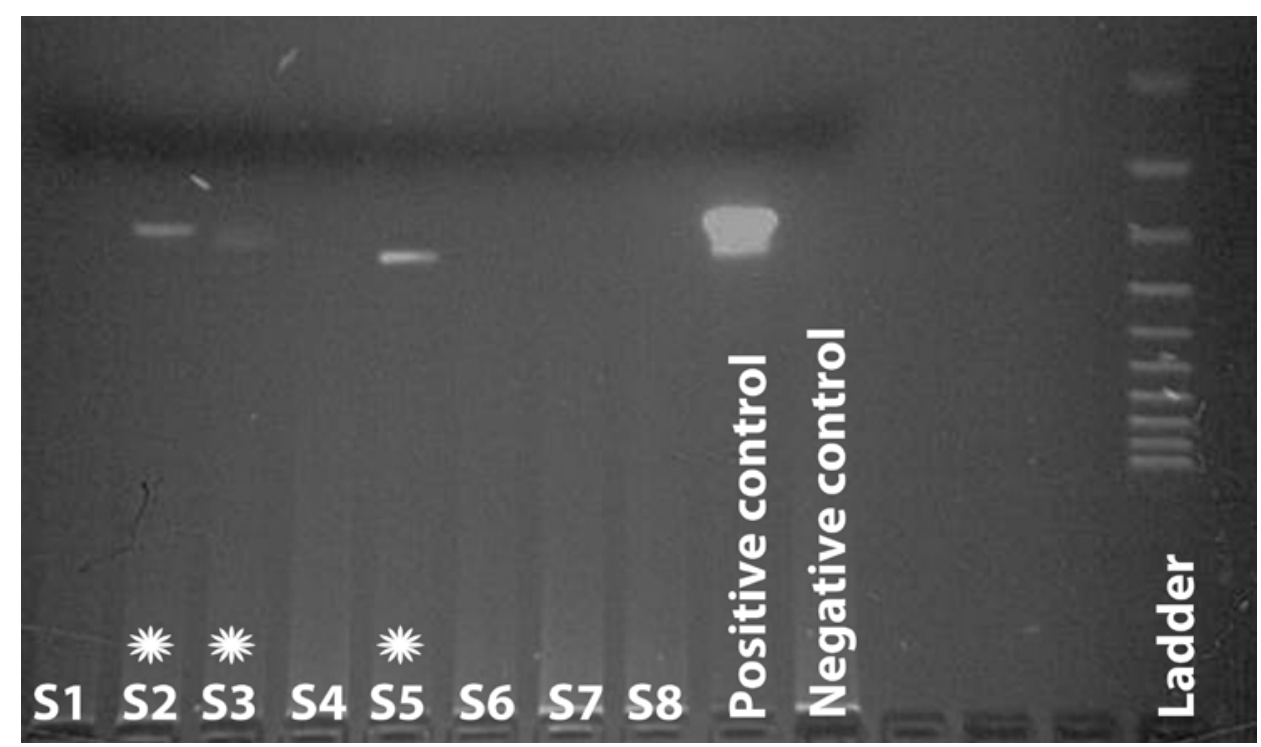

Fig. 9 Microsatellite loci D104 PCR products loaded on a $3 \%$ agarose gel stained with Ethidium Bromide. Lanes $1-8$ represent different gastropod settlers, lane 9 is positive control, lane 10 a negative control and lane 14 is a $1000 \mathrm{~kb}$ ladder. Symbol represents positive A. cincta ID. 
A.cincta larvae were positively identified in all sampling stations and the great majority (90.5\%; $\mathrm{n}=392)$ of the $A$. cincta settlers were recorded in the first 3 stations (Fig.9).

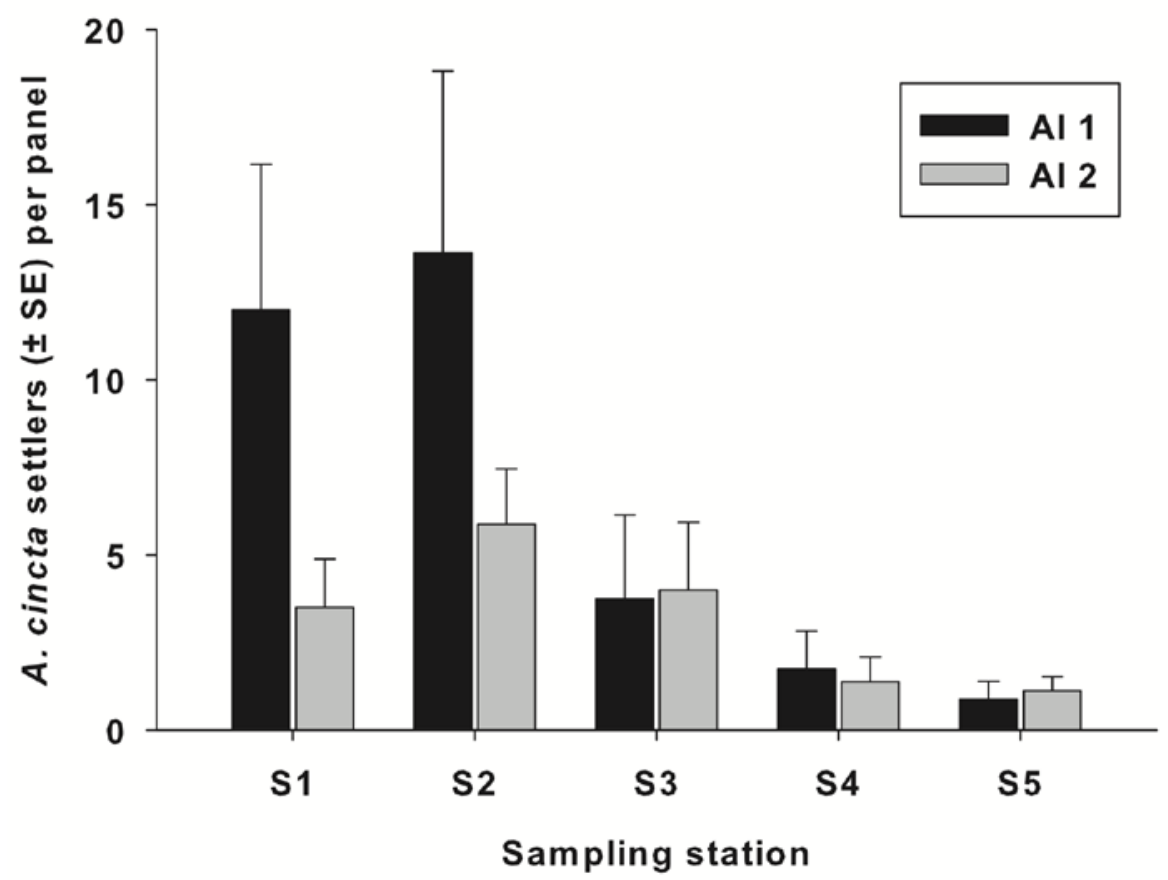

Fig. 10 Austrolittorina cincta settlers $( \pm \mathrm{SE})$ per settlement panel $(15$ x $8 \mathrm{~cm}$ Scotch-Brite scouring pads) on two replicate artificial islands (AI) at five different sampling stations (S1 - S5) deployed around Kapiti Island, NZ

\subsubsection{Plankton tows}

A total of 15 plankton tows were conducted at the 5 different sampling stations and 1011 gastropod larvae were recorded in the $300 \mathrm{ml}$ subsample $(150 \times 2$ ml subsamples); (Fig.10). Forty percent of the 15 plankton tows were sub-sampled, and the total number of gastropod larvae present was 2527 individuals with a density of 4.69 individuals per $\mathrm{m}^{3}$ of filtered seawater. Gastropod larvae were significantly $(p<0.05)$ more abundant at the stations closer to Kapiti Island than those further away (Fig.10). 


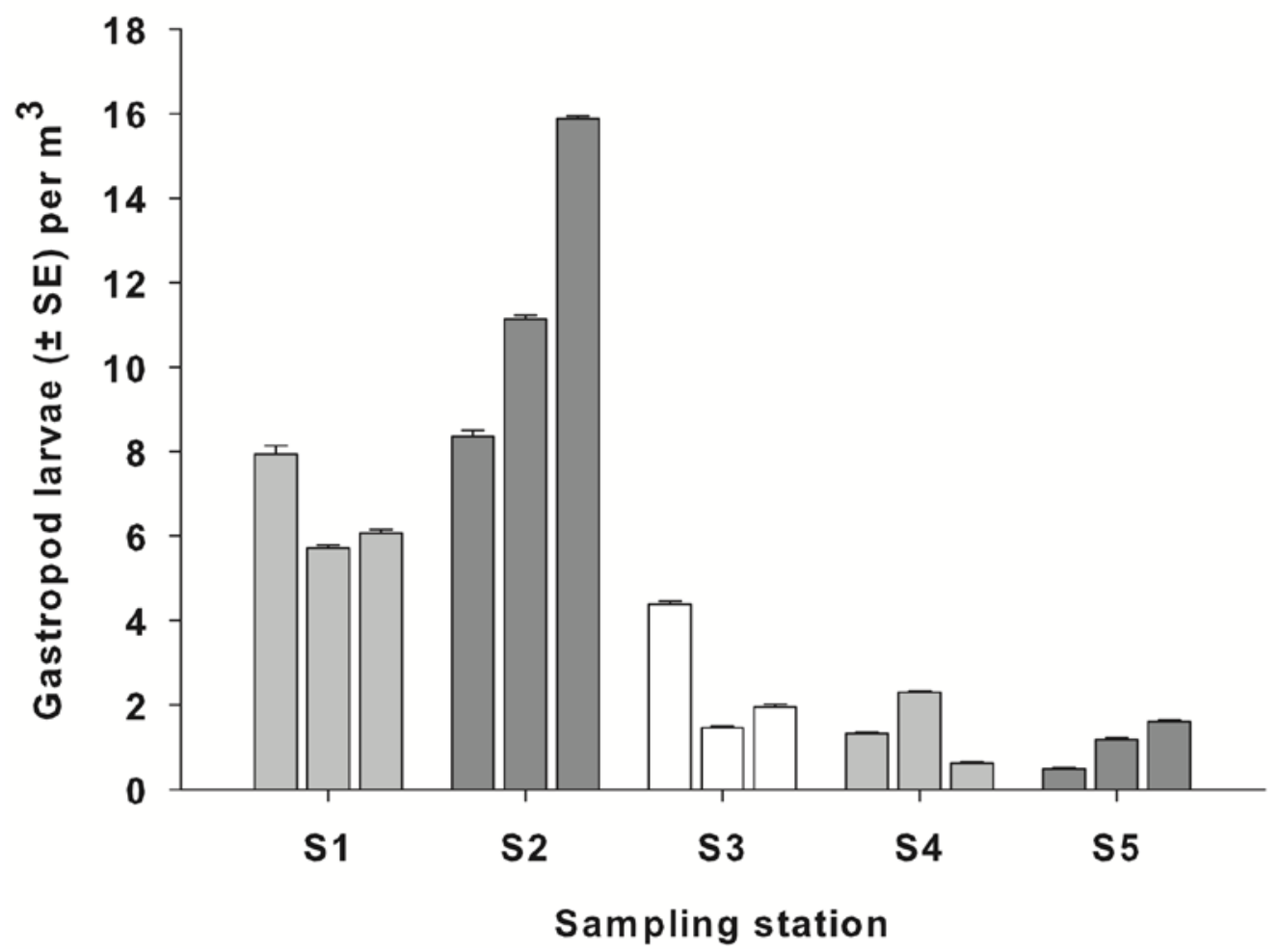

Fig. 11 Gastropod larvae $( \pm S E)$ per $\mathrm{m}^{3}$ of filtered seawater on three different plankton tows conducted at five different sampling stations (S1 - S5) around Kapiti Island, NZ

Out of the 1011 gastropod larvae recorded in the plankton tows, 247 (50 per station, except station 5 where 47 larvae were analysed) were assayed using the microsatellite markers. Larvae were positively identified at all sampling stations and a total of 18 larvae out of 247 (7.2\%) were positively identified as A. cincta larvae (Table 7). Eight percent of the larvae at Station 1 were positively identified as $A$. cincta larvae; $12 \%$ at Station 2: $8 \%$ at Station 3: $4 \%$ at Station 4 ; and $4 \%$ at Station 5. Extrapolating this percentage of positively identified $A$. cincta larvae to the total number of gastropod larvae recorded at each station, I obtained an estimate of $242 \mathrm{~A}$. cinta larvae in all of the plankton samples, with a total overall concentration of 2.6 A.cinta larvae per $\mathrm{m}^{3}$ of water 
Table 7 Summary of the results of microsatellite analysis on gastropod larvae collected in 15 plankton tows (3 replicate tows per station) at 5 sampling stations around Kapiti Island.

\begin{tabular}{|c|c|c|c|c|c|}
\hline & $\begin{array}{c}\text { Larvae } \\
\text { recorded } \\
\text { (Total larvae) }\end{array}$ & $\begin{array}{c}\text { Larvae } \\
\text { analyzed } \\
(\% \text { recorded })\end{array}$ & $\begin{array}{c}\text { Positively ID } \\
\text { larvae } \\
\text { (\% analyzed) }\end{array}$ & $\begin{array}{l}\text { Total } \\
\text { A. cincta } \\
\text { Larvae }\end{array}$ & $\begin{array}{l}\text { A. cincta } \\
\text { larvae } \\
\text { per } \mathbf{m}^{3}\end{array}$ \\
\hline Station 1 & $\begin{array}{c}283 \\
(707)\end{array}$ & $\begin{array}{c}50 \\
(18 \%)\end{array}$ & $\begin{array}{c}4 \\
(8 \%)\end{array}$ & 57 & 0.53 \\
\hline Station 2 & $\begin{array}{c}508 \\
(1270)\end{array}$ & $\begin{array}{c}50 \\
(10 \%)\end{array}$ & $\begin{array}{c}6 \\
(12 \%)\end{array}$ & 152 & 0.57 \\
\hline Station 3 & $\begin{array}{c}112 \\
(280)\end{array}$ & $\begin{array}{c}50 \\
(45 \%)\end{array}$ & $\begin{array}{c}4 \\
(8 \%)\end{array}$ & 22 & 1.4 \\
\hline Station 4 & $\begin{array}{c}61 \\
(152)\end{array}$ & $\begin{array}{c}50 \\
(82 \%)\end{array}$ & $\begin{array}{c}2 \\
(4 \%)\end{array}$ & 6 & 0.05 \\
\hline Station 5 & $\begin{array}{c}47 \\
(117)\end{array}$ & $\begin{array}{c}47 \\
(100 \%)\end{array}$ & $\begin{array}{c}2 \\
(4.2 \%)\end{array}$ & 5 & 0.046 \\
\hline Total & $\begin{array}{c}1011 \\
(2527)\end{array}$ & 247 & 18 & 242 & 2.596 \\
\hline $\begin{array}{l}\text { Mean } \\
( \pm \text { SE) }\end{array}$ & $\begin{array}{l}202 \pm 87.2 \\
(505 \pm 218)\end{array}$ & $\begin{array}{c}49.4 \pm 0.6 \\
(24.4 \% \pm 0.17)\end{array}$ & $\begin{array}{l}3.6 \pm 0.74 \\
(7 \% \pm 1.4)\end{array}$ & $48.4 \pm 27.5$ & $0.52 \pm 0.24$ \\
\hline
\end{tabular}

\subsection{Discussion}

The west coast of New Zealand's north Island is under the influence of three major current systems: the West Auckland current flowing south from the top of the NZ north island; the D’Urville current flowing south-east through Cook Strait and the Westland current flowing north from the west of the south Island (Heath, 1985). Of these currents, the D’Urville current is the one more likely to have an strong influence around Kapiti Island. It is remarkable that $A$. cincta larvae are able to travel at the scale of $50 \mathrm{~km}$ against the prevailing southward current, therefore I am not able to exclude the possibility that some of the $A$. cincta settlers and larvae present on some of the stations are from northern Wanganui populations, although this is highly unlikely given the decline in A. cincta settlers/larvae away from Kapiti Island. However, if this is the case, then the A. cincta larvae would still have been dispersing 
a minimum distance of $50 \mathrm{~km}$ (S5 is located halfway between Kapiti Island and Wanganui Jetty), but potentially could be dispersing up to 75 or $95 \mathrm{~km}$ if they have managed to reach S4 and S3, respectively. Although the predominant current direction is southerly, in periods of sustained southerly wind, a wind induced northflowing current may be established, which could facilitate the northward movement of larvae from Kapiti Island, although southerly winds rarely blow for long periods as a result of variability in NZ weather (Stanton 1976). In order to get a better understanding of the exact origin of $A$. cincta larvae and settlers, a future study could consider genotyping larvae at multiple microsatellite loci larvae and settlers recorded on the sampling stations, together with adult $A$. cincta populations at Kapiti Island and Wanganui jetty. However, in my previous chapter I conducted microsatellite analysis on the adult $A$. cincta population of Wanganui jetty and Kapiti Island that revealed a lack of genetic differentiation between these two populations, which suggests a high level of connectivity through larval exchange or adult rafting. Future studies should also consider genotyping the larvae pool population, and this data could be used to conduct assignment testing to identify where larval have come from (Christie et al. 2010, Hedgecock 2010), although this may be difficult given the low overall levels of genetic differentiation.

It is difficult to compare my estimates of larval movement to other studies that have directly measured larval dispersal given that the majority of these studies have been conducted on species with very short pelagic larval duration (e.g. Davis and Butler, 1989) or on different taxa (e.g. Planes et al. 2009). Dethier et al. (2003) compared the abundance of several benthic species on an artificial exposed rocky jetty surrounded by dissimilar habitat (i.e. sandy beaches) on the coast of Washington state (USA), to those at the two closest (43 km to the north and $70 \mathrm{~km}$ to 
the south) rocky sites. These authors found the littorinid gastropods with a planktonic larval dispersal stage, Littorina scutulata and L. plana, on the jetty and although they did not directly measured dispersal distance for these gastropod species, they suggested that the larvae must have dispersed at least $40 \mathrm{~km}$, as this was the distance to the nearest source of larvae. Finally, it is possible to compare my results to those obtained by Planes et al. (2009), who used DNA parentage analysis on the orange clown fish Amphiprion percula. Planes and colleagues reported the longest direct measure of larval dispersal for any marine fish species to date, given they located juveniles that were produced by adults on the isolated Kimbe Island on neighboring reefs up to $35 \mathrm{~km}$ away, a dispersal distance similar to the one obtained in my study.

Most of the dispersal estimates for species with long PLD have been indirectly estimated. For example, McQuaid and Phillips (2000) determined the dispersal potential of the invasive intertidal mussel Mytilus galloprovincialis in South Africa by investigating larval movement from single point source. The authors revealed that the maximum effective dispersal of mussel larvae in that area was in the scale of $<100 \mathrm{~km}$, with the great majority (90\%) of individuals remaining just 5 $\mathrm{km}$ from the point of origin 4 years after the invasion; this is similar to my study, given that I recorded $90 \%$ of $A$. cincta settlers within $5 \mathrm{~km}$ of Kapiti Island. Similarly, Becker et al. (2007) used elemental fingerprinting to estimate mussel larval movement on the Californian coast. These authors found that mussel larvae can be retained within $30-35 \mathrm{~km}$ of their natal origin, a dispersal figure similar to my study. Modern biophysical models have been also proved useful tools to estimate larval dispersal as shown by Cowen et al. (2006). This model combined flow trajectories from a high-resolution oceanic model together with several biological parameters such as pelagic larval duration (PLD), larval vertical migration and adult 
spawning strategies, to investigate fish larval movement in the Caribbean. These authors showed that typical larval dispersal distances providing ecologically significant numbers of settlers were on the scale of 50 to $100 \mathrm{~km}$, with a high rate of self recruitment (averaging $21 \%$ but as high as $55 \%$ for some regions) and recruitment from adjacent areas.

\subsubsection{Localized dispersal vs long distance dispersal}

The results obtained by this study support the population genetics results obtained for this area in chapter 3, where no genetic differentation was observed between Kapiti Island MR and Wanganui populations. The results obtained in chapter 4 suggest that larvae might travel in scales larger than $50 \mathrm{~km}$, given that these two populations were separated by over $100 \mathrm{~km}$. Chiswell and Stevens (2010) used Lagrarian and Eulerian estimates to measure current estimates around Kapiti Island and reported that the mean flow was to the south-west, towards the Cook Strait. Their findings support the movement of $A$. cincta larvae from the Wanganui population towards the Kapiti population. Furthermore, this mean south-west current movement provides some oceanographic evidence that could explain the lack of genetic differentation between Kapiti Island MR and Tonga Island MR, located on the north-west of the South Island. In addition to this, recent research using real wind data for the Kapiti - Wanganui coast during the time of this study (Neubauer, unpublish data) revealed that during southerly blowing periods, the mean current flow is reversed to the north. Thus, this wind driven northwards current will facilitate the movement of larvae from Kapiti Island towards the Wanganui population.

The fact that the vast majority of the settlers and larvae recorded were present within $5 \mathrm{~km}$ of the source of larvae suggest that only a small proportion of the larvae travel over large distances. These few long distance travellers might be responsible 
for the lack of genetic differentation between Kapiti and Wanganui populations, since only few migrant per generations are required to bring similar allele frequencies across populationa (Palumbi 2003). However, in areas where oceanographic currents are not as strong as the ones around the Kapiti - Wanganui coast and/or oceanographic features such as eddies are present, long distance dispersal might be limited. This could be the case of Long Island MR, given its location within a fiord, and may help explain why the Long Island population is genetically different from all the other population sampled in chapter 3 . Thus, the results obtained in chapter 3 and 4, highlight the vital importance of understading the local oceanographic features in combination with population genetics for an adequate understanding of patterns of connectivity among marine populations. 


\title{
Chapter 5. The effect of locally available larvae upon coral settlement rates: a preliminary comparison of methods to monitor settlement
}

\author{
Manuscript accepted for publication in Estuarine, coastal and shelf science \\ Salinas de Leon P. Costales Carrera A., Smith DJ and Bell J.J. Scleractinian \\ settlement patterns to natural cleared reef substrata and artificial settlement panels on \\ an Indonesian coral reef. \\ Author contribution: PS designed the study and performed the field work, \\ analyzed the data and wrote the manuscript. ACC assisted with the fieldwork. \\ DJS and JJB co-designed the study and edited the manuscript.
}

\begin{abstract}
Scleractinian corals have been recently suggested to be largely self seeding and despite the importance of understanding coral settlement, we still have a poor understanding of settlement processes in the Coral triangle region, which contains the most biodiverse marine ecosystems in the world. The aim of this study was to compare settlement rates to artificial settlement panels with cleared areas of natural reef in order to assess the best methodology to study coral settlement in this area. This methodology was then used for an inter-annual and seasonal study (chapter 6) investigating the effect of locally available larve upon coral seetlement. In this study I recorded coral settlement rates to settlement panels made of two different materials (concrete and terracotta), attached to the reef at two different orientations (vertical and horizontal), and compared these settlement rates to those on cleared areas of natural reef positioned on vertical reef walls, over a 12 month period. I examined settlement rates at four sites in the Wakatobi National Marine Park, south east Sulawesi, Indonesia; two reefs were light-limited, high sedimented regimes with low
\end{abstract}


coral cover $(<10 \%)$ and two had moderate coral cover (approx. 40\%) and lower sedimentation rates. Panels were directly attached to the reef at 6-7 $\mathrm{m}$ depth. The number of settlers per tile ranged from 0 to 34 and no significant differences were reported between the settlement rates to cleared natural reef areas and settlement panels. Significantly higher numbers of recruits settled on the cryptic (back) side of the panels, while no significant difference was found between settlement rates to the different panel materials, or between the different orientations or any combination of these two factors. I did, however, report a significant difference in the settlement rates between sites, for both settlement panels and permanent cleared areas, with higher settlement rates at higher live coral cover sites. I conclude that both concrete and terracotta panels yield similar settlement rates, and orientation makes no difference to settlement rates when panels are directly attached to the reef. My results demonstrate that artificial substrata provide comparable settlement rate data to natural substrates and therefore are suitable for monitoring coral settlement rates in the future.

\subsection{Introduction}

Recent evidence suggests many marine populations display localised recruitment and might be less demographically open than previouslty predicted (see review by Levin 2006), including scleractinian corals (Sammarco and Andres, 1988; Ayre et al. 1997; Underwood et al. 2007, 2009). Understanding coral recruitment process is of key importance giving it is an importnat factor driving the population dynamics of scleractinian corals and it is an essential factor in both promoting the recovery of degraded reefs and in maintaining healthy reef populations (Babcock \& Mundy 1996, Fox 2004). Patterns of hard coral recruitment are influenced by a number of factors including the level of live coral cover in the source population/s, abundance 
and diversity of coral larvae, hydrodynamic variability, sedimentation, temperature, settlement inhibition by other benthic taxa, eutrophication levels, grazing pressure, light levels and connectivity between reefs (Sammarco 1980, Babcock \& Davies 1991, Tomascik 1991, Maida et al. 1995, Roberts 1997, Mundy \& Babcock 1998, Hughes \& Connell 1999, Hughes et al. 2000, Carpenter \& Edmunds 2006).

Detecting coral recruits is difficult because of their small size and preference for cryptic habitats (Babcock et al. 2003). For this reason many authors have used artificial substrata (i.e. settlement panels) to measure coral settlement rates as they can be removed from the water for microscopic examination. Newly settled coral larvae can easily be detected on panels because they secrete a calcium carbonate skeleton within hours of settlement, which leaves a record that can be detected even after the recruit dies (Babcock et al. 2003). Many different materials have been used for coral settlement studies, often reflecting the cost and local availability of materials, and include: glazed and unglazed terracotta tiles; dead or alive coral fragments; petri dishes; brick fired tiles; carbonic or PVC plates; rubber; concrete blocks or crushed coral rubble limestone tiles; and pulverised fuel ash blocks (Harriott \& Fisk 1987, Tomascik 1991, Smith 1992, Reyes \& Yap 2001, Lam 2003, Soong et al. 2003, Field et al. 2007, Schmidt-Roach et al. 2008).

The deployment angle of settlement panels may also influence settlement patterns (Fisk, 1990). Generally, corals tend to settle in microhabitats where they can avoid being grazed by fish or smothered by sediment, while still receiving adequate light (Fisk \& Harriott 1990). Several authors have reported higher settlement rates to vertically orientated tiles, potentially as a consequence of reduced sedimentation compared to horizontal tiles (Fisk \& Harriott 1990, Babcock \& Mundy 1996). To my knowledge no study has compared the effect of orientation combined with panels 
made from different materials that have been directly attached to the reef substrate, although some authors have independently investigated the effect of orientation (Mundy 2000) and panel material (Field et al. 2007) for panels directly attached to the substrate.

More recently, Piniak et al. (2005) described a new approach to facilitate the measurement of settlement in situ that uses an Underwater Fluorescence Technique (UFT); this technique may be useful in complementing panel studies. Both corals and their associated symbiotic dinoflagellates contain fluorescent pigments that absorb light at a certain wavelength and re-emit it at a different wavelength, so when they are excited with a blue light, corals often fluorescence green (Piniak et al. 2005). These authors used this technique to measure settlement rates to natural reef substrate and concluded that this technique recorded between 20 and $30 \%$ more recruits than daylight surveys alone. Although several authors have used entire dead coral colonies (Edmunds 2000b) or dead coral fragments (Harriott \& Fisk 1987) to measure coral settlement to natural substrata, to date, no study has investigated the levels of coral settlement to natural cleared reef areas. The UFT approach provides a new opportunity to monitor settlement to natural substrata and compare settlement rates to those on the artificial substrata.

The aims of my study were: 1) to compare settlement rates to natural areas of cleared reef with those reported from panels; 2) to investigate the effect of material type and orientation on coral settlement rates for panels directly attached to the reef substrata (after Mundy 2000). The best method to monitor coral settlement revealed by this study will be then used to conduct an inter-annual and seasonal study to investigate the effects of locally available larvae upon coral settlement (Chapter 6). 


\subsection{Materials and methods}

\subsubsection{Site description}

The WNMP is located in southeast Sulawesi (Fig.11) and is Indonesia's second largest Marine Protected Area (MPA) covering 1.39 million hectares. Previous research in this region revealed very high coral diversity with more than 390 hermatypic scleractinian coral species belonging to 68 genera and 13 families (Turak 2003).

I selected four sites within two reef systems (two replicate sites within each reef system type); two sites (B3, B4) were within the Hoga home reef system and two sites (S1, S2) were within the Kaledupa reef system (Fig. 11).

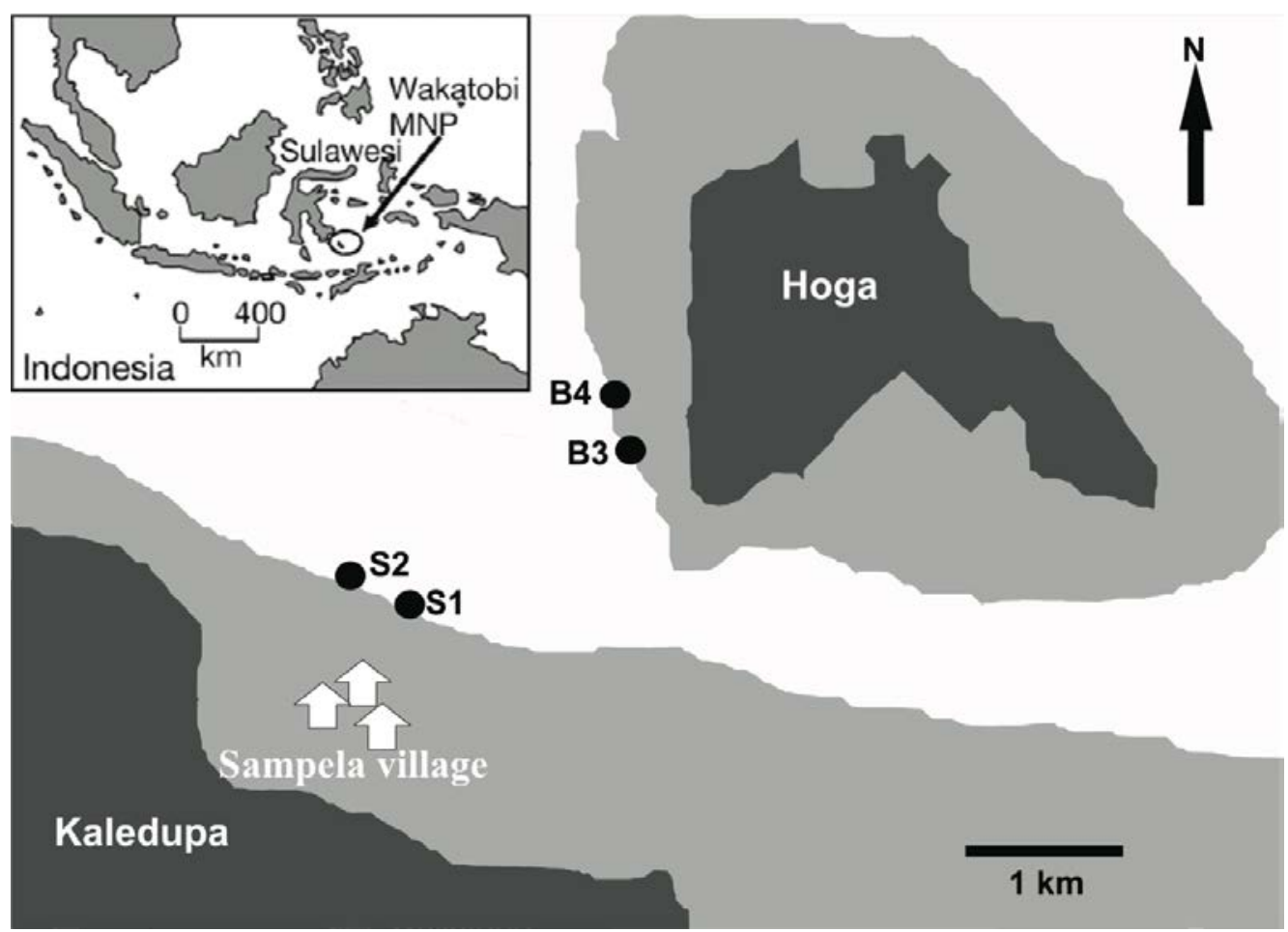

Fig. 12 Sampling sites within the Wakatobi National Park in SE Sulawesi, Indonesia. Sites B3 and B4 are located within the Hoga Island reef system, Sites S1 and S2 were located within the Sampela reef system and are adjacent to a Bajau village (represented on the map by three white houses).

Replicate sites within reefs were more than $250 \mathrm{~m}$ apart and were selected based on preliminary surveys that revealed significantly higher coral coverage at 
Hoga sites B3 and B4 (approximately 40\%), compared to Kaledupa sites S1 and S2 (approximately 10\%). Kaledupa sites S1 and S2 are located near the Bajo village of Sampela and have been subjected to severe anthropogenic disturbances including overfishing, blast and cyanide fishing, coral mining, and increased sedimentation from untreated sewage discharge and mangrove removal. Hoga reef gross sedimentation deposition rates are $7.54 \pm 0.76$ g d.wt. $\mathrm{m}^{-2}$ day $^{-1}$ and $20.16 \pm 1.76 \mathrm{~g}$ d.wt. $\mathrm{m}^{-2}$ day $^{-1}$ at Sampela (Bell \& Smith 2004). Current flow rates range between 10$20 \mathrm{~cm} \mathrm{~s}^{-1}$ at all four sites.

\subsubsection{Sampling}

\subsubsection{Settlement to permanent cleared quadrats}

In July 2007 four reef areas ( $25 \times 25 \mathrm{~cm})$ were cleared at $6 \mathrm{~m}$ depth at each of the four sites to determine coral recruitment rates to natural substrata (Fig. 12). Quadrats were placed on vertical walls and were permanently marked by four galvanised nails. The quadrats were placed in the vicinity of the settlement panels and all benthic organisms present within the quadrat were removed. Cleared areas were positioned at least $5 \mathrm{~m}$ away from each other. No horizontal cleared reef areas were created due to the difficulty in finding suitable areas of horizontal substrate at the study sites without severely damaging live coral colonies. 

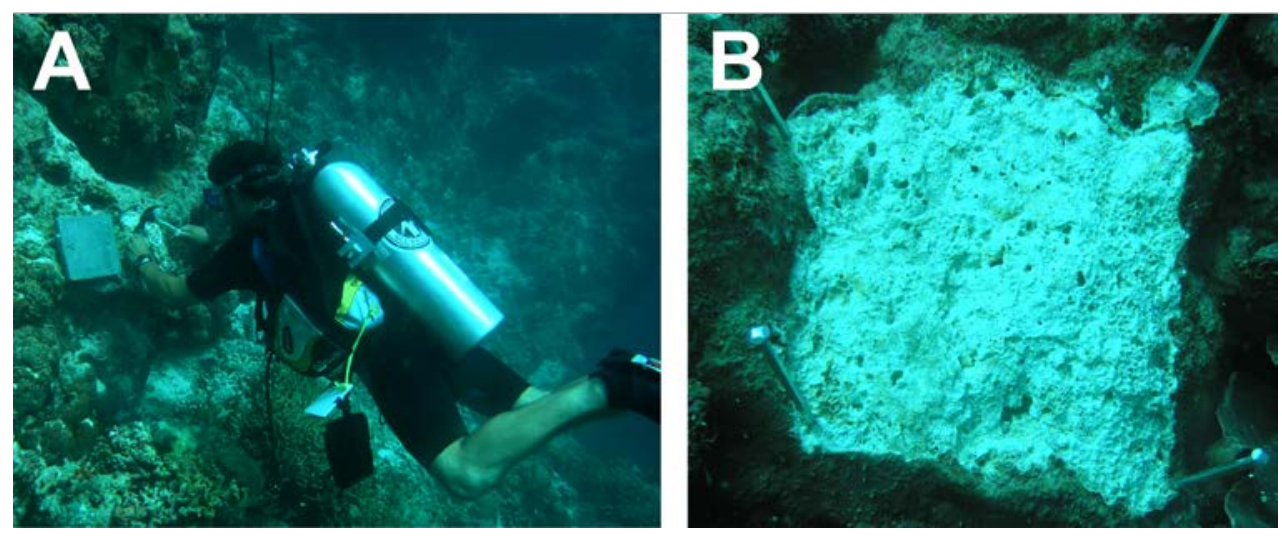

Fig. 13 A) Diver clearing quadrats for coral settlement study; B) Recently cleared quadrat

Permanent cleared areas were surveyed after 12 months. Areas were surveyed by eye both during the day and night. Initial surveys were conducted during the day and all coral settlers present in the quadrats were recorded and identified to the closest taxonomic level possible. The settlers observed were marked with a small nail next to each recruit. A second night survey was conducted using the Underwater Fluorescence Technique described by Piniak et al. (2005). Permanent cleared areas were re-surveyed with a blue light (Nightsea, Inc.) and a yellow barrier filter was placed over the divers mask (Nightsea, Inc.) to facilitate the detection of coral settlers. False positives can be caused by a number of other organisms that also fluorescence. I minimised this effect by using a strong white light as described by Baird et al. (2006). Coral settlers missed under daylight conditions were recorded, measured and identified to the closest taxonomic level possible.

\subsubsection{Settlement to panels}

Settlement panels were made of two locally available materials and were deployed in July 2007. Panels were either unglazed terracotta tiles (20 x 10 x 0.7 cm) or concrete tiles (20 x $20 \times 4 \mathrm{~cm}$ ); (Fig. 13). Panels of different materials were haphazardly placed between 6-7 m water depth at the four study sites and were at least $5 \mathrm{~m}$ from each other. Four panels of each material were attached to both vertical 
and horizontal surfaces interspersed among the cleared areas at each of the four study sites. Panels were attached to the substrate using a modification of the method described by Mundy (2000). Two holes were drilled in the concrete tiles and they were attached to the reef substrate using two galvanised nails. A small piece of hardwood $(2 \times 2 \times 2 \mathrm{~cm})$ was placed between the tile and reef to leave a $2 \mathrm{~cm}$ gap, as this is known to facilitate coral settlement (Harriott \& Fisk 1987, 1988). It was not possible to drill through the terracotta tiles due to their fragility. Instead, terracotta tiles were cable-tied to a thin hardwood plank with the unglazed surface facing out. The wood was then drilled and panels were attached to the reef as for concrete tiles.
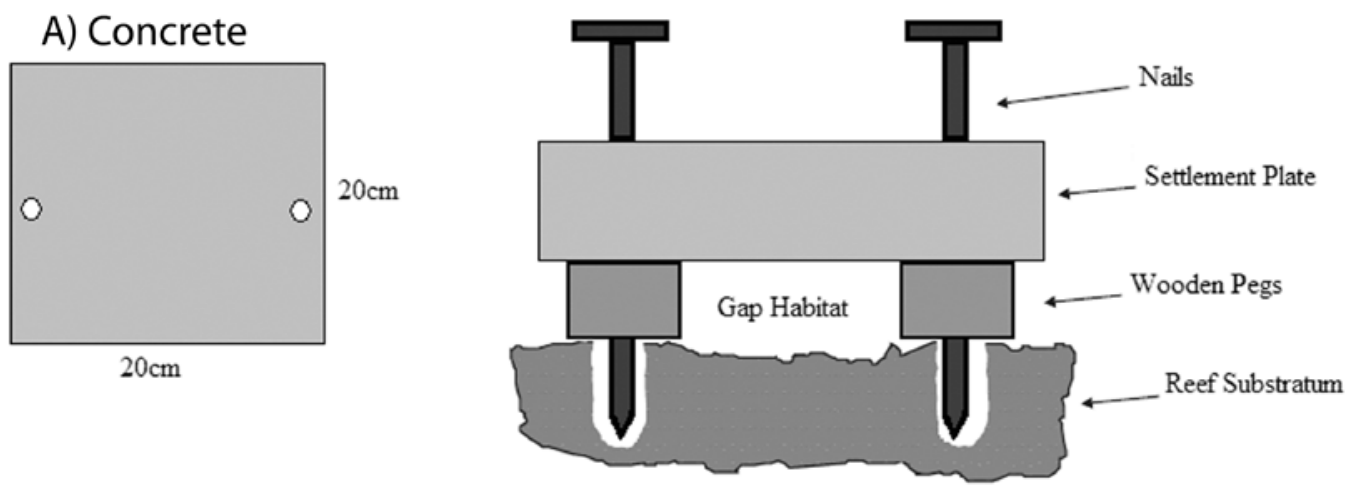

\section{B) Terracotta}
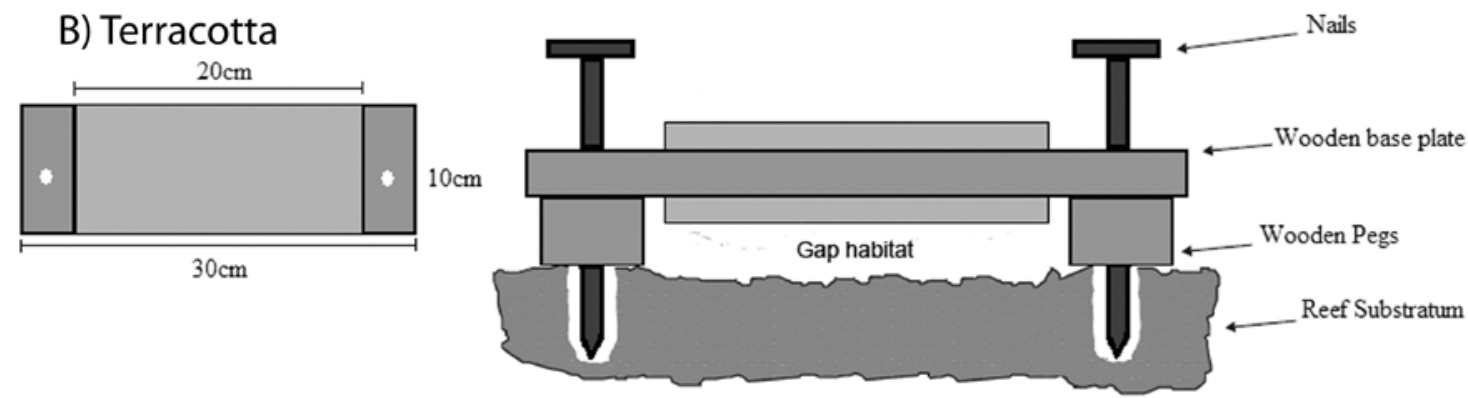

Fig. 14 Diagram of the different settlement panels and method of deployment used to monitor scleractinian coral settlement across four different sites in the Wakatobi National Marine Park in South-East Sulawesi, Indonesia.

Settlement panels were submerged for 12 months. On collection during July 2008, panels were labelled and transported back to the laboratory in fresh seawater. 
An initial search for coral recruits was conducted while panels were still fresh using a dissecting microscope and all spat were counted and marked. After this initial search, panels were bleached in a chlorine solution for 24 hours, then rinsed in freshwater to remove excess bleach before being air dried. The panels were searched twice again by two different observers at different microscope magnifications (10X and 20X). The panel edges were not analysed given their small area (terracotta tiles were only $0.7 \mathrm{~cm}$ thick). Recruits were identified as belonging to the families Acroporidae, Pocilloporidae and Poritidae based on the photomicrographs described by English et al. (1997) and Babcock et al. (2003). The remaining settlers, including the ones too damaged to identify, were designated as 'others'.

\subsubsection{Statistical analysis}

Differences in the abundance of coral settlers to the cleared reef areas during the day and night surveys were analysed using a t-test, whereas the differences in the number of coral settlers between the cleared areas and the settlement panels were analysed using PERMANOVA in PRIMER v.6. The PERMANOVA design had three fixed factors: materials (three levels cleared areas, concrete and terracotta), reefs (two levels: low coral cover and medium coral cover) and site as a nested factor (four levels: B3, B4, S1 and S2) within the factor reef. Only recruits that settled on the cryptic side of the settlement panels were included in this analysis given the small number of settlers that settled on the front of the panels. The horizontal concrete and terracotta panels were excluded from this analysis since there were no horizontal cleared reef areas. Data was standardised and a square root transformation was applied before the resemblance matrix was created.

Many zero values were recorded on the non-cryptic side of the panels, so a non-parametric Kruskal-Wallis test was conducted to determine the effect of panel 
side (cryptic versus non-cryptic) on the abundance of coral settlers. Only data from the back of panels were used to investigate the effect of material, panel orientation and reef on settlement. The PERMANOVA design had four fixed factors: material (two levels; concrete and terracotta); orientation (two levels; vertical and horizontal); reef (two levels: low coral cover and medium coral cover); and site as a nested factor (four levels B3, B4, S1 and S2). Data was standardised and a square root transformation was applied before the resemblance matrix was created. To allow easy comparison with previous studies, the number of recruits per tile was standardised to the number of recruits per $100 \mathrm{~cm}^{2}$.

\subsection{Results}

\subsubsection{Settlement to cleared reef areas}

All cleared areas created in July 2007 were relocated in July 2008 and a total of 91 settlers were found across all sites and replicates. The t-test revealed a significant difference ( $\mathrm{t}=-3.72 ; \mathrm{p}=0.002)$ between the daylight and UFT surveys, with a significantly higher number of coral settlers recorded at night using the UFT (Fig. 14).

I found no significant differences $(\mathrm{P}=0.881)$; (Table 8) between the number of settlers recorded in permanent cleared areas $\left(1.42 \pm 0.33\right.$ per $\left.100 \mathrm{~cm}^{2}\right)$ compared with concrete $(1.72 \pm 0.64$ SE per $100 \mathrm{~cm} 2)$ or terracotta $\left(1.47 \pm 0.25\right.$ per $\left.100 \mathrm{~cm}^{2}\right)$ panels. 


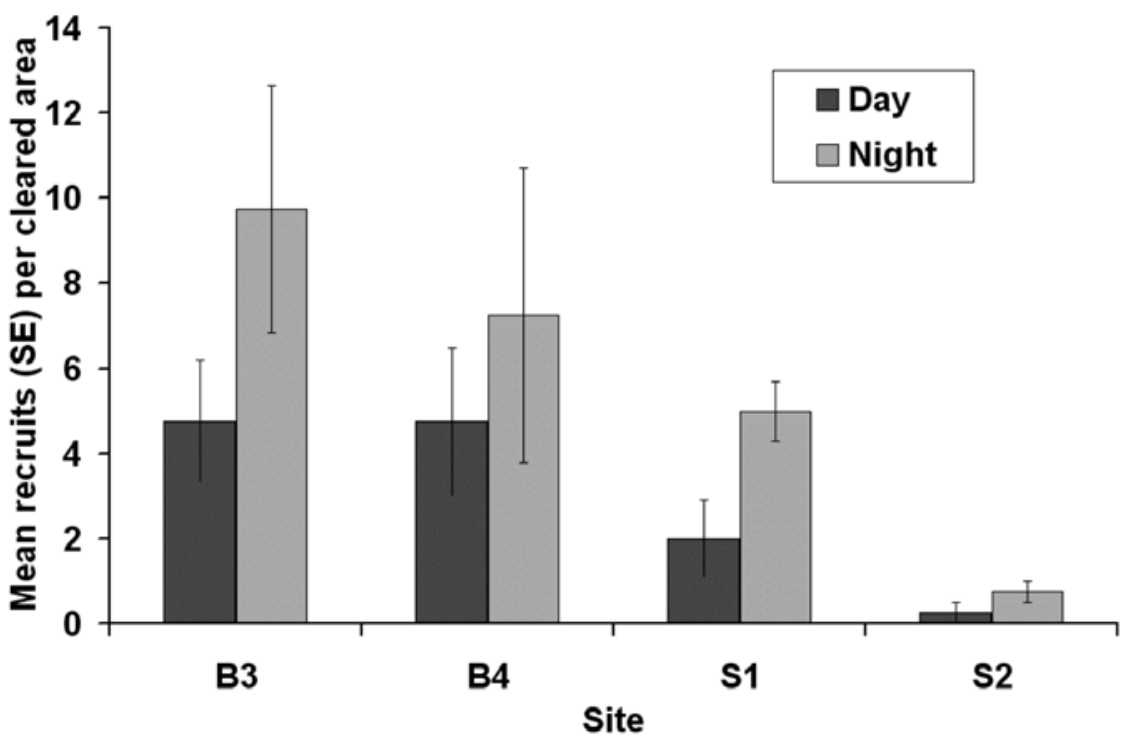

Fig. 15 Mean ( \pm Standard Error) number of coral settlers (per $100 \mathrm{~cm}^{2}$ ) per taxonomic group on settlement plates made of different materials (concrete and terracotta) and deployed at two different orientations (vertical and horizontal) across four different sites in the Wakatobi National Marine Park, SE Sulawesi, Indonesia.

The PERMANOVA (Table 8) showed a significant difference $(\mathrm{P}=0.001)$ between the two reefs, with a higher number of settlers being found at Hoga reefs compared with the Kaledupa reefs (see chapter 6 where this is explored further).

Table 8 Results of the PERMANOVA comparing the factors: reefs (Kaledupa and Hoga), sites (B3 and B4 in Hoga. S1 and S2 in Kaledupa) nested within reef, materials (concrete vertical, terracotta vertical and cleared vertical) and their interactions for hard coral settlement in the Wakatobi National Marine Park, Indonesia.

\begin{tabular}{l|ccccc} 
Source of variation & $\mathbf{d F}$ & SS & MS & Pseudo F & p \\
\hline Material & 2 & 61.877 & 30.939 & 0.19885 & 0.881 \\
Reef & 1 & 2099.7 & 2099.7 & 13.496 & $\mathbf{0 . 0 0 1}$ \\
Site (Reef) & 2 & 570.42 & 285.21 & 1.8332 & 0.168 \\
Material * Reef & 2 & 593.6 & 296.8 & 1.9077 & 0.135 \\
Material * Site (Reef) & 4 & 565.6 & 141.4 & 0.90883 & 0.474 \\
Res & 36 & 5601.1 & 155.59 & & \\
Total & 47 & 9492.3 & & &
\end{tabular}




\subsubsection{Settlement to panels}

I recovered all 64 panels deployed in 2007 and found a total of 354 coral settlers on the panels. Across all the settlers reported from the panels $21 \%$ belonged to the family Acroporidae, $14 \%$ to the family Pocilloporidae, $16 \%$ to the Poritidae and $49 \%$ were classified as 'others' (Fig. 15).

The mean number $( \pm \mathrm{SE})$ of settlers per tile ranged between 0 and 8.5 for concrete panels and 0 and 6.5 for terracotta panels. A significantly higher number of settlers were recorded on the cryptic side of both concrete (Kruskal-Wallis $\mathrm{H}=32.14$, $\mathrm{DF}=1, \mathrm{p}<0.0001$ ) and terracotta panels (Kruskal-Wallis $\mathrm{H}=18.14, \mathrm{DF}=1, \mathrm{p}<0.0001$ ). The settlers that settled on the non-cryptic side of the panels (19 in concrete, 20 in terracotta) were dominated by the family Pocilloporidae (72\%) followed by Poritids (13.6\%) Acroporids (3.4\%) and ‘others' (12\%).

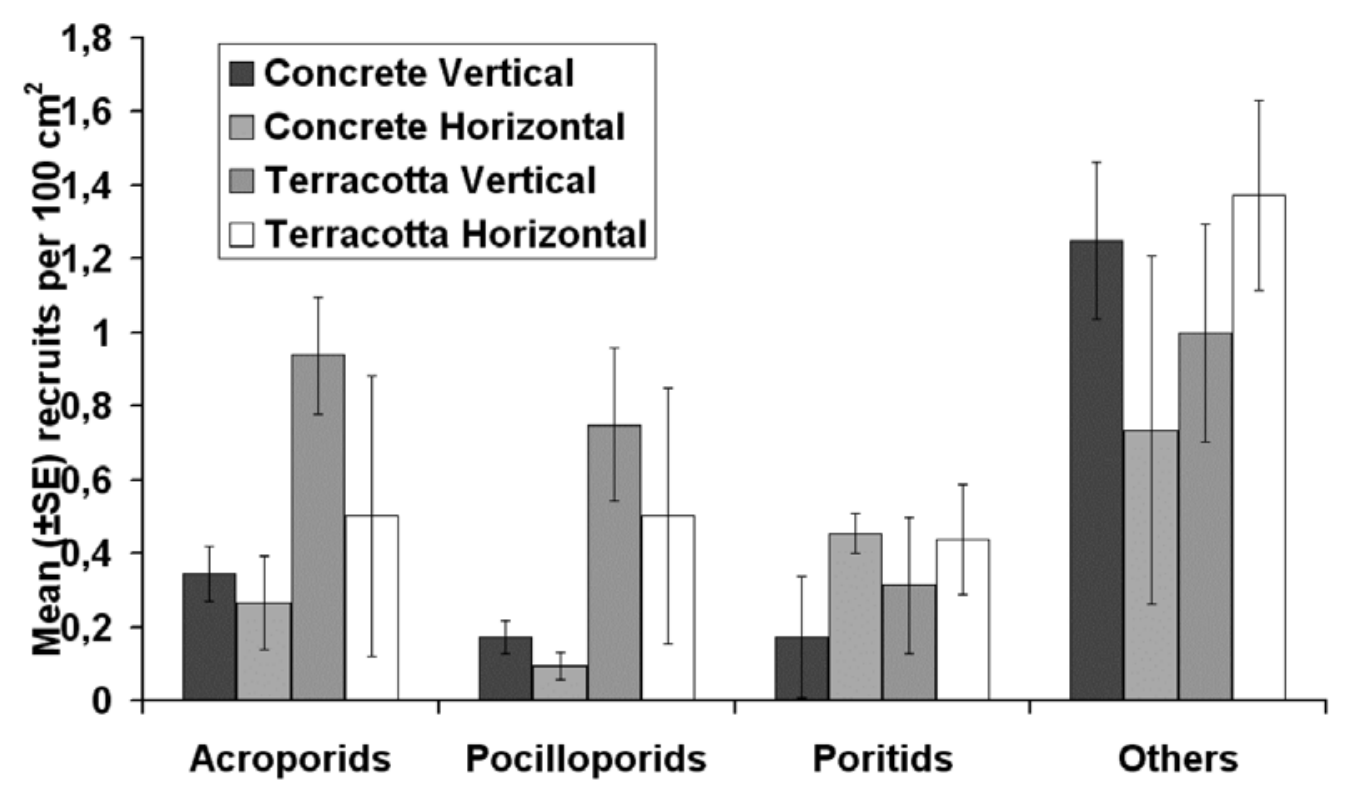

Fig. 16 Mean ( \pm Standard Error) number of coral settlers (per $100 \mathrm{~cm}^{2}$ ) on settlement plates made of two materials (concrete and terracotta) averaged across four sites (B3 and B4 at Hoga reefs; S1 and S2 at Kaledupa reefs) in the Wakatobi National Marine Park, SE Sulawesi, Indonesia Note: panel material data is presented for data pooled from vertical and horizontal surfaces. 
The PERMANOVA revealed no significant differences $(\mathrm{P}>0.05)$ between the mean number of settlers for panels made of different materials, panel orientation or any of the interaction terms between factors (Table 9). Unidentified and damaged polyps (others) were the most common recruits found on the settlement panels irrespective of material or orientation, followed by Acroporids, with the exception of horizontal concrete plates, where Poritids were the second most abundant group (Fig. 15, Table 9).

I found a significant difference in the number of coral settlers between reefs, with a higher number of recruits reported at the Hoga reef sites (B3, B4), compared to the Kaledupa reefs (S1, S2) (Table 9; Fig. 15). No significant interaction terms were detected terms between any combinations of material type, orientation and sites (Table 9).

Table 9 Results of the PERMANOVA comparing the factors: panel materials (concrete and terracotta), panel orientation (vertical and horizontal), reef (Hoga and Kaledupa), sites (B3, B4, S1, S2) and their interactions, for hard coral settlement in the Wakatobi National Marine Park. Indonesia.

\begin{tabular}{l|ccccc|} 
Source of variation & $\mathbf{d F}$ & SS & MS & Pseudo F & p \\
\hline Material & 1 & 14.653 & 14.653 & $4.4553 \mathrm{E}-2$ & 0.918 \\
Orientation & 1 & 108.55 & 108.55 & 0.33007 & 0.595 \\
Reef & 1 & 4009.6 & 4009.6 & 12.192 & $\mathbf{0 . 0 0 1}$ \\
Site (Reef) & 2 & 166.5 & 83.248 & 0.25313 & 0.82 \\
Material * Orientation & 1 & 255.98 & 255.98 & 0.77835 & 0.395 \\
Material * Reef & 1 & 37.146 & 37.146 & 0.11295 & 0.802 \\
Material * Site (Reef) & 2 & 744.45 & 372.23 & 1.1318 & 0.321 \\
Orientation * Reef & 1 & 441.58 & 441.58 & 1.3427 & 0.227 \\
Orientation * Site (Reef) & 2 & 588.27 & 294.14 & 0.89436 & 0.408 \\
Material * Orientation * Reef & 1 & 198.33 & 198.33 & 0.60306 & 0.455 \\
Material * Orientation * Site (Reef) & 2 & 289.58 & 144.79 & 0.44025 & 0.654 \\
Res & 112 & 36834 & 328.88 & & \\
Total & 63 & 26.8836 & & &
\end{tabular}




\subsection{Discussion}

I reported a significantly higher number of settlers to the back of the panels and there were no significant differences between different panel materials or orientation. I did, however, report a significant difference in the number of settlers between the two different reef systems (see chapter 6). These results support the use of a single material and orientation for future settlement studies in the WNMP, and also highlights the significant inter-site variability in settlement rates despite sites only being several km apart. I also found no significant difference between artificial substrata and natural substrata, which demonstrates that panels are a suitable surrogate for assessing settlement rates to coral reefs in the WNMP.

\subsubsection{Settlement to permanent cleared areas}

The UFT proved a very useful tool for detecting coral settlers to cleared reef areas and my results are similar to those obtained by Baird et al. (2006), who reported much higher coral settlement rates to natural substrata than were observed at night, compared with observations made during the day. There are some problems in using this technique including the presence of false positives from other fluorescing taxa, which I minimised by using a white light in conjunction with the fluorescence light. More important is the fact that some Poritid species do not fluoresce and might therefore be be missed (Baird et al. 2006). I believe that the best way to overcome this problem is to conduct daylight surveys, combined with digital photography. Schmidt-Roach et al. (2008) were able to detect non-fluorescent and fluorescent settlers during daylight conditions by placing a blue exciter on an underwater strobe and a yellow barrier filter on the camera lens, which they combined with fast shutter speeds. I found no significant differences between the permanent cleared areas (1.42 \pm 0.33 per $\left.100 \mathrm{~cm}^{2}\right)$, compared with concrete $(1.72 \pm 0.64$ SE per $100 \mathrm{~cm} 2)$ or 
terracotta $\left(1.47 \pm 0.25\right.$ per $\left.100 \mathrm{~cm}^{2}\right)$ panels. This suggests that coral settlement to artificial settlement panels provides a reliable indicator of coral settlement rates to natural substrata.

\subsubsection{Effect of panel side, orientation and material on coral settlement}

I found that the majority of settlers settled to the cryptic (back) side of the panels, which was not unexpected as several previous studies have documented this preference for the 'gap' at the back of panel habitats (Harriott \& Fisk 1987, 1988). Settlement to panels is believed to be light dependant, with corals at deeper sites preferring the upper sides of panels in order to maximise the available light (Harriott \& Banks 1995, Babcock \& Mundy 1996). Several authors have suggested that upper surfaces in shallow waters are less favoured by coral settlers, possibly because higher levels of grazing reduce the survival of settling corals (Fisk \& Harriott 1990, Harrison \& Wallace 1990, Harriott \& Banks 1995).

I found no significant effect of angle of deployment, panel material, or any combination of these factors on coral settlement rates. My panel orientation results are similar to those obtained by Mundy (2000) from the GBR, who reported no difference in coral settlement rates between panels deployed directly on the reef substrate at different angles. Despite the lack of significant differences between deployment angles in my study, I recommend a vertical orientation for future settlement panel deployment at similar depths in the WNMP given that the predominant reef environment are reef slopes and walls. When considering the similarities between settlement rates to different panel materials directly attached to the reef substrate, my results are consistent with those of Field et al. (2007) who found no difference in settlement rates to brick fired and terracotta panels in the Red 
Sea. Therefore I believe that terracotta panels represent the best material for future settlement studies as they are widely used among coral reef ecologists allowing easier comparisons between studies.

\subsubsection{Coral settlement in the WNMP compared with other localities}

This study provides the first data on coral settlement rates for two reefs in the highly diverse WNMP. Comparisons between coral settlement studies are difficult because of the variability in settlement panel size, method of panel deployment and orientation, time of the year when panels were deployed and collected, depth, and the duration of panel deployment. The most comparable study to ours was conducted by Mundy (2000), as he also attached terracotta panels directly to the reef. Mundy (2000) reported similar settlement rates to my results (between $1.3 \pm 0.4$ SE $-1.1 \pm$ $0.3 \mathrm{SE}$ recruits per $100 \mathrm{~cm}^{2}$ ) on panels deployed for 6 months at $9 \mathrm{~m}$ depth at Heron island reefs on the GBR. Another relevant study, due to its close proximity to the WNMP is Fox (2004), who measured settlement rates around the reefs of the Komodo National Park, also in south-east Indonesia. Fox (2004) reported mean settlement rates of 3 recruits per $100 \mathrm{~cm}^{2}$ across 25 sites, including reports of settlement rates as high as 25 recruits per $100 \mathrm{~cm}^{2}$. These settlement figures are considerably higher than those obtained in my study, which may be explained in a number of ways. Firstly, Fox (2004) used a different method of panel deployment to my study, where terracotta panels were attached to wooden planks driven into the substrata, so panels were vertically orientated $25 \mathrm{~cm}$ over the substrata. There is the possibility that these raised structures had an effect on the local water flow patterns, causing a larvae 'trapping' artefact as described by Butman (1987), which may have influenced the supply of larvae to the settlement plates (Mundy 2000). Such an 
explanation, however, does not explain the high settlement rates (average 4 recruits per $100 \mathrm{~cm}^{2}$, no SE provided) reported by Field et al. (2007) on reefs in the Red Sea using the same direct attachment method that was used by Mundy (2000) and in my study. Another more likely explanation to explain these differences is the different amount of time that the panels were submerged. In my study, panels were submerged for 12 months, while in the Red Sea and Komodo studies, panels were submersed for only 4 and 6 months respectively. It is likely that the longer the panels are deployed the higher the chance that corals may settle on them. Alternatively, the longer the deployment time, the more likely that post-settlement mortality will occur, such as fish grazing or overgrowth by other fast-growing species such as ascidians, which will remove the newly settled corals. On chapter 6 I will deploy panels for shorter periods of time to determine if there is any influence of seasonality upon coral settlement. 


\section{Chapter 6. The effect of locally available larvae upon coral settlement rates: temporal and spatial variability}

\section{Manuscript submitted for publication in Marine Ecology Progress Series}

Salinas de Leon P., Dryden C., Smith D.J. and Bell J.J. Temporal and spatial variability in coral larval settlement on an Indonesia coral reef

Author contribution: PS designed the study and performed the field work, analyzed the data and wrote de manuscript. CD assisted with the fieldwork. DJS and JJB codesigned the study and edited the manuscript.

\section{Abstract}

In chapter 5, I investigted the best methdology to study coral settlement to reefs in the Wakatobi National Marine Park and I revealed significant differences in the number of coral settlers at sites with different levels of adult coral cover. In this chapter I measured coral settlement rates with the following aims: 1) to further examine the influence of different levels of coral cover and environmental quality on settlement rates and juvenile coral abundance; and 2) to determine inter-annual and seasonal variation in coral settlement rates to artificial settlement panels $(6-7 \mathrm{~m}$ depth) and cleared areas of natural reef. I examined settlement rates and juvenile coral abundance at the same sites described in chapter 5. I found a significant difference in the settlement rates between sites, with higher settlement rates and juvenile abundance at sites with higher live coral cover sites. Coral settlement was two-fold higher in 2008-2009 than in 2007-2008 and a seasonal peak was recorded between November 2008 and March 2009. I hypothesise that the lower settlement rates and juvenile abundance recorded at the degraded sites are a consequence of a number of factors, including the lower abundance of locally available larvae due to the small number of live coral colonies, the high sedimentation rates and the higher post-settlement mortality rate. My research highlights the need for steps to be taken 
to prevent further declines in coral cover and promote restoration programmes if degraded reefs in this region are likely to recover over short to medium term time scales

\subsection{Introduction}

Coral reefs are in decline worldwide as a consequence of natural and anthropogenic disturbance (Hughes 1994, Bellwood et al. 2004, Mora 2008). Localscale human impacts including: overfishing; the use of destructive fishing techniques, such as blast and cyanide fishing; coral removal; disease; eutrophication; and increased sedimentation from mangrove removal and changes in land-use. These impacts, in combination with the global threats of global climate change and ocean acidification, have caused severe damage to over $30 \%$ of the world's reefs and close to $60 \%$ may be lost completely by 2030 (Gardner et al. 2003, Hughes et al. 2003, Hoegh-Guldberg et al. 2007, Carpenter et al. 2008). Over the last 20 years, this decline in coral abundance has been well-documented throughout the Caribbean, with an $80 \%$ reduction in average hard coral cover from $50 \%$ in the 1970 s to $10 \%$ at present (Gardner et al. 2003). Indo-Pacific coral reefs are also under serious threat and recent estimates show a 32\% region-wide decline in coral cover since the 1970's (Bruno \& Selig 2007). Despite these alarming figures, still little it is known about many of the most basic ecological processes that regulate reef biodiversity in the central Indo-Pacific, despite reefs around Indonesia and the Philippines containing the highest diversity of coral species and reef-associated organisms (Burke et al. 2002).

Recruitment has long been recognised as one of the most important factor driving the ecology of scleractinian corals and recruitment is critical for the maintenance of viable reef populations and for promoting the recovery of coral reefs 
after disturbance (Babcock \& Mundy 1996, Connell et al. 1997, Hughes et al. 2000). Hard coral recruitment is influenced by a number of factors including the amount of live coral cover in the source population/s (Hughes et al. 2000), abundance and diversity of coral larvae (Potts et al. 1985), hydrodynamic variability (Amar et al. 2007), sedimentation (Babcock \& Davies 1991), temperature (Nozawa \& Harrison 2007), settlement cues from other benthic taxa (Harrington et al. 2004), settlement inhibition by other benthic taxa (Maida et al. 1995), eutrophication levels (Tomascik 1991), grazing pressure (Sammarco 1980), light levels (Mundy \& Babcock 1998) and connectivity between reefs (Roberts 1997). Some of these factors positively affect coral recruitment, such as the presence of crustose coralline algae (CCA), while others negatively affect coral recruitment, such as increased sedimentation or macroalgae and/or soft coral competition (Benayahu \& Loya 1985, Babcock \& Davies 1991, Maida et al. 1995). Some authors have reported significantly lower settlement rates at degraded, low coral cover sites, suggesting that the condition of the reef might have some influence upon recruitment rates (Nzali et al. 1998). In a study by Sammarco \& Andrews (1988), where settlement panels were deployed with increasing distance from an isolated reef, the majority of coral recruits were recorded within just $300 \mathrm{~m}$ of the reef; this suggests that some proportion of corals might be self-recruiting and that reefs are self-seeding. Recent genetic evidence supports this view, as it has been shown that a great proportion of coral recruits, especially for brooding species, settle close to home (Underwood et al. 2007, 2009); however, some larvae might still disperse over large distances (van Oppen et al. 2008, Nakajima et al. 2010). If self-recruitment is a common process, local-scale degradation of adult coral breeding stocks could limit a reefs ability to recover naturally, potentially resulting in recruitment failure. However, several other authors 
have shown that settlement levels can remain high in the absence of local adult coral populations through an influx of larvae produced at other reefs (Harriott \& Fisk 1988, Fox 2004).

Burke et al. (2002) suggested that more than $85 \%$ of Indonesia's reefs are threatened by anthropogenic impacts and there have only been a few previous settlement studies conducted around the Coral Triangle region (Tomascik et al. 1996, Reyes \& Yap 2001, Fox et al. 2003, Fox 2004, Schmidt-Roach et al. 2008). From these studies only, Fox et al. (2003) and Fox (2004) were conducted in more than one locality and were temporally replicated; these studies revealed spatial and temporal variation in coral settlement patterns. These studies highlight the need to understand hard coral dynamics in the region that contains the highest concentration of marine biodiversity on the planet if effective management plans are to be developed and healthy coral populations sustained.

My study investigated settlement and early recruitment of coral spat to four sites (within two reef systems) that have been subjected to different levels of past anthropogenic disturbance and as a consequence have different levels of live adult coral cover and environmental conditions. The objectives of this study were: (1) to determine if differences occur in coral settlement rates between reefs with different levels of coral coverage; and (2) to measure inter-annual and seasonal variation in coral settlement rates at selected sites in the Wakatobi National Park, SE Sulawesi, Indonesia

\subsection{Materials and methods}

\subsubsection{Study sites}

The sites for this study in the Wakatobi National Marine Park (WNMP) were the same as those described in chapter 5 . 


\subsubsection{Site characterisation}

Benthic habitat composition was characterised at each study site to determine the amount of live coral cover, the taxonomic composition of the coral community and the abundance of other benthic taxa, since in some coral taxa the relative abundance of spat populations are similar to adult populations and the presence of other benthic groups influences coral recruitment (Smith 1992, Harrington et al. 2004). Benthic habitat composition was determined using the continual line intercept method described by English et al. (1997). Ten haphazardly placed $10 \mathrm{~m}$ long transects were sampled at $6 \mathrm{~m}$ depth using the line intercept method at each of the 4 study sites. For each individual transect, any coral colony lying underneath the transect tape was identified to genus level and recorded. Other benthic categories that were recorded include bare substrate, sand, coral rubble, dead coral, soft corals, algae, crustose coralline algae (CCA), sponges and ascidians.

Temperature was recorded throughout the study period using HOBO pendant temperature loggers (Onset Corporation, US) placed at $6 \mathrm{~m}$ depth at two sites (B3, S1), one on each reef system. Current strength and direction was measured using a Valeport model 106 flow meter (Valeport Oceanographic instruments, UK) positioned at 7-8 $\mathrm{m}$ depth. Only three $24 \mathrm{~h}$ deployments, during both neap and spring tides, at each of the four study sites were conducted due to logistical limitations. Sedimentation rates were obtained by placing three replicated sediment traps (cylinders $7 \mathrm{~cm}$ diameter and $20 \mathrm{~cm}$ tall made of plastic) at $6 \mathrm{~m}$ for 7 days at each of the study sites during November 2008 and July 2009. Sediment was washed out of the traps and filtered, and then oven dried for $24 \mathrm{~h}$ and weighed to the nearest $0.01 \mathrm{~g}$. Sedimentation rates were averaged between the three depths. 


\subsubsection{Settlement}

The settlement panels deployed to monitor coral settlement were made of locally available unglazed terracotta tiles $(20 \times 10 \times 0.7 \mathrm{~cm})$. Each set consisted of eight panels attached to vertical surfaces at each of the four sites. This method of tile deployment was based on a previous study that revealed no significant effect of panel angle on settlement rates (Chapter 5).

Different sets of panels were submerged for two different periods of time to record yearly and seasonal coral settlement rates. One set of panels was deployed for 12 months between July 2007 and July 2008. Upon retrieval a new set of panels was placed during July 2008 and retrieved 12 months later in July 2009. Another set of panels were deployed during July 2008 for the seasonal settlement study. Panels deployed in July 2008 were retrieved and replaced by another set every 4 months, providing three 4-monthly settlement data sets: from July 2008 to November 2008; November 2008 to March 2009; and March 2009 to July 2009. Indonesia’s climate is dominated by the monsoon seasons, with the northwest monsoon (wet season) occurring between November and March and the southeast monsoon (dry season) season between May and September.

When panels were collected, they were labelled and transported back to the laboratory in seawater. Panels were photographed and an initial search for coral spat was conducted while panels were still fresh using a dissection microscope and all spat were counted and marked. After this initial search, panels were bleached in a chlorine solution for $24 \mathrm{~h}$, then rinsed in freshwater to remove excess bleach before being air dried. Panels were searched twice again by two different observers at different microscope magnifications (10X and 20X). The panel edges were not analysed given their small area (i.e., panels were $0.7 \mathrm{~cm}$ thick). Settlers were 
identified as belonging to the families Acroporidae, Pocilloporidae and Poritidae based on the photomicrographs described by English et al. (1997) and Babcock et al. (2003), with the remaining spat, including the ones too damaged to identify, being designated as 'others'.

\subsubsection{Settlement to natural reef cleared areas}

Four permanent cleared reef areas $(25 \times 25 \mathrm{~cm})$ per site were placed to further investigate coral settlement rates. Permanent cleared areas were created in July 2007 and July 2008 and they were surveyed after 12 months, during July 2008 and July 2009, respectively. Permanent cleared areas were cleared and surveyed as described in chapter 5.

\subsubsection{Juvenile coral abundance and diversity}

Juvenile coral abundance and diversity was assessed during July 2008 using twenty $50 \mathrm{~cm}^{2}$ quadrats positioned haphazardly along a $50 \mathrm{~m}$ transect at the $6 \mathrm{~m}$ contour at each of the four sampling sites. Prior to surveying the quadrats, sediment was removed to facilitate counts of the small juvenile corals. Juvenile corals were defined as colonies $<40 \mathrm{~mm}$ in diameter that were attached to the substratum and did not have the fractured surface characteristic of asexual recruits (Edmunds 2000a). Corals present in the quadrats were identified to genus level and measured to the nearest mm using a set of callipers.

\subsubsection{Statistical analysis}

Data were analysed by statistical packages MINITAB v16, PRIMER v6 and PERMANOVA v1.0.2. Differences in the benthic cover composition between sites were analysed using a Kruskal Wallis test for each of the benthic categories. PERMANOVA is a permutation-based version of the multivariate analysis of 
variance (Anderson, 2001). It uses the distances between samples to partition variance and randomizations or permutations of the data to produce the p-value for the hypothesis test. It is non-parametric and, therefore, robust to the assumption of multivariate normality making it less prone to Type I errors. Differences in the yearly settlement rates to panels and settlement to cleared reef areas were analysed using a PERMANOVA model with two fixed factors: year (two levels: 2008, 2009) and site (four levels: B3, B4, S1 and S2). The PERMANOVA seasonal settlement data statistical design had two fixed factors: season (three levels: November, March and July) and site (four levels: B3, B4, S1 and S2). The PERMANOVA model created for the juvenile distribution data included the factor site (four levels: B3, B4, S1 and S2) given that surveys were only conducted during 2008.

\subsection{Results}

\subsubsection{Site biological and physical characteristics}

Hoga and Sampela sites had significantly different benthic substrata and community composition (Fig. 17 a, b). Hoga sites (B3, B4) were dominated by hard corals (Table 10), while Sampela sites were dominated by bare substrate and coral rubble, followed by hard corals (Table 10). There were also significant differences ( $<<0.05$, Kruskal-Wallis) in the percentage cover of CCA and sand between the two reefs (Fig. 17 a), with higher CCA abundance at the Hoga sites and higher sand cover at the Sampela sites. The Hoga reef coral assemblage at $6 \mathrm{~m}$ depth was dominated by the Acroporidae and Poritidae families, while the Sampela reef coral assemblage was dominated by corals of the families Faviidae and Poritidae (Fig. 17 b). 

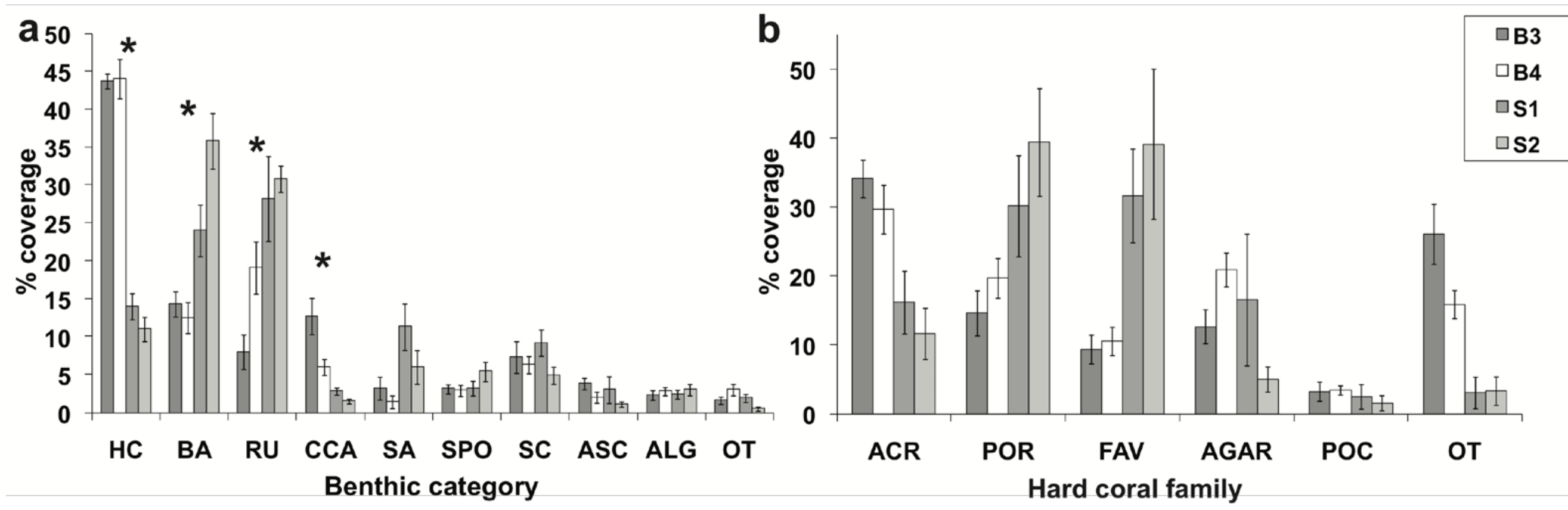

Fig. 17 Mean percentage coverage ( \pm SE) of the major benthic groups (a) and coral families (b) at four different sites (B3 and B4 at Hoga reef; S1 and S2 at Sampela reef) in the Wakatobi National Park, SE Sulawesi, Indonesia. (*) indicates significant differences between sites (Kruskal Wallis, p<0.05). HC: Hard coral, BA: Bare, RU: Rubble, CCA: Coralline Algae, SA: Sand, SPO: Sponge, ASC: Ascidian, ALG: Algae, OT: Other 
Hoga and Sampela sites had similar water flow rates and water temperatures over the length of the study (Table 10). Sedimentation rates were higher on the Sampela reef sites compared to Hoga reef sites during both sampling seasons (Table $10)$.

Table 10 Site characterisation table showing mean \% coral cover ( \pm Standard Error); water flow range $\left(\mathrm{cm} \mathrm{s}^{-1}\right)$; mean sedimentation rates in $\mathrm{g} \mathrm{d}^{-1}\left( \pm\right.$ Standard Error); and mean temperature $\left({ }^{\circ} \mathrm{C}\right)( \pm$ Standard Error), including the minimum and maximum mean monthly temperatures across four different sites

(B3 and B4 at Hoga reef; S1 and S2 at Sampela reef) in the Wakatobi National Marine Park, SE Sulawesi, Indonesia.

\begin{tabular}{|c|c|c|c|c|c|c|c|c|}
\hline \multirow[b]{2}{*}{ Reef } & \multirow[b]{2}{*}{ Site } & \multirow[b]{2}{*}{$\begin{array}{l}\% \text { coral } \\
\text { cover } \\
( \pm \mathrm{SE})\end{array}$} & \multirow[b]{2}{*}{$\begin{array}{l}\text { Water } \\
\text { flow }\end{array}$} & \multicolumn{2}{|c|}{ Sedimentation } & \multicolumn{3}{|c|}{ Temperature } \\
\hline & & & & $\begin{array}{c}\text { Dry } \\
( \pm \text { SE) }\end{array}$ & $\begin{array}{c}\text { Wet } \\
( \pm \text { SE })\end{array}$ & $\begin{array}{l}\text { Mean } \\
\text { yearly } \\
( \pm \mathrm{SE})\end{array}$ & $\begin{array}{c}\text { Min mean } \\
\text { monthly } \\
( \pm \mathrm{SE})\end{array}$ & $\begin{array}{c}\text { Max mean } \\
\text { monthly } \\
( \pm \text { SE })\end{array}$ \\
\hline Hoga & B4 & $\begin{array}{c}43.7 \\
\pm 0.97 \\
44 \\
\pm 2.58\end{array}$ & & $\begin{array}{c}0,14 \\
\pm 0.04 \\
0,16 \\
\pm 0.04\end{array}$ & $\begin{array}{c}0.12 \\
\pm 0.02 \\
0.18 \\
\pm 0.05\end{array}$ & $\begin{array}{c}28.36 \pm \\
0,25 \\
(' 07-108)\end{array}$ & 26.8 & 29.9 \\
\hline Sampela & $\begin{array}{l}\mathrm{S} 1 \\
\mathrm{~S} 2\end{array}$ & $\begin{array}{c}14 \\
\pm 1.71 \\
11 \\
\pm 1.59\end{array}$ & $10-20$ & $\begin{array}{c}0,23 \\
\pm 0.04 \\
0,29 \\
\pm 0.09\end{array}$ & $\begin{array}{c}0.33 \\
\pm 0.05 \\
0.32 \\
\pm 0.11\end{array}$ & $\begin{array}{c}28.85 \pm \\
0,3 \\
(' 08-' 09)\end{array}$ & $\begin{array}{l} \pm 0,004 \\
\text { (Aug '07) }\end{array}$ & $\begin{array}{l} \pm 0,006 \\
\text { (Apr '09) }\end{array}$ \\
\hline
\end{tabular}

\subsubsection{Settlement}

\subsubsection{Yearly settlement}

A total of 114 and 268 coral spat were recorded on the 32 panels across all sites in 2008 and 2009, respectively. In 2008 panels, 25\% belonged to the family Acroporidae, $21 \%$ to the family Pocilloporidae, $13 \%$ to the Poritidae and $41 \%$ were classified as 'others'. In 2009, $12 \%$ belonged to the family Acroporidae, $10 \%$ to the family Pocilloporidae, $16 \%$ to the family Poritidae and $62 \%$ were classified as 'others'. This inter-annual variation in coral settlement was found to be highly significant (Fig. 18a; Table 11). 

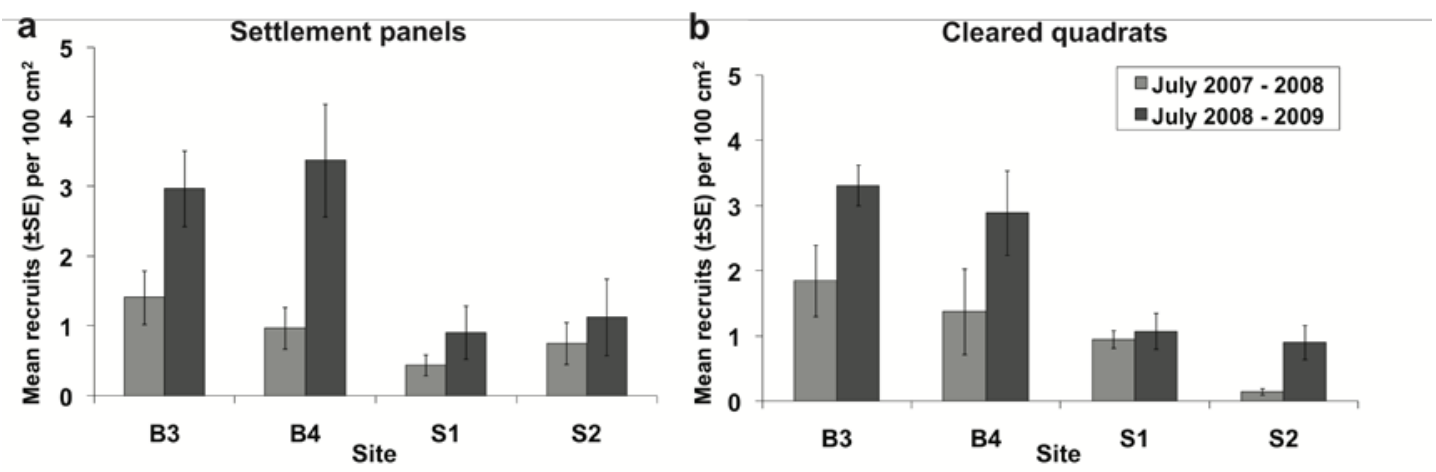

Fig. 18 Mean $\left( \pm\right.$ SE) number of coral spat (per $100 \mathrm{~cm}^{2}$ ) on settlement plates (a) and cleared reef areas (b) deployed during 2008 and 2009 across four different sites (B3 and B4 at Hoga reef; S1 and S2 at Sampela reef) in the Wakatobi National Park, SE Sulawesi, Indonesia.

The number of coral spat found on panels also varied between sites, with a higher number of spat reported at the Hoga reef sites (B3, B4), compared to Sampela reef sites (S1, S2) during both years (Fig. 18a; Table 11).

Table 11 Results of the PERMANOVA comparing the factors: year $(2008,2009)$ and site (B3 and B4 at Hoga; S1 and S2 at Sampela) and their interactions, for hard coral settlement to terracotta settlement panels in the Wakatobi National Marine Park, Indonesia.

\begin{tabular}{l|ccccc}
\hline \multicolumn{1}{c}{ Source of variation } & Df & SS & MS & Pseudo-F & P(perm) \\
\hline Year & 1 & 6290.2 & 6290.2 & 9.96 & $\mathbf{0 . 0 0 1}$ \\
Site & 3 & 16138 & 5379.35 & 8.52 & $\mathbf{0 . 0 0 1}$ \\
Year x Site & 1 & 3420.4 & 1140.1 & 1.80 & 0.133 \\
Res & 120 & 75759 & 631.32 & & \\
Total & 127 & $1.02 \mathrm{E}+05$ & & &
\end{tabular}

\subsubsection{Seasonal settlement}

Significantly higher coral settlement rates were recorded during the November 2008-March 2009 period, with more than five and three times the numbers recorded in July 2008-November 2008 and March 2009-July 2009 periods, respectively (Fig. 19; Table 12). The higher settlement rates during this period matched the increase in sea surface water temperature (SST) during the wet 
northwest monsoon (Fig. 19). Settlement rates of acroporids were also higher during the March-July period $\left(0.58 \pm 0.08\right.$ SE spat per $\left.100 \mathrm{~cm}^{2}\right)$, compared to the JulyNovember $\left(0.14 \pm 0.04\right.$ SE spat per $\left.100 \mathrm{~cm}^{2}\right)$ and March-July $(0.04 \pm 0.01$ SE spat per $100 \mathrm{~cm}^{2}$ ) period (Fig. 20). In a similar way to the yearly settlement study, significantly higher numbers of coral spat were recorded at Hoga sites compared to Sampela sites across all seasons (Fig. 19; Table 12).

Month

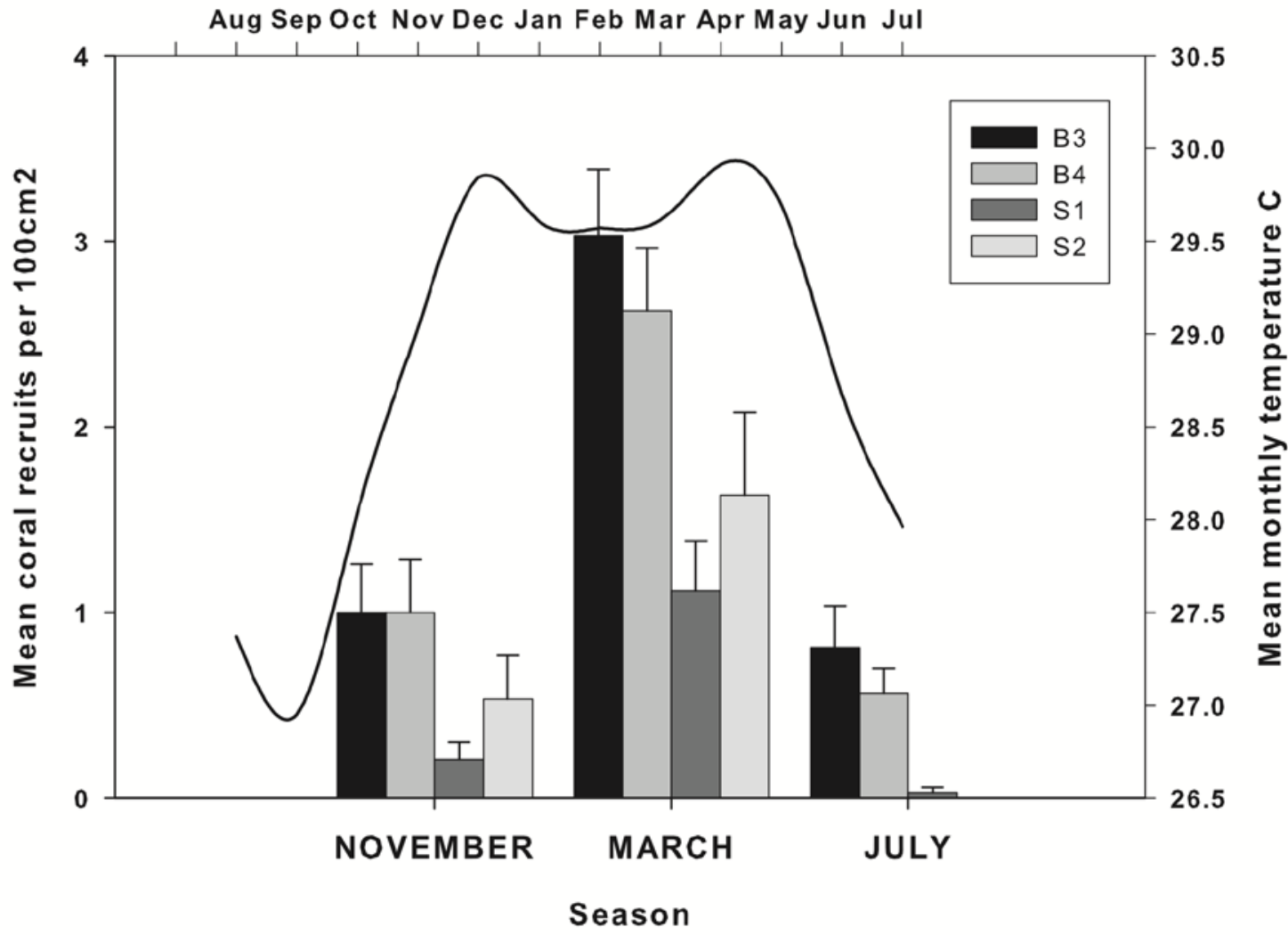

Fig. 19 Left Axis: Mean ( \pm SE) number of coral settlers (per $\left.100 \mathrm{~cm}^{2}\right)$ on settlement plates during the three different submersion periods at four sites (B3 and B4 at Hoga reef; S1 and S2 at Sampela reef) in the Wakatobi National Marine Park, SE Sulawesi, Indonesia. Right axis: mean monthly sea temperature (averaged across two sites). 
Table 12 Results of the PERMANOVA comparing the factors: season (November, March and July) and site (B3 and B4 at Hoga; S1 and S2 at Sampela) and their interactions for hard coral settlement to terracotta settlement panels in the Wakatobi National Marine Park, Indonesia.

\begin{tabular}{l|ccccc}
\hline \multicolumn{1}{c}{ Source of variation } & Df & SS & MS & Pseudo-F & P(perm) \\
\hline Season & 2 & 55222 & 27611 & 33.213 & $\mathbf{0 . 0 0 3}$ \\
Site & 3 & 30649 & 10216 & 17.099 & $\mathbf{0 . 0 0 1}$ \\
Season x Site & 6 & 4988 & 831.33 & 1.3914 & 0.16 \\
Res & 180 & $1.07 \mathrm{E}+05$ & 597.49 & & \\
Total & 191 & $1.98 \mathrm{E}+05$ & & &
\end{tabular}

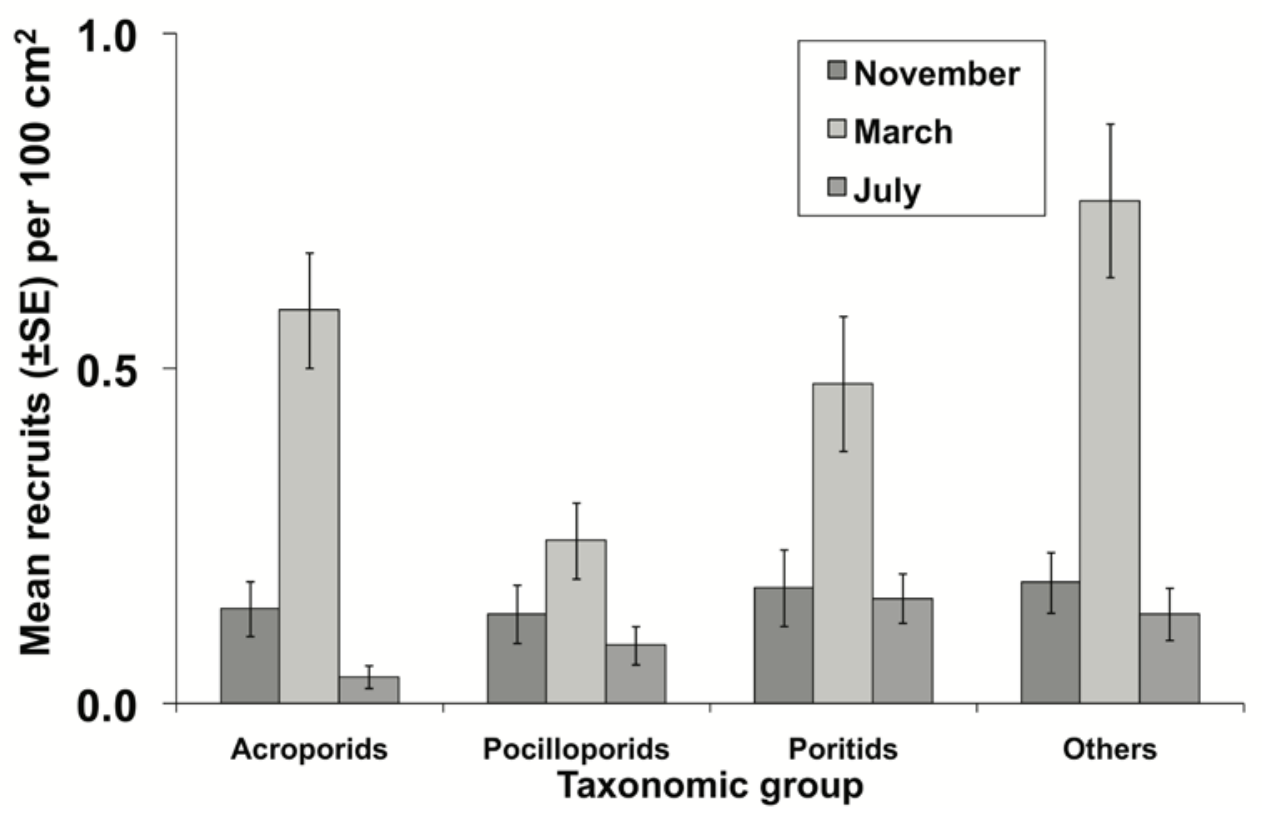

Fig. 20 Mean $\left( \pm\right.$ SE) number of coral settlers (per $100 \mathrm{~cm}^{2}$ ) per taxonomic group on settlement plates during the three different submersion periods across four different sites (B3 and B4 at Hoga reef; S1 and S2 at Sampela reef) in the Wakatobi National Marine Park, SE Sulawesi, Indonesia.

\subsubsection{Settlement to cleared reef areas}

A total of 91 and 167 coral settlers were recorded on the cleared reefs areas across all sites in 2008 and 2009, respectively. Significant differences (Fig. 18b; Table 13) were recorded between the inter-annual settlement rates, with higher settlement rates recorded during the 2008-2009 period. In addition, significantly higher settler numbers were recorded for both years at the Hoga sites compared to the Sampela sites (Fig. 18b; Table 13). 
Table 13 Results of the PERMANOVA comparing the factors: year $(2008,2009)$ and site (B3 and B4 at Hoga; S1 and S2 at Sampela) and their interactions for hard coral settlement to cleared reef areas in the Wakatobi National Marine Park, Indonesia.

\begin{tabular}{l|ccccc}
\hline Source of variation & df & SS & MS & Pseudo-F & P(perm) \\
\hline Year & 1 & 4590.3 & 4590.3 & 4.7913 & $\mathbf{0 . 0 1 3}$ \\
Site & 3 & 15900 & 5300.1 & 5.5322 & $\mathbf{0 . 0 0 1}$ \\
Year x Site & 3 & 5293 & 1764.3 & 1.8416 & 0.058 \\
Res & 24 & 22993 & 958.05 & & \\
Total & 31 & 48777 & & &
\end{tabular}

\subsubsection{Juvenile coral abundance and diversity}

Juvenile coral abundance ranged from 0 to 19 per $0.5 \mathrm{~m}^{2}$ in the 80 quadrats surveyed $\left(40 \mathrm{~m}^{2}\right)$. Juveniles of the family Faviidae were the most abundant across all sites (28.3\%), followed by Poritidae (24.5\%), Agariciidae (18.9\%), Acroporidae (10.7\%) and Pocilloporidae (4.22\%). Significantly higher numbers of juveniles were recorded at Hoga sites compared to Sampela sites (Fig. 21; $\mathrm{df}=3$ Pseudo-F=6.46, $\mathrm{p}=0.001)$ 


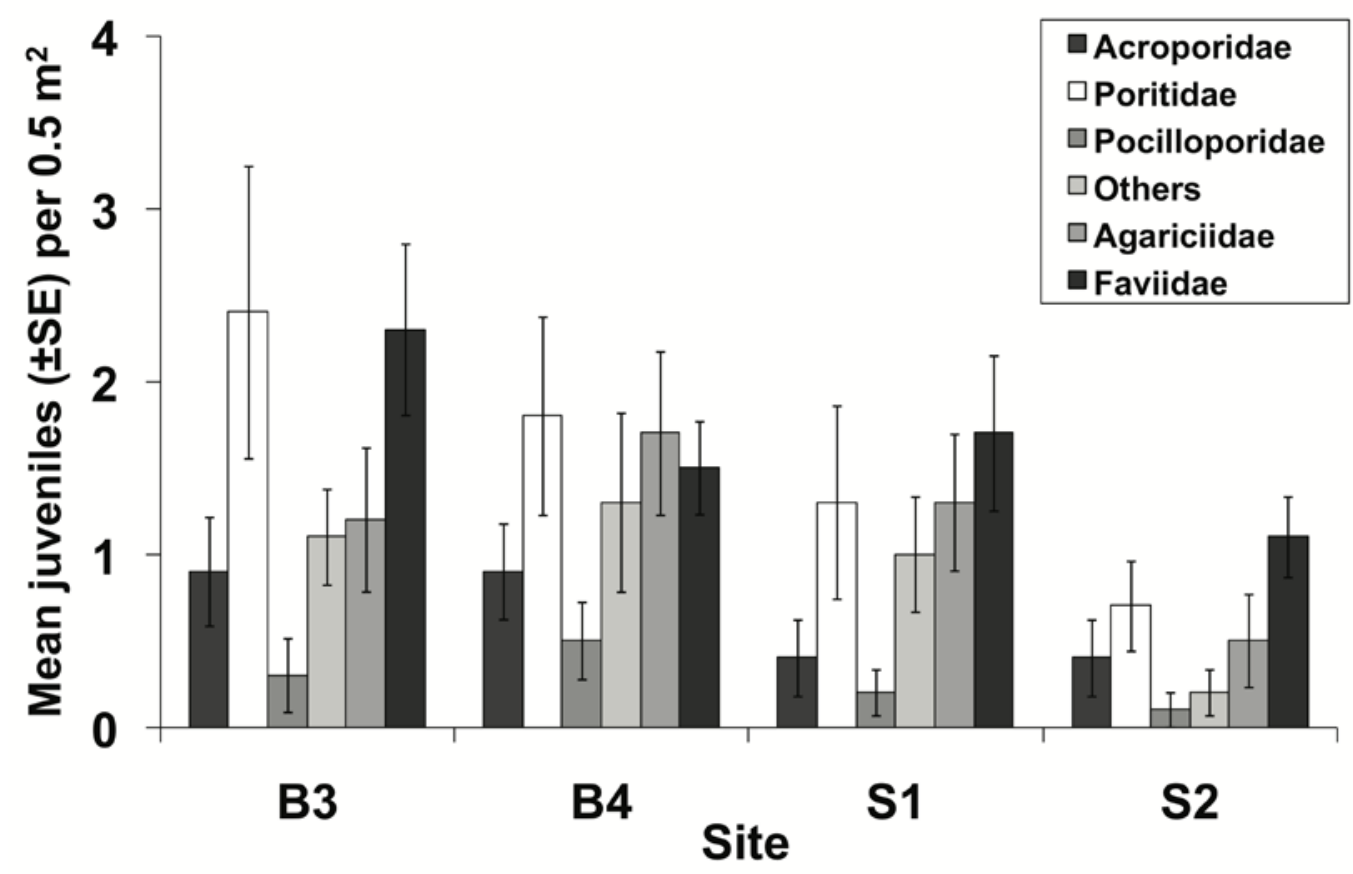

Fig. 21 Mean $\left( \pm S E\right.$ ) number of coral juveniles (per $0.5 \mathrm{~m}^{2}$ ) for each taxonomic group across four different sites (B3 and B4 at Hoga reef; S1 and S2 at Sampela reef) in the Wakatobi National Marine Park, SE Sulawesi, Indonesia.

\subsection{Discussion}

I found that settlement rates were consistently lower over the two-year-period at sites with low adult coral cover (that has resulted from long-term anthropogenic disturbance) and high levels of sedimentation. I also found significant inter-annual and seasonal variation in coral settlement rates in the Wakatobi National Park. The three different approaches utilised in this study (settlement panels, cleared reef areas and quantification of juvenile coral abundance) showed similar patterns and in combination with reef surveys suggests that the Sampela reefs may be recruitment limited.

\subsubsection{Variation between sites}

Large differences were found in the number of settlers between the Hoga and Sampela reefs, which was consistent between years and seasons. Firstly, these 
settlement rate differences could be driven by the different levels of live coral coverage between the reefs given that coral coverage is significantly lower at the Sampela sites compared to the Hoga sites, although these results should be interpreted with caution given the small number of study sites. There is increasing evidence to suggest that a high proportion of the coral larvae produced locally might be retained close to the parental population (Sammarco \& Andrews 1988, Underwood et al. 2007, 2009). If this is the case and reefs are largely self-seeding, the abundance of locally available larvae will be a function of the local abundance of adult corals. The reefs around Sampela have been subjected to severe anthropogenic disturbance over the last few decades and coral coverage has been severely reduced. I hypothesise that the lower larval availability at the Sampela sites has some influence on the levels of coral settlement.

Despite the strong evidence to suggest that the differences in coral settlement rates between sites are the result of differences in coral cover, it is also possible that these differences in settlement rates are driven by variability in the amount of coral larvae being transported away from the reefs or by different levels of subsidies from other nearby reefs. Although there is no information regarding the water circulation models for this area, data from the flow-meter deployments suggest similar current strength (between 10-20 cm s) and direction (southeast during incoming tide and northwest during high tide) at the Hoga and Sampela sites. Based on the close proximity between Hoga and Sampela sites $(1.5 \mathrm{~km})$ I assume that the levels of larvae being transported away from the reef or coming from other systems (for example, Wanci Island reefs, which are located $10 \mathrm{~km}$ away) are similar. Furthermore, my results are similar to those reported by Nzali et al. (1998) who recorded lower settlement rates at low coral cover sites that had been severely degraded by blast 
fishing, when compared to an unblasted higher coral cover site. However, other authors have not reported such settlement differences between blasted vs. unblasted sites (Fox 2004). Further research is thus needed to determine coral source and sink population dynamics and connectivity patterns among reefs of the Wakatobi in order to further understand settlement patterns.

Another possible explanation for the differences in settlement rates between sites is the higher levels of sedimentation recorded at the Sampela sites. Enhanced levels of sedimentation have severely degraded many reefs around the world (Rogers 1990) and increased sedimentation and eutrophication are known to affect growth and calcification (Tomascik \& Sander 1985); reproduction rates (Tomascik \& Sander 1987b), respiration, feeding and photosynthesis (Fabricius 2005); fecundity (Tomascik \& Sander 1987b); community structure (Tomascik \& Sander 1987a) and settlement processes of scleratinian corals (Hunte \& Wittenberg 1992). The effect of sedimentation varies considerably between coral species, but also between sediment types and environmental conditions (Fabricius 2005). Previous studies by Crabbe and Smith (2005) have revealed reduced coral growth rates of both branching and non-branching corals, and changes in branching morphology at the same study sites that I used. Thus, the lower settlement rates reported at Sampela sites might in part be influenced by the higher sedimentation rates recorded here. Sedimentation and associated turbidity are known to affect planula settlement behaviour through direct physical action in the water column (Tomascik 1991), as well as inhibiting planula settlement (Babcock \& Davies 1991). In this study I found that the majority of the recruits settled to the cryptic (back) side of the panels during both years, which was expected given that previous studies have shown this preference for the 'gap' at the back panel habitats (Harriott \& Fisk 1987). In addition, it might not be possible for 
corals to settle on the front side of panels at the Sampela sites, because of sediment accumulation. On collection, many plates had a layer of sediment deposited on the front side of the panels, and although the vast majority of recruits recruited to the back of the panels, a lower number of recruits was recorded on the front of panels at the Sampela sites compared to Hoga sites, which does suggest some effect of sediment on settlement, although the reverse side of the panels does control for sedimentation, suggesting that the level of live coral cover may better explain the differences in settlement rates between the reef systems.

In addition to the lower levels of spat arriving to Sampela sites and the influence of sedimentation, it is possible that spat settling on Sampela might suffer higher postsettlement mortality rates compared to Hoga. My benthic surveys (Fig. 17) revealed higher levels of coral rubble on Sampela and it has been shown that rubble fields created after chronic blast fishing create environments unsuitable for coral recruit survival, as spat settling onto coral rubble are killed by the continuous shifting of rubble with strong currents (Fox et al. 2003). Coral assemblages at Sampela could therefore be in a negative feedback loop where the higher settler mortality will negatively influence the levels of spat recruiting into the system, which then will reduce the number of larvae produced in the system reaching maturity, further reducing the available spat.

\subsubsection{Inter-annual and seasonal variation}

I reported considerable inter-annual variation in the settlement rates of scleractinian corals. Settlement was two-fold higher during the second year of my study compared to the first year. Such inter-annual variation has been recorded in other studies including a study in the Komodo National Park in Indonesia (Fox et al. 2003) and also in other biogeographic regions, such as the Red Sea (Glassom et al. 
2004) and the GBR, Australia (Harriott \& Banks 1995, Dunstan \& Johnson 1998). This annual variability might be caused by a number of factors, for example, some corals show considerable variation in their reproductive outputs between years. Tissue analysis of adult corals from the GBR in the days prior to a mass spawning event showed that up to $35 \%$ of adult colonies of Acropora cyntherea, a species known to synchronously spawn, did not spawn or contained immature eggs suggesting that colonies of some species might not reproduce every year, or may release gametes over a number of months (Hughes et al. 2000).

The seasonal differences reported in my study are likely to be driven by family level reproductive differences. Broadcasting corals usually exhibit spawning synchrony within populations (Harrison et al. 1984). Richmond \& Hunter 1990 predicted that for equatorial regions, where sea surface temperature variations and tidal amplitude are small, reproductive seasonality and synchrony between species would be reduced. In contrast to this prediction, recent work on coral reefs close to equatorial regions, including Singapore (Guest et al. 2005) and several locations within Eastern Indonesia (Baird et al. 2009), has revealed that multiple species show synchronous spawning or 'mass' coral spawning. From these studies, it is now believed that Acroporid spawning occurs in Indonesia either during the days following the full moon between March and April, and October and November, depending on the species (Baird et al. 2009). For example, 16 Acropora species were reported to spawn during March/April in Manado (north Sulawesi), while in Makassar (south Sulawesi) 18 Acropora species spawned in March-April, and 10 spawned in October-November (Baird et al. 2009). Although I cannot specify when Acroporid spawning exactly occurs in the WMP (given that panels were replaced every four months), my settlement results support a spawning season somewhere 
between November and March. This seasonal peak coincided with the period of warmest sea surface temperature during the northwest Monsoon and my results are similar to those reported by Fox (2004) in Komodo (Central Indonesia). A wide number of factors might influence the timing of reproduction in coral and traditionally, changes in sea surface temperature has been considered a major seasonal cue for reproduction as broadcast spawning often happens as waters are warming or close to the annual maxima (Guest et al. 2008). During this period I also recorded the highest abundance of spat across all families suggesting that there might also be a seasonal reproductive cycle for other coral families. For example, Guest et al. (2005) reported gamete release by species belonging to the families Faviidae, Merulininidae, Oculinidae and Pectiniidae following the full moon in March and April in reefs surrounding Singapore. Further research is needed to determine the spawning periods and extent of spawning synchrony for coral species within the coral triangle region.

\subsubsection{Settlement in the Wakatobi Marine Park}

Comparisons between different coral settlement studies are difficult because of the variability in settlement panel size, method of panel deployment and orientation, time of the year when the panels were deployed and collected, depth where the panels were placed, and the duration of panel deployment (Harriott \& Fisk 1987, Mundy 2000, Field et al. 2007). However, a comparison of my study with other recent settlement studies enables comparisons with other biogeographic regions (see Table 5 for comparison between different studies since 2000). The number of coral spat per plate recorded at sites within the Wakatobi was slightly lower than those recorded in other settlement studies within Indonesia (Manado and Komodo), but much lower compared with those reported at many locations along the central 
GBR (Table 14). It is difficult to interpret these differences in settlement rates because of the above mentioned methodology differences between panel studies. Furthermore, the environmental and biological conditions will vary considerably between study sites, and these are already known to influence coral settlement rates (Glassom et al. 2004). The most important difference between my study and other previous studies is the taxonomic composition of the spat (see Table 14). Studies in the GBR have revealed that the composition of coral settlers is strongly influenced by the time when plates are deployed. Most of the spat recorded on plates deployed during summer within the central GBR belonged to the family Acroporidae (Hughes et al. 2000), while the family Pocilloporidae regularly dominated plates deployed in winter (Harriott \& Fisk 1988). Studies within the Red Sea (Glassom et al. 2004), Kenya (Mangubhai et al. 2007) and South Africa (Glassom et al. 2006) have reported a wide occurrence of Pocilloporid settlers. In my study, the greatest proportion of settlers belonged to the 'other' taxonomic group. It is likely that these differences in my study are driven by the much higher diversity of the adult coral assemblage of the reefs that I sampled.

Identification of juvenile scleractinian corals is difficult given that few scleractinian juveniles have enough skeletal characters to distinguish them from other taxa, and only juveniles form the families Acroporidae, Pocilloporidae and Poritidae can be reliably distinguished (Babcock et al. 2003). A high abundance of corals from the families: Agariciidae, including the genus Pavona and Leptoseris; Faviidae, including the genera Diploastrea, Favia and Favites; and Dendrophylliidae, mainly the genus Tubastrea, were present at my study sites, which may account for a greater proportion of the spat classified as 'others'. This hypothesis is supported by the juvenile distribution data, given that a high proportion 
of the juvenile corals recorded belonged to the families Faviidae and Agariciidae (Fig. 21). 
Table 14 Summary ot coral setlement studies using artificial settlement substrate. Table includes study location, number of sites used, depth at which panesl were deployed, duration panels were placed, method of deployment and number of recruits recorded.

\begin{tabular}{|c|c|c|c|c|c|c|c|}
\hline Author/s & $\begin{array}{l}\text { Study } \\
\text { location }\end{array}$ & $\begin{array}{l}\text { Number } \\
\text { of sites }\end{array}$ & $\begin{array}{l}\text { Depth } \\
\text { (m) }\end{array}$ & $\begin{array}{c}\text { Time } \\
\text { immersed } \\
\text { (months) }\end{array}$ & $\begin{array}{c}\text { Method of } \\
\text { deployment }\end{array}$ & $\begin{array}{l}\text { Material and dimensions } \\
\qquad(\mathrm{mm})\end{array}$ & $\begin{array}{c}\text { Recruits } \\
(\text { per } 100 \mathrm{~cm} 2)^{+}\end{array}$ \\
\hline This study & $\begin{array}{l}\text { Wakatobi, } \\
\text { Indonesia }\end{array}$ & 4 & 6 & $\begin{array}{l}4 \text { monthly }(1 \\
\text { year) } \\
12\end{array}$ & Direct attachment & Terracotta (200x100) & $\begin{array}{l}\text { - } 12 \text { mo: } 0.9-2.09 \\
\text { - (Jul-Nov): } 0.68 \\
\text { - (Nov-Mar): } 2.09 \\
\text { - (Mar-Jul): } 0.35\end{array}$ \\
\hline $\begin{array}{l}\text { Schmidt-Roach et } \\
\text { al. (2008) }\end{array}$ & $\begin{array}{l}\text { Manado. } \\
\text { Indonesia }\end{array}$ & 1 & 8 & 4 & Steel frames & Limestone (150 x 150) & - 2.56 (overall mean) \\
\hline Field et al. (2007) & $\begin{array}{l}\text { Eilat, } \\
\text { Red Sea }\end{array}$ & 1 & 5 & $\begin{array}{l}4 \text { monthly } \\
\text { (for } 1 \text { year) }\end{array}$ & $\begin{array}{l}\text { Direct attachment } \\
\text { Settlement racks }\end{array}$ & $\begin{array}{l}\text { Unglazed Ceramic (100x100) } \\
\text { Brick fired (115x115) }\end{array}$ & $\begin{array}{l}\text { - (Nov-March): 0; (June-Sept): 0.6- } \\
\text { 0.8;(March-July) } \\
\text { - (overall mean): } \\
\text { Ceramic / racks: } 10.3 \\
\text { Ceramic / directly: } 4 \\
\text { Brick / racks: } 4 \\
\text { Brick / directly: } 3.9\end{array}$ \\
\hline $\begin{array}{l}\text { Lopez-Perez et al. } \\
\text { (2007) }\end{array}$ & $\begin{array}{l}\text { Huatulco, } \\
\text { Mexican } \\
\text { Pacific coast }\end{array}$ & 6 & $\begin{array}{l}\text { Not } \\
\text { provided }\end{array}$ & $11-13$ & Metal racks & Terracotta $(280 \times 140)$ & $-0.0085-0.2$ \\
\hline $\begin{array}{l}\text { Mangubhai et al. } \\
\text { (2007) }\end{array}$ & $\begin{array}{l}\text { Kenya, West } \\
\text { Indian }\end{array}$ & 2 & $0-1.5 m$ & $\begin{array}{l}3 \text { monthly } \\
\text { ( } 2 \text { years) }\end{array}$ & Mesh frames & Ceramic (150 x150) & $\begin{array}{l}\text { - } 1.02 \text { - } 8 \text { (yearly mean range) } \\
\text { - } 3.92 \text { - } 32.4 \text { (max mean range) }\end{array}$ \\
\hline $\begin{array}{l}\text { Perkol-Finkel \& } \\
\text { Benayahu (2007) }\end{array}$ & $\begin{array}{l}\text { Eilat, } \\
\text { Red Sea }\end{array}$ & 2 & 14 and 24 & 6,12 and 18 & Metal racks & PVC (115 x 200) & $\begin{array}{l}\text { - 6mo NR: } 0.05-1.3 \\
-12 \text { mo NR: } 0.17-0.78 \\
-18 \text { mo NR: } 0.17-.30 \\
\end{array}$ \\
\hline $\begin{array}{l}\text { Glassom et al. } \\
\text { (2006) }\end{array}$ & $\begin{array}{l}\text { Sodwana Bay, } \\
\text { South Africa }\end{array}$ & 9 & $\begin{array}{l}\text { Not } \\
\text { provided }\end{array}$ & $\begin{array}{l}\text { From } 1 \text { to } 16 \\
\text { (3 years) }\end{array}$ & Metal frames & $\begin{array}{l}\text { Pair Unglazed ceramic }(120 \times 120) \\
\text { Single unglazed ceramic }(120 \quad \text { x } \\
120)\end{array}$ & $\begin{array}{l}\text { - } 0.49 \text { (mean/ year) } \\
\text { - } 1.39 \text { (mean/ 2years) } \\
\text { - } 3.42 \text { Mar (max mean) }\end{array}$ \\
\hline $\begin{array}{l}\text { Nozawa et al. } \\
(2006)\end{array}$ & $\begin{array}{l}\text { Amakusa, } \\
\text { SW Japan }\end{array}$ & 1 & 5 & $\begin{array}{l}3 \\
\text { (3 years) }\end{array}$ & Direct attachment & Not specified (100 x 100) & $-0.01-0.02$ \\
\hline $\begin{array}{l}\text { Shearer and } \\
\text { Coffroth (2006) }\end{array}$ & $\begin{array}{l}\text { Gulf } \\
\text { Mexico }\end{array}$ & 7 & 10 and 24 & $\begin{array}{l}12 \\
\text { (2 years) }\end{array}$ & PVC frames & Unglazed ceramic (150 x150) & $\begin{array}{l}-0.279-6.802 \text { (mean range over two } \\
\text { years) }\end{array}$ \\
\hline
\end{tabular}




\begin{tabular}{|c|c|c|c|c|c|c|c|}
\hline $\begin{array}{l}\text { Abelson et al. } \\
\text { (2005) }\end{array}$ & $\begin{array}{l}\text { Eilat, } \\
\text { Red Sea }\end{array}$ & 5 & 10 and 30 & 5 and 12 & Metal mesh & Ceramic tiles & - 0.35 mean over 3yr \\
\hline Fox et al. (2004) & $\begin{array}{l}\text { Komodo NP, } \\
\text { East Indonesia }\end{array}$ & 15 & $6-10$ & $\begin{array}{l}6 \text { monthly } \\
\text { (3 years) }\end{array}$ & Vertical post & Terracotta $(200 \times 100)$ & $\begin{array}{l}\text { - } 3.09 \text { (overall mean) } \\
\text { - Min 0.0075, max. } 8.625\end{array}$ \\
\hline $\begin{array}{l}\text { Glassom et al., } \\
\text { (2004) }\end{array}$ & $\begin{array}{l}\text { Eilat, } \\
\text { Red Sea }\end{array}$ & 20 & 6 & $\begin{array}{l}3 \text { monthly } \\
\text { (2 years) }\end{array}$ & Metal racks & Unglazed ceramic (100 x 100) & $\begin{array}{l}\text { - Mar: } 0-1.4 \\
\text { - Jun: } 0.1-10 \\
\text { - Sept: } 0.1-1.3 \\
\text { - } 15 \text { months } 0-10\end{array}$ \\
\hline Lam (2003) & $\begin{array}{l}\text { Hong Kong, } \\
\text { Pacific }\end{array}$ & 1 & 7 & $\begin{array}{l}3,6,9,12,14,18,21 \\
, 24\end{array}$ & Blocks & Pulverised fuel ash (150 x 150) & $\begin{array}{l}-0,0,0.2,0.5,0.51,0.63,-0.65 \text {, } \\
0.48 \text { (mean / time submersed) }\end{array}$ \\
\hline Soong et al. (2003) & $\begin{array}{l}\text { Taiwan, } \\
\text { Pacific }\end{array}$ & 8 & 5 & 1,2 & Not provided & $\begin{array}{l}\text { Unglazed terracotta }(150 \times 150) \\
\text { PVC }(150 \times 150) \\
\text { Carbonic plates }(150 \times 150)\end{array}$ & - $0-4.44$ (all materials) \\
\hline $\begin{array}{l}\text { Reyes and Yap. } \\
\text { (2001) }\end{array}$ & $\begin{array}{l}\text { Philippines, } \\
\text { Indo-Pacific }\end{array}$ & 2 & 12 & 5 & Iron frame & $\begin{array}{l}\text { Concrete }(100 \times 100) \\
\text { Rubber }(100 \times 100) \\
\text { Crushed coral rubble }(100 \times 100)\end{array}$ & $\begin{array}{l}-2.2-6.3) \\
-0.2-0.3 \\
-2.4-7.6\end{array}$ \\
\hline $\begin{array}{l}\text { Baird and Hughes } \\
\text { (2000) }\end{array}$ & $\begin{array}{ll}\text { Lizard Is, } \\
\text { GBR }\end{array}$ & 1 & 2 & 2 & $\begin{array}{l}\text { Galvanized wire } \\
\text { racks }\end{array}$ & Clay tiles $(110 \times 110)$ & $\begin{array}{l}\text { - } 1.47 \text { (mean Jan-Mar) } \\
\text { - } 12.76 \text { (mean Nov-Jan) } \\
\text { (under not included) }\end{array}$ \\
\hline
\end{tabular}




\subsubsection{Management implications}

The results from this study are not very encouraging for the future of the Sampela reef sites considering that natural coral replenishment is likely to take a long time given the low settlement rates, the possible higher post-settlement mortality rates and that the reef is already highly degraded. Despite the presence of a management plan coordinated through the National Park authority, with technical support from The Nature Conservancy (TNC) and WWF, which includes a zoning system with no take zones, a great proportion of the park reefs are still subjected to severe anthropogenic disturbance. Low levels of enforcement and lack of community involvement (Clifton 2003) have resulted in a continuous environmental degradation due to a lack of adequate protection (authors unpublished data). A strong future conservation focus is urgently needed in the WMP, including promoting local stakeholder involvement through education and adequate enforcement and major fisheries reforms to reduce overfishing (Clifton 2003, Rice 2009). In addition, total ecosystem protection (e.g., no take areas (NTA)) should be effectively enforced, as they have been widely accepted as one of the most practical and effective methods of conserving reef resources (Lubchenco et al. 2003). For example, a MR in the Bahamas facilitated coral recruitment and hence adult coral recovery, through a reduction on macroalgal cover driven by increased hebivory fish grazing due to reserve protection (Mumby et al. 2007, Mumby \& Harborne 2010). A network of adequately enforced no take areas would facilitate reef conservation and protection priority should be given to reefs on the outer boundaries of the park that have been isolated by distance from destructive practices and overfishing, and still have relatively high conservation status. 


\section{Chapter 7. General discussion}

The chapters of this thesis investigated the levels of population connectivity; larval movement and settlement; and the importance of locally available larvae on larval settlement rates under different scenarios and, overall, they highlight the importance of understanding connectivity patterns for conservation management. The key findings of my thesis are: i) the marine reserves in the Cook strait region are not as connected as was previously assumed (Chapter 3); ii) most long-lived pelagic larvae (8-10 weeks PLD) settle within $5 \mathrm{~km}$ of where they were produced, although some larvae are able to disperse and settle as far as $50 \mathrm{~km}$ (Chapter 4); iii) adult abundance directly influences settlement rates (cChapter 5 and 6).

In this chapter I will discuss how the use of genetic tools to investigate marine population connectivity has evolved over the past 15-20 years and what the results obtained in chapters 2-4 add to this field. I will then discuss what the results obtained in chapters 3-6 add to the current ongoing debate on the levels of connectivity between marine populations and I will comment on their relevance to marine management.

\subsection{Genetic tools to investigate population connectivity: past, present and future}

The past 15-20 years have witnessed shifting paradigms in perceptions on the levels of connectivity between marine populations (see review by Levin 2006). Until recently most marine scientists assumed marine populations were demographically 'open', with marine larvae travelling on the scale of $1000 \mathrm{~km}$ 's, connecting marine

populations separated over large spatial scales (see review by Caley et al. 1996). This view was based on the perception that most marine species produced very abundant, passively dispersed, relatively long-lived pelagic larval that are easily transported by 
oceanic currents and it was supported by the genetic homogeneity over large scales revealed by the use of the early available molecular markers, such as allozymes (Shulman and Birmingham, 1995; Apte and Gardner, 2001). The development of new technological advances like more variable nuclear DNA markers such as microsatellites (e.g. Planes et al. 2009) together with the development of other approaches to measure connectivity such as artificial markers (Jones et al. 1999), natural markers (Swearer et al. 1999) or mathematical models (e.g. Cowen et al. 2006) have revealed that self-recruitment (i.e. proportion of the larvae retained within the parental population or that comes back to the parental population) might be more important than previously thought. A good example on how the technological advances in molecular markers have provided the necessary tools to investigate population connectivity are the studies by Apte and Gardner (2001; 2002) and chapters 2 and 3 of this thesis. Apte and Gardner investigated the genetic structuring of the mussel Perna canaliculus across New Zealand's North and South Islands. First, Apte and Gardner (2001) conducted allozyme analysis in 30 wild and 5 cultured mussel populations throughout New Zealand and they found no evidence of a north-south split or an isolation-by-distance model. The following year Apte and Gardner (2002) conducted Single-strand conformation polymorphism (SSCP) analysis of the NADH IV region of the mitochondrial DNA for 22 populations of $P$. canaliculus from NZ's North, South and Stewart Islands. In this study, Apte and Gardner revealed a strong north-south population genetic structuring pattern and determined that the genetic split occurred south of Cook Strait at $\sim 42^{\circ} \mathrm{S}$ latitude, implying that $P$. canaliculus populations at the north of the South island (above the $\sim 42^{\circ} \mathrm{S}$ latitude) were genetically more similar to those on the North island. In this thesis I have developed highly polymorphic microsatellite loci (Chapter 2) for the 
common intertidal gastropod $A$. cincta to further investigate connectivity patterns in the Cook Strait region. I choose to develop microsatellite markers since they have been proven more adequate to detect differentiation between populations at smaller spatial scales (<100 km); (Hellberg, 2007) and microsatellites have often identified contemporary population structure that has not been revealed by mitochondrial DNA analysis (e.g. Lukoschek et al. 2008). In the population genetics study (Chapter 3), I revealed significant genetic differentiation between $A$. cincta populations across the Cook Strait region, which suggests the presence of barriers to larval dispersal. My research not only supports the results from previous studies that have revealed a north-south split below $42^{\circ}$ S latitude (Apte and Gardner, 2002; Waters and Roy, 2004; Goldstein et al., 2006) but it also reveals the presence of processes restricting gene flow between populations within the Cook strait region that were not detected by previous genetic studies using mtDNA markers.

In Chapter 4 and thanks to the development of the species-specific microsatellite markers (Chapter 2) and the natural features of the study site, I was able use a novel approach to directly measure A. cincta larval movement and settlement from an isolated source. This study provides one of the first direct estimates of how far long-lived pelagic larvae travel and it revealed that larvae are able to travel and settle as far as $50 \mathrm{~km}$ but most larvae settle within $5 \mathrm{~km}$ of the isolated source. Until recently, direct larval movement estimates were based on field observations of larval movements of species with very short (i.e. minutes to hours) PLD (see Shanks et al. 2003 for review). However, the use of tagging studies (e.g. Jones et al. 1999; Almany et al. 2007) or molecular markers (e.g. Plenes et al. 2009; chapter 4) have provided means to directly measure larval movement of species with long-lived planktonic larvae. The results obtained by these studies and from Chapter 
4 further support the hypothesis that larval settlement might be more localised than previously thought.

Since I began my thesis there have been a number of technical developments that have significantly improved the development of microsatellite markers. For example, the introduction of the Roche 454 sequencing technique has allowed the development of these markers much more quickly and cheaply for a wide range of non-target species and together with the development of new statistical approaches (Manel et al. 2003) have resulted in a large increase in the number of studies using microsatellite markers to study connectivity between marine populations.

New genetic approaches, such as assignment methods (Carreras-Carbonell et al., 2007; Underwood et al., 2007) and parentage analysis (Jones et al. 2005; Planes et al. 2009), have provided valuable data on the levels of connectivity between marine populations. However, the newest and more promising molecular technique is the use of Single Nucleotide Polymorphism (SNPs) markers: DNA sequence variations caused when a single nucleotide in the genome varies between individuals. For example Nielsen et al. (2010) used SNPs analysis to investigate evidence for selection on population of the Atlantic cod Gadhus morhua across its northern Atlantic distribution. Nielsen and colleagues revealed that populations are structured on a finer-scale than previously thought and they can follow semi-independent adaptive evolutionary trajectories driven by selection in their local environments. These authors argued that adaptive population divergence seems to be possible and may even be prevalent despite seemingly high levels of gene flow often found in marine fishes. The results from Nielsen et al. have profound implications for the sustainable management of marine fishes and open a new conservation era: managers cannot rely on immigration to rehabilitate declining populations, since non-native 
individuals will have lower fitness and therefore are less likely to be successful in their new environment.

\subsection{Long distance vs. localized dispersal}

It is now evident from a wide range of studies that some larvae travel far less than previously predicted and localised dispersal and 'self-recruitment' are a common feature in many marine populations (Jones et al. 1999; Swearer et al. 1999; Taylor and Hellberg, 2003; Almany et al. 2007; Becker et al. 2007; CarrerasCarbonell et al. 2007; Wood and Gardner, 2007), although high levels of larval dispersal have been observed in many other studies (Ball and Chapman, 2003; Craig et al. 2007). A review of estimated dispersal distances by Kinlan \& Gaines (2003) revealed a wide range (i.e. $\mathrm{m}$ to $1000 \mathrm{~km}$ ) of distances, but with modal distances closer to the tens to hundreds of kilometers range for many fish species, and even less for coastal invertebrates and plants. In chapter 3 I revealed significant genetic differences between populations of a species with a long lived-planktonic larvae (810 weeks) separated by as little as $55 \mathrm{~km}$. Restricted dispersal for this species was supported by the results obtained in Chapter 4 where most of the larvae settled within $5 \mathrm{~km}$, although I recorded larvae travelling as far as $50 \mathrm{~km}$. These results are similar to other studies that have revealed genetic structuring of species with a long-lived planktonic larvae over relatively short distances (Costantini et al. 2007; Bell 2008a, b; Marko et al 2007; Dupont et al. 2007; Gruenthal and Burton, 2008). However, my results contrast with previous studies on the sister species A. antipodium that revealed no genetic structuring within New Zealand using mtDNA markers (Waters et al. 2007) and highlight the advantages of using hyper-variable DNA markers to investigate finer-scale patterns of population differentiation.

Coral reef fish have been shown to be largely self-seeding (Jones et al. 1999; 
Swearer et al. 1999; Taylor and Hellberg, 2003; Jones et al. 2005; Cowen et al. 2006; Almany, 2007; Planes et al. 2009); and settlement studies (Sammarco and Andres, 1988); larval studies (Harii et al. 2002; Miller and Mundy, 2003; and genetic analysis (Ayre et al. 1997; Baums et al. 2005; Maier et al. 2005, 2007; Underwood et al. 2007, 2009) have revealed that scleractinian corals might also display localised recruitment. In addition to this, Hughes et al (2000) revealed that corals exhibit a stock-recruitment relationship, with adult larval production being the major determinant of levels of larval settlement and recruitment. In chapters 5-6 I provide evidence for localised coral larval settlement in an Indonesian coral reef as I revealed that adult coral cover (i.e. number of larva produced locally) has a significant influence on the levels of larvae settling into reefs under different levels of adult coral cover. In these chapters I also provide the first evidence for a seasonal trend in coral larval production and settlement in the Wakatobi National Park, which highlights the need for further research to understand population dyamics in Indonesia's third largest MPA.

\subsection{The importance of connectivity for effective management}

Marine Reserves and networks of Marine Reserves have been widely recognised as a successful tool to protect marine ecosystems under increasing anthropogenic pressures (Halpern and Warner, 2003). However, we have a limited understanding of the patterns of connectivity between marine reserves (Palumbi, 2003). Although there is relatively good information on the level of adult movement in and out of reserves (Halpern and Warner, 2002), little is still known about the levels of larval movement (Levin, 2006). In chapter 4, I provided the first available data on the levels of larval connectivity between marine reserves in central New 
Zealand and I revealed significant genetic differentiation between marine reserve populations, therefore the so-desired marine reserve 'network' might not be achieving its desired goals. Of special consideration is the fact that I used a model species with a very large population size, wide distribution and long-lived PLD (Vander Veur 2010; Chapter 3, 4). It is likely that species with smaller population sizes, more restricted distributions or different life history strategies might show lower levels of connectivity (Bell 2008a). For example, several fish larvae have been shown to display a range of behavioural traits to help them remain close to their parental reef, therefore reducing their dispersal potential (Leis et al. 2007: O’Connor et al. 2007). Chapters 3-4 are also relevant in the context of the ongoing bioregional New Zealand MPA policy and implementation plan that aims to create a MPA network that will complement the existing 33 MRs by protecting other habitats. My results highlight the importance of understanding regional connectivity patterns before reserve designation to ensure MRs in networks are actually connected.

Given the localised dispersal in many marine populations, it is important to ensure management efforts are achieving their goals since the replenishment of a protected area will heavily rely on the reproductive output of the adult population within the reserve and/or nearby reserves. Scleractinian corals have been shown to be largely self seeding Jones et al. 1999; Swearer et al. 1999; Taylor and Hellberg, 2003; Jones et al. 2005; Cowen et al. 2006; Almany, 2007; Planes et al. 2009) and recent molecular evidence suggests that ecologically relevant dispersal is in the scale of $100 \mathrm{~m}$ for brooding species while broadcasters disperse within km to a few tens of km (Underwood et al. 2009). In Chapters 5-6 I provide evidence of how lack of adequate management in a protected area resulted in significant adult coral cover loss at some locations and in turn this adult coral loss had an effect on the levels or larvae 
settling into that reef. These results imply that recovery of these degraded locations are likely to take a very long time and are in concordance with studies that suggested slow population recovery in species with localized dispersal (Marko et al. 2007; Gruenthal and Burton, 2008). Overall, the results obtained in Chapters 3-6 highlight the importance of an adequate understanding on the scales of populations connectivity between marine reserves to ensure their future viability.

\subsection{Concluding remarks}

The field of marine population connectivity has experienced considerable development over the past 15-20 years, although there are still many uncertainties about the levels of larval movement between populations. In this thesis I have provided new molecular tools (Chapter 2) and experimental approaches (Chapter 4) to investigate population connectivity. I have also presented valuable data (Chapter 3-6) with direct implication to marine management which highlights the need for population connectivity studies to ensure marine management efforts achieve their desired goals. 


\section{References}

Abelson A, Olinky R, Gaines S (2005) Coral recruitment to the reefs of Eilat, Red Sea: temporal and spatial variation, and possible effects of anthropogenic disturbances. Marine Pollution Bulletin 50:576-582

Alberto F, Raimondi PT, Reed DC, Coelho NC, Leblois R, Whitmer A, Serrao EA (2010) Habitat continuity and geographic distance predict population genetic differentiation in giant kelp. Ecology 91:49-56

Almany GR, Berumen ML, Thorrold SR, Planes S, Jones GP (2007) Local replenishment of coral reef fish populations in a marine reserve. Science $316: 742-744$

Allison GW, Gaines SD, Lubchenco J, Possingham HP (2003) Ensuring persistence of marine reserves: Catastrophes require adopting an insurance factor. Ecological Applications 13:S8-S24

Allison GW, Lubchenco J, Carr MH (1998) Marine reserves are necessary but not sufficient for marine conservation. Ecological Applications 8:S79-S92

Amar KO, Chadwick NE, Rinkevich B (2007) Coral planulae as dispersion vehicles: biological properties of larvae released early and late in the season. Marine Ecology-Progress Series 350:71-78

Anderson, MJ (2001) Permutation tests for univariate or multivariate analysis of variance and regression. Canadian Journal of Fisheries and Aquatic Sciences 58: 626-639.

Apte S, Gardner JPA (2002) Population genetic subdivision in the New Zealand greenshell mussel (Perna canaliculus) inferred from single-strand conformation polymorphism analysis of mitochondrial DNA. Molecular Ecology 11:1617-1628 
Ayers KL, Waters JM (2005) Marine biogeographic disjunction in central New Zealand. Marine Biology 147:1045-1052

Babcock R, Davies P (1991) Effects of Sedimentation on Settlement of AcroporaMillepora. Coral Reefs 9:205-208

Babcock R, Mundy C (1996) Coral recruitment: Consequences of settlement choice for early growth and survivorship in two scleractinians. Journal of Experimental Marine Biology and Ecology 206:179-201

Babcock RC, Baird AH, Piromvaragorn S, Thomson DP, Willis BL (2003) Identification of scleractinian coral recruits from Indo-Pacific reefs. Zoological Studies 42:211-226

Babcock RC, Kelly S, Shears NT, Walker JW, Willis TJ (1999) Changes in community structure in temperate marine reserves. Marine Ecology-Progress Series 189:125-134

Baird AH, Guest JR, Willis BL (2009) Systematic and Biogeographical Patterns in the Reproductive Biology of Scleractinian Corals. Full Journal Title 40:551571

Baird AH, Hughes TP (2000) Competitive dominance by tabular corals: an experimental analysis of recruitment and survival of understorey assemblages. Journal of Experimental Marine Biology and Ecology 251:117132

Baird AH, Salih A, Trevor-Jones A (2006) Fluorescence census techniques for the early detection of coral recruits. Coral Reefs 25:73-76

Ballantine WJ, Gordon DP (1979) New-Zealands 1st Marine Reserve, Cape Rodney to Okakari Point, Leigh. Biological Conservation 15:273-280 
Ballantine WJ, Langlois TJ (2008) Marine reserves: the need for systems.

Hydrobiologia 606:35-44

Banks SA, Skilleter GA (2010) Implementing marine reserve networks: A comparison of approaches in New South Wales (Australia) and New Zealand. Marine Policy 34:197-207

Barber PH, Moosa MK, Palumbi SR (2002a) Rapid recovery of genetic populations on Krakatau: diversity of stomatopod temporal and spatial scales of marine larval dispersal. Proceedings of the Royal Society of London Series BBiological Sciences 269:1591-1597

Barber PH, Palumbi SR, Erdmann MV, Moosa MK (2000) Biogeography - A marine Wallace's line? Nature 406:692-693

Barber PH, Palumbi SR, Erdmann MV, Moosa MK (2002b) Sharp genetic breaks among populations of Haptosquilla pulchella (Stomatopoda) indicate limits to larval transport: patterns, causes, and consequences. Molecular Ecology 11:659-674

Becker BJ, Levin LA, Fodrie FJ, McMillan PA (2007) Complex larval connectivity patterns among marine invertebrate populations. Proceedings of the National Academy of Sciences of the United States of America 104:3267-3272

Bell JJ (2008a) Connectivity between island Marine Protected Areas and the mainland. Biological Conservation 141:2807-2820

Bell JJ (2008b) Similarity in connectivity patterns for two gastropod species lacking pelagic larvae. Marine Ecology-Progress Series 357:185-194

Bell JJ, Okamura B (2005) Low genetic diversity in a marine nature reserve: reevaluating diversity criteria in reserve design. Proceedings of the Royal Society B-Biological Sciences 272:1067-1074 
Bell JJ, Smith D (2004) Ecology of sponge assemblages (Porifera) in the Wakatobi region, south-east Sulawesi, Indonesia: richness and abundance. Journal of the Marine Biological Association of the United Kingdom 84:581-591

Bellwood DR, Hughes TP, Folke C, Nystrom M (2004) Confronting the coral reef crisis. Nature 429:827-833

Benayahu Y, Loya Y (1985) Settlement and Recruitment of a Soft Coral - Why Is Xenia-Macrospiculata a Successful Colonizer. Bulletin of Marine Science $36: 177-188$

Blanquer A, Uriz MJ (2010) Population genetics at three spatial scales of a rare sponge living in fragmented habitats. Bmc Evolutionary Biology 10

Booth JD, Bradford E, Renwick J (2000) Jasus edwardsii puerulus settlement levels examined in relation to the ocean environment and to subsequent juvenile and recruit abundance

Brownlow RJ, Dawson DA, Horsburgh GJ, Bell JJ, Fish JD (2008) A method for genotype validation and primer assessment in heterozygote-deficient species, as demonstrated in the prosobranch mollusc Hydrobia ulvae. Bmc Genetics 9

Bruno JF, Selig ER (2007) Regional decline of coral cover in the Indo-Pacific: Timing, extent, and subregional comparisons. PLos ONE 2(8)

Burke L, Selig E, Spalding M (2002) Reefs at risk in South East Asia, Vol. World Resources Institute, Washington DC

Butman CA (1987) Larval Settlement of Soft-Sediment Invertebrates - the Spatial Scales of Pattern Explained by Active Habitat Selection and the Emerging Role of Hydrodynamical Processes. Oceanography and Marine Biology 25:113-165 
Caley MJ, Carr MH, Hixon MA, Hughes TP, Jones GP, Menge BA (1996)

Recruitment and the local dynamics of open marine populations. Annual Review of Ecology and Systematics 27:477-500

Carpenter KE, Abrar M, Aeby G, Aronson RB, Banks S, Bruckner A, Chiriboga A, Cortes J, Delbeek JC, DeVantier L, Edgar GJ, Edwards AJ, Fenner D, Guzman HM, Hoeksema BW, Hodgson G, Johan O, Licuanan WY, Livingstone SR, Lovell ER, Moore JA, Obura DO, Ochavillo D, Polidoro BA, Precht WF, Quibilan MC, Reboton C, Richards ZT, Rogers AD, Sanciangco J, Sheppard A, Sheppard C, Smith J, Stuart S, Turak E, Veron JEN, Wallace C, Weil E, Wood E (2008) One-third of reef-building corals face elevated extinction risk from climate change and local impacts. Science 321:560-563

Carpenter RC, Edmunds PJ (2006) Local and regional scale recovery of Diadema promotes recruitment of scleractinian corals. Ecology Letters 9:268-277 Carreras-Carbonell J, Macpherson E, Pascual M (2007) High self-recruitment levels in a Mediterranean littoral fish population revealed by microsatellite markers. Marine Biology 151:719-727

Clifton J (2003) Prospects for co-management in Indonesia's marine protected areas. Mar Policy 27:389-395

Colson I, Hughes RN (2004) Rapid recovery of genetic diversity of dogwhelk (Nucella lapillus L.) populations after local extinction and recolonization contradicts predictions from life-history characteristics. Molecular Ecology $13: 2223-2233$ 
Connell JH, Hughes TP, Wallace CC (1997) A 30-year study of coral abundance, recruitment, and disturbance at several scales in space and time. Ecological Monographs 67:461-488

Couceiro L, Barreiro R, Ruiz JM, Sotka EE (2007) Genetic isolation by distance among populations of the netted dog whelk Nassarius reticulatus (L.) along the European Atlantic coastline. Journal of Heredity 98:603-610

Cowen RK, Lwiza KMM, Sponaugle S, Paris CB, Olson DB (2000) Connectivity of marine populations: Open or closed? Science 287:857-859

Cowen RK, Paris CB, Srinivasan A (2006) Scaling of connectivity in marine populations. Science 311:522-527

Cowen RK, Sponaugle S (2009) Larval Dispersal and Marine Population Connectivity. Annual Review of Marine Science 1:443-466

Crabbe MJC, Smith DJ (2005) Sediment impacts on growth rates of Acropora and Porites corals from fringing reefs of Sulawesi, Indonesia. Coral Reefs 24:437441

Cudney-Bueno R, Lavin MF, Marinone SG, Raimondi PT, Shaw WW (2009) Rapid Effects of Marine Reserves via Larval Dispersal. Plos One 4

Chiswell SM \& Stevens CL (2010) Lagrangian and Eulerian estimates of circulation in the lee of Kapiti Island, New Zealand. Continental Shelf Research 30 (5): $515-532$

Christie MR, Johnson DW, Stallings CD, Hixon MA (2010) Self-recruitment and sweepstakes reproduction amid extensive gene flow in a coral-reef fish. Molecular Ecology 19:1042-1057

Denny CM, Willis TJ, Babcock RC (2004) Rapid recolonisation of snapper Pagrus auratus: Sparidae within an offshore island marine reserve after 
implementation of no-take status. Marine Ecology-Progress Series 272:183190

Dethier MN, McDonald K, Strathmann RR (2003) Colonization and connectivity of habitat patches for coastal marine species distant from source populations. Conservation Biology 17:1024-1035

Doherty PJ, Planes S, Mather P (1995) Gene Flow and Larval Duration in 7 Species of Fish from the Great-Barrier-Reef. Ecology 76:2373-2391

Dunstan PK, Johnson CR (1998) Spatio-temporal variation in cores recruitment at different scales on Heron Reef, southern Great Barrier Reef. Coral Reefs $17: 71-81$

Duran S, Pascual M, Estoup A, Turon X (2004) Strong population structure in the marine sponge Crambe crambe (Poecilosclerida) as revealed by microsatellite markers. Molecular Ecology 13:511-522

Edmunds PJ (2000a) Patterns in the distribution of juvenile corals and coral reef community structure in St. John, US Virgin Islands. Marine EcologyProgress Series 202:113-124

Edmunds PJ (2000b) Recruitment of scleractinians onto the skeletons of corals killed by black band disease. Coral Reefs 19:69-74

English S, Wilkinson C, Baker V (1997) Survey manual for tropical marine resources, Vol. Australian Institute of Marine Science, Townsville

Excoffier L, Lischer HEL (2010) Arlequin suite ver 3.5: a new series of programs to perform population genetics analyses under Linux and Windows. Molecular Ecology Resources 10:564-567

Fabricius KE (2005) Effects of terrestrial runoff on the ecology of corals and coral reefs: review and synthesis. Marine Pollution Bulletin 50:125-146 
Fernandes L, Day J, Lewis A, Slegers S, Kerrigan B, Breen D, Cameron D, Jago B, Hall J, Lowe D, Innes J, Tanzer J, Chadwick V, Thompson L, Gorman K, Simmons M, Barnett B, Sampson K, De'ath G, Mapstone B, Marsh H, Possingham H, Ball I, Ward T, Dobbs K, Aumend J, Slater D, Stapleton K (2005) Establishing representative no-take areas in the Great Barrier Reef: Large-scale implementation of theory on marine protected areas. Conservation Biology 19:1733-1744

Field SN, Glassom D, Bythell J (2007) Effects of artificial settlement plate materials and methods of deployment on the sessile epibenthic community development in a tropical environment. Coral Reefs 26:279-289

Fisk DA, Harriott VJ (1990) Spatial and Temporal Variation in Coral Recruitment on the Great-Barrier-Reef - Implications for Dispersal Hypotheses. Marine Biology 107:485-490

Fox HE (2004) Coral recruitment in blasted and unblasted sites in Indonesia: assessing rehabilitation potential. Marine Ecology-Progress Series 269:131139

Fox HE, Pet JS, Dahuri R, Caldwell RL (2003) Recovery in rubble fields: long-term impacts of blast fishing. Marine Pollution Bulletin 46:1024-1031

Game ET, Watts ME, Wooldridge S, Possingham HP (2008) Planning for persistence in marine reserves: A question of catastrophic importance. Ecological Applications 18:670-680

Gardner JPA, Bell JJ, Constable HB, Ritchie PA, Zuccarello GC (2010) Multispecies coastal marine connectivity: a literature review with recommendations for further research. A report prepared for the NZ Ministries of Fisheries, Vol. Project ZBD2009-10 
Gardner TA, Cote IM, Gill JA, Grant A, Watkinson AR (2003) Long-term regionwide declines in Caribbean corals. Science 301:958-960

Gilg MR, Kirby SE, Sullivan R, Knapp LW, Hilbish TJ (2007) Dispersal vs. retention: correspondence of species-specific reproductive cycles and settlement periods in a blue mussel hybrid zone. Marine Ecology-Progress Series 351:151-161

Gillanders BM, Able KW, Brown JA, Eggleston DB, Sheridan PF (2003) Evidence of connectivity between juvenile and adult habitats for mobile marine fauna: an important component of nurseries. Marine Ecology-Progress Series 247:281-295

Glassom D, Celliers L, Schleyer MH (2006) Coral recruitment patterns at Sodwana Bay, South Africa. Coral Reefs 25:485-492

Glassom D, Chadwick NE (2006) Recruitment, growth and mortality of juvenile corals at Eilat, northern Red Sea. Marine Ecology-Progress Series 318:111122

Glassom D, Zakai D, Chadwick-Furman NE (2004) Coral recruitment: a spatiotemporal analysis along the coastline of Eilat, northern Red Sea. Marine Biology 144:641-651

Goldstien SJ, Schiel DR, Gemmell NJ (2006) Comparative phylogeography of coastal limpets across a marine disjunction in New Zealand. Molecular Ecology 15:3259-3268

Graham EM, Baird AH, Connolly SR (2008) Survival dynamics of scleractinian coral larvae and implications for dispersal. Coral Reefs 27:529-539 
Guest JR, Baird AH, Clifton KE, Heyward AJ (2008) From molecules to moonbeams: Spawning synchrony in coral reef organisms. Invertebrate Reproduction \& Development 51:145-149

Guest JR, Baird AH, Goh BPL, Chou LM (2005) Reproductive seasonality in an equatorial assemblage of scleractinian corals. Coral Reefs 24:112-116

Haapkyla J, Seymour AS, Trebilco J, Smith D (2007) Coral disease prevalence and coral health in the Wakatobi Marine Park, south-east Sulawesi, Indonesia. J Mar Biol Assoc U K 87:403-414

Halpern BS (2003) The impact of marine reserves: Do reserves work and does reserve size matter? Ecological Applications 13:S117-S137

Halpern BS, Warner RR (2002) Marine reserves have rapid and lasting effects. Ecology Letters 5:361-366

Halpern BS, Warner RR (2003) Matching marine reserve design to reserve objectives. Proceedings of the Royal Society of London Series B-Biological Sciences 270: 1871-1878

Harley CDG, Hughes AR, Hultgren KM, Miner BG, Sorte CJB, Thornber CS, Rodriguez LF, Tomanek L, Williams SL (2006) The impacts of climate change in coastal marine systems. Ecology Letters 9:228-241

Harrington L, Fabricius K, De'Ath G, Negri A (2004) Recognition and selection of settlement substrata determine post-settlement survival in corals. Ecology 85:3428-3437

Harriott VJ (1992) Recruitment Patterns of Scleractinian Corals in an Isolated Subtropical Reef System. Coral Reefs 11:215-219 
Harriott VJ, Banks SA (1995) Recruitment of Scleractinian Corals in the SolitaryIslands-Marine-Reserve, a High-Latitude Coral-Dominated Community in Eastern Australia. Marine Ecology-Progress Series 123:155-161

Harriott VJ, Fisk DA (1987) A Comparison of Settlement Plate Types for Experiments on the Recruitment of Scleractinian Corals. Marine EcologyProgress Series 37:201-208

Harriott VJ, Fisk DA (1988) Recruitment Patterns of Scleractinian Corals - a Study of 3 Reefs. Australian Journal of Marine and Freshwater Research 39:409416

Harrison PL, Babcock RC, Bull GD, Oliver JK, Wallace CC, Willis BL (1984) Mass Spawning in Tropical Reef Corals. Science 223:1186-1189

Harrison PL, Wallace CC (1990) Reproduction, dispersal and recruitment of scleractinian corals. In: Dubinsky Z (ed) Ecosystems of the World Coral Reefs. Elseiver, Amsterdam, p 133-207

Heath RA (1974) Physical oceanographic observations in Marlborough Sounds. New Zealand Journal of Marine and Freshwater Research 8:691-708

Hedgecock D (2010) Determining parentage and relatedness from genetic markers sheds light on patterns of marine larval dispersal. Molecular Ecology 19:845847

Hellberg ME (1994) Relationships between Inferred Levels of Gene Flow and Geographic Distance in a Philopatric Coral, Balanophyllia Elegans. Evolution 48:1829-1854

Hellberg ME (2007) Footprints on water: the genetic wake of dispersal among reefs. Coral Reefs 26:463-473 
Hellberg ME, Burton RS, Neigel JE, Palumbi SR (2002) Genetic assessment of connectivity among marine populations. Bulletin of Marine Science 70:273290

Hennige SJ, Smith DJ, Perkins R, Consalvey M, Paterson DM, Suggett DJ (2008) Photoacclimation, growth and distribution of massive coral species in clear and turbid waters. Marine Ecology-Progress Series 369:77-88

Hennige SJ, Smith DJ, Walsh SJ, McGinley MP, Warner ME, Suggett DJ (2010) Acclimation and adaptation of scleractinian coral communities along environmental gradients within an Indonesian reef system. J Exp Mar Biol Ecol 391:143-152

Hoegh-Guldberg O, Mumby PJ, Hooten AJ, Steneck RS, Greenfield P, Gomez E, Harvell CD, Sale PF, Edwards AJ, Caldeira K, Knowlton N, Eakin CM, Iglesias-Prieto R, Muthiga N, Bradbury RH, Dubi A, Hatziolos ME (2007) Coral reefs under rapid climate change and ocean acidification. Science 318:1737-1742

Hughes TP (1994) Catastrophes, Phase-Shifts, and Large-Scale Degradation of a Caribbean Coral-Reef. Science 265:1547-1551

Hughes TP, Baird AH, Bellwood DR, Card M, Connolly SR, Folke C, Grosberg R, Hoegh-Guldberg O, Jackson JBC, Kleypas J, Lough JM, Marshall P, Nystrom M, Palumbi SR, Pandolfi JM, Rosen B, Roughgarden J (2003) Climate change, human impacts, and the resilience of coral reefs. Science 301:929-933

Hughes TP, Baird AH, Dinsdale EA, Moltschaniwskyj NA, Pratchett MS, Tanner JE, Willis BL (2000) Supply-side ecology works both ways: The link between benthic adults, fecundity, and larval recruits. Ecology 81:2241-2249 
Hughes TP, Connell JH (1999) Multiple stressors on coral reefs: A long-term perspective. Limnology and Oceanography 44:932-940

Hunte W, Wittenberg M (1992) Effects of Eutrophication and Sedimentation on Juvenile Corals .2. Settlement. Marine Biology 114:625-631

Johnson MS, Black R (1998) Effects of isolation by distance and geographical discontinuity on genetic subdivision of Littoraria cingulata. Marine Biology 132:295-303

Johnson MS, Black R (2006) Islands increase genetic subdivision and disrupt patterns of connectivity of intertidal snails in a complex archipelago. Evolution 60:2498-2506

Jones GP, Milicich MJ, Emslie MJ, Lunow C (1999) Self-recruitment in a coral reef fish population. Nature 402:802-804

Jones GP, Planes S, Thorrold SR (2005) Coral reef fish larvae settle close to home. Current Biology 15:1314-1318

Karl SA, Avise JC (1992) Balancing Selection at Allozyme Loci in Oysters Implications from Nuclear Rflps. Science 256:100-102

Kelly S, MacDiarmid AB (2003) Movement patterns of mature spiny lobsters, Jasus edwardsii, from a marine reserve. New Zealand Journal of Marine and Freshwater Research 37:149-158

Kelly S, Scott D, MacDiarmid AB, Babcock RC (2000) Spiny lobster, Jasus edwardsii, recovery in New Zealand marine reserves. Biological Conservation 92:359-369

Knowlton N, Keller BD (1986) Larvae which fall far short of their potential - highly localized recruitment in an Alpherid shrimp with extended larval development. Bulletin of Marine Science 39:213-223 
Kyle CJ, Boulding EG (2000) Comparative population genetic structure of marine gastropods (Littorina spp.) with and without pelagic larval dispersal. Marine Biology 137:835-845

Lam KKY (2003) Coral recruitment onto an experimental pulverised fuel ashconcrete artificial reef. Marine Pollution Bulletin 46:642-653

Langlois TJ, Anderson MJ, Babcock RC, Kato S (2006) Marine reserves demonstrate trophic interactions across habitats. Oecologia 147:134-140

Langlois TJ, Ballantine WJ (2005) Marine ecological research in New Zealand: Developing predictive models through the study of no-take marine reserves. Conservation Biology 19:1763-1770

Latch EK, Dharmarajan K, Glaubitz JC, Rhodes OC (2006) Relative performance of Bayesian clustering software for inferring population substructure and individual assignment at low levels of population differentiation. Conservation Genetics 7: 295-302

Leis JM, Wright KJ, and Johnson RN (2007) Behaviour that influences dispersal and connectivity in the small, young larvae of a reef fish. Marine Biology 153: 103-117

Lemer S, Rochel E, Planes S (2011) Correction method for null alleles in species with variable microsatellite flanking regions, a case study of the Black-lipped pearl oyster Pinctada margaritifera. Journal of Heredity 1: 102(2): 243-246

Levin LA (2006) Recent progress in understanding larval dispersal: new directions and digressions. Integrative and Comparative Biology 46:282-297

Lopez-Perez RA, Mora-Perez MG, Leyte-Morales GE (2007) Coral (Anthozoa : Scleractinia) recruitment at Bahias de Huatulco, western Mexico: 
Implications for coral community structure and dynamics. Pacific Science 61:355-369

Lopez-Pinon MJ, Insua A, Mendez J (2002) Identification of four scallop species using PCR and restriction analysis of the ribosomal DNA internal transcribed spacer region. Marine Biotechnology 4:495-502

Lubchenco J, Palumbi SR, Gaines SD, Andelman S (2003) Plugging a hole in the ocean: The emerging science of marine reserves. Ecological Applications 13:S3-S7

Maggio T, Lo Brutto S, Garoia F, Tinti F, Arculeo M (2009) Microsatellite analysis of red mullet Mullus barbatus (Perciformes, Mullidae) reveals the isolation of the Adriatic Basin in the Mediterranean Sea. Ices Journal of Marine Science 66:1883-1891

Maida M, Sammarco PW, Coll JC (1995) Effects of Soft Corals on Scleractinian Coral Recruitment .1. Directional Allelopathy and Inhibition of Settlement. Marine Ecology-Progress Series 121:191-202

Maier E, Tollrian R, Rinkevich B, Nurnberger B (2005) Isolation by distance in the scleractinian coral Seriatopora hystrix from the Red Sea. Marine Biology $147: 1109-1120$

Mangubhai S, Harrison PL, Obura DO (2007) Patterns of coral larval settlement on lagoon reefs in the Mombasa Marine National Park and Reserve, Kenya. Marine Ecology-Progress Series 348:149-159

McClanahan TR, Mangi S (2000) Spillover of exploitable fishes from a marine park and its effect on the adjacent fishery. Ecological Applications 10:1792-1805 McInerney CE, Allcock AL, Johnson MP, Prodohl PA (2009) Characterization of polymorphic microsatellites for the rough periwinkle gastropod, Littorina 
saxatilis (Olivi, 1792) and their cross-amplification in four congeners.

Conservation Genetics 10:1989-1992

McQuaid CD, Phillips TE (2000) Limited wind-driven dispersal of intertidal mussel larvae: in situ evidence from the plankton and the spread of the invasive species Mytilus galloprovincialis in South Africa. Marine Ecology-Progress Series 201:211-220

Mora C (2008) A clear human footprint in the coral reefs of the Caribbean. Proceedings of the Royal Society B-Biological Sciences 275:767-773

Mora C, Sale PF (2002) Are populations of coral reef fish open or closed? Trends in Ecology \& Evolution 17:422-428

Moran AL, Marko PB (2005) A simple technique for physical marking of larvae of marine bivalves. Journal of Shellfish Research 24:567-571

Morgan TS, Rogers AD (2001) Specificity and sensitivity of microsatellite markers for the identification of larvae. Marine Biology 139:967-973

Mumby PJ, Harborne AR (2010) Marine Reserves Enhance the Recovery of Corals on Caribbean Reefs. Plos One 5

Mumby PJ, Harborne AR, Williams J, Kappel CV, Brumbaugh DR, Micheli F, Holmes KE, Dahlgren CP, Paris CB, Blackwell PG (2007) Trophic cascade facilitates coral recruitment in a marine reserve. Proc Natl Acad Sci USA 104:8362-8367

Mundy CN (2000) An appraisal of methods used in coral recruitment studies. Coral Reefs 19:124-131

Mundy CN, Babcock RC (1998) Role of light intensity and spectral quality in coral settlement: Implications for depth-dependent settlement? Journal of Experimental Marine Biology and Ecology 223:235-255 
Nakajima Y, Nishikawa A, Iguchi A, Sakai K (2010) Gene Flow and Genetic Diversity of a Broadcast-Spawning Coral in Northern Peripheral Populations. Plos One 5

Neubert MG, Caswell H (2000) Demography and dispersal: Calculation and sensitivity analysis of invasion speed for structured populations. Ecology $81: 1613-1628$

Nozawa Y, Harrison PL (2007) Effects of elevated temperature on larval settlement and post-settlement survival in scleractinian corals, Acropora solitaryensis and Favites chinensis. Marine Biology 152:1181-1185

Nozawa Y, Tokeshi M, Nojima S (2006) Reproduction and recruitment of scleractinian corals in a high-latitude coral community, Amakusa, southwestern Japan. Marine Biology 149:1047-1058

Nzali LM, Johnstone RW, Mgaya Y (1998) Factors affecting scleractinian coral recruitment on a nearshore reef in Tanzania. Ambio 27:717-722

Olson RR (1985) The Consequences of Short-Distance Larval Dispersal in a Sessile Marine Invertebrate. Ecology 66:30-39

O'Connor MI, Bruno JF, Gaines SD, Halpern BS, Lester SE, Kinlan BP, and Weiss J. M. (2007) Temperature control of larval dispersal and the implications for marine ecology, evolution, and conservation. Proceedings of the National Academy of Sciences of the USA 104: 1266-1271.

Paetkau D, Calvert W, Stirling I, Strobeck C (1995) Microsatellite Analysis of Population-Structure in Canadian Polar Bears. Molecular Ecology 4:347-354 Palumbi SR (2001) The ecology of marine protected areas, Vol. Sinauer, Sunderland, Massachusetts 
Palumbi SR (2003) Population genetics, demographic connectivity, and the design of marine reserves. Ecological Applications 13:S146-S158

Palumbi SR (2004) Marine reserves and ocean neighborhoods: The spatial scale of marine populations and their management. Annual Review of Environment and Resources 29:31-68

Pande A, MacDiarmid AB, Smith PJ, Davidson RJ, Cole RG, Freeman D, Kelly S, Gardner JPA (2008) Marine reserves increase the abundance and size of blue cod and rock lobster. Marine Ecology-Progress Series 366:147-158

Paris CB, Cowen RK (2004) Direct evidence of a biophysical retention mechanism for coral reef fish larvae. Limnology and Oceanography 49:1964-1979

Pelc RA, Baskett ML, Tanci T, Gaines SD, Warner RR (2009) Quantifying larval export from South African marine reserves. Marine Ecology-Progress Series 394:65-78

Perkol-Finkel S, Benayahu Y (2007) Differential recruitment of benthic communities on neighboring artificial and natural reefs. Journal of Experimental Marine Biology and Ecology 340:25-39

Phillips NE, Wood AR, Hamilton JS (2008) Molecular species identification of morphologically similar mussel larvae reveals unexpected discrepancy between relative abundance of adults and settlers. Journal of Experimental Marine Biology and Ecology 362:90-94

Piniak GA, Fogarty ND, Addison CM, Kenworthy WJ (2005) Fluorescence census techniques for coral recruits. Coral Reefs 24:496-500

Planes S, Jones GP, Thorrold SR (2009) Larval dispersal connects fish populations in a network of marine protected areas. Proceedings of the National Academy of Sciences of the United States of America 106:5693-5697 
Potts DC, Done TJ, Isdale PJ, Fisk DA (1985) Dominance of a Coral Community by the Genus Porites (Scleractinia). Marine Ecology-Progress Series 23:79-84

Purcell JFH, Cowen RK, Hughes CR, Williams DA (2006) Weak genetic structure indicates strong dispersal limits: a tale of two coral reef fish. Proceedings of the Royal Society B-Biological Sciences 273:1483-1490

Queller DC, Strassmann JE, Hughes CR (1993) Microsatellites and Kinship. Trends in Ecology \& Evolution 8:285-\&

Reid DG, Williams ST (2004) The subfamily Littorininae (Gastropoda : Littorinidae) in the temperate southern hemisphere: The genera Nodilittorina, Austrolittorina and Afrolittorina. Records of the Australian Museum 56:75122

Reusch TBH (2002) Microsatellites reveal high population connectivity in eelgrass (Zostera marina) in two contrasting coastal areas. Limnology and Oceanography 47:78-85

Reyes MZ, Yap HT (2001) Effect of artificial substratum material and resident adults on coral settlement patterns at Danjugan Island, Philippines. Bulletin of Marine Science 69:559-566

Rice J (2009) Preliminary Report on the Management Implications and Effectiveness of Potential Bylaws in the Kaledupa Fisheries, Wakatobi Marine National Park Indonesia, Operation Wallacea

Richmond RH, Hunter CL (1990) Reproduction and Recruitment of Corals Comparisons among the Caribbean, the Tropical Pacific, and the Red-Sea. Marine Ecology-Progress Series 60:185-203 
Ridgway T, Riginos C, Davis J, Hoegh-Guldberg O (2008) Genetic connectivity patterns of Pocillopora verrucosa in southern African Marine Protected Areas. Marine Ecology-Progress Series 354:161-168

Roberts CM (1997) Connectivity and management of Caribbean coral reefs. Science 278:1454-1457

Roberts CM, Bohnsack JA, Gell F, Hawkins JP, Goodridge R (2001) Effects of marine reserves on adjacent fisheries. Science 294:1920-1923

Rogers CS (1990) Responses of Coral Reefs and Reef Organisms to Sedimentation. Marine Ecology-Progress Series 62:185-202

Rooker JR, Bremer JRA, Block BA, Dewar H, De Metrio G, Corriero A, Kraus RT, Prince ED, Rodriguez-Marin E, Secor DH (2007) Life history and stock structure of Atlantic bluefin tuna (Thunnus thynnus). Reviews in Fisheries Science 15:265-310

Rousset F (2008) GENEPOP ' 007: a complete re-implementation of the GENEPOP software for Windows and Linux. Molecular Ecology Resources 8:103-106

Russ GR, Cheal AJ, Dolman AM, Emslie MJ, Evans RD, Miller I, Sweatman H, Williamson DH (2008) Rapid increase in fish numbers follows creation of world's largest marine reserve network. Current Biology 18:R514-R515

Sala E, Aburto-Oropeza O, Paredes G, Parra I, Barrera JC, Dayton PK (2002) A general model for designing networks of marine reserves. Science 298:19911993

Sammarco PW (1980) Diadema and Its Relationship to Coral Spat Mortality Grazing, Competition, and Biological Disturbance. Journal of Experimental Marine Biology and Ecology 45:245-272 
Sammarco PW, Andrews JC (1988) Localized Dispersal and Recruitment in Great Barrier-Reef Corals - the Helix Experiment. Science 239:1422-1424

Sammarco PW, Andrews JC (1989) The Helix Experiment - Differential Localized Dispersal and Recruitment Patterns in Great Barrier-Reef Corals. Limnology and Oceanography 34:896-912

Schmidt-Roach S, Kunzmann A, Arbizu PM (2008) In situ observation of coral recruitment using fluorescence census techniques. Journal of Experimental Marine Biology and Ecology 367:37-40

Shanks AL, Grantham BA, Carr MH (2003) Propagule dispersal distance and the size and spacing of marine reserves. Ecological Applications 13:S159-S169

Shearer TL, Coffroth MA (2006) Genetic identification of Caribbean scleractinian coral recruits at the Flower Garden Banks and the Florida Keys. Marine Ecology-Progress Series 306:133-142

Shears NT, Babcock RC (2002) Marine reserves demonstrate top-down control of community structure on temperate reefs. Oecologia 132:131-142

Shears NT, Babcock RC (2003) Continuing trophic cascade effects after 25 years of no-take marine reserve protection. Marine Ecology-Progress Series 246:1-16

Shears NT, Smith F, Babcock RC, Duffy CAJ, Villouta E (2008) Evaluation of biogeographic classification schemes for conservation planning: Application to New Zealand's coastal marine environment. Conservation Biology 22:467481

Siegel DA, Kinlan BP, Gaylord B, Gaines SD (2003) Lagrangian descriptions of marine larval dispersion. Marine Ecology-Progress Series 260:83-96 
Smith SR (1992) Patterns of Coral Recruitment and Postsettlement Mortality on Bermudas Reefs - Comparisons to Caribbean and Pacific Reefs. American Zoologist 32:663-673

Sokolov EP (2000) An improved method for DNA isolation from mucopolysaccharide-rich molluscan tissues. Journal of Molluscan Studies $66: 573-575$

Sokolov EP, Sokolova IM, Portner HO (2002) Polymorphic microsatellite DNA markers from the marine gastropod Littorina saxatilis. Molecular Ecology Notes 2:27-29

Soong K, Chen MH, Chen CL, Dai CF, Fan TY, Li JJ, Fan HM (2003) Spatial and temporal variation of coral recruitment in Taiwan. Coral Reefs 22:224-228

Sotka EE, Palumbi SR (2006) The use of genetic clines to estimate dispersal distances of marine larvae. Ecology 87:1094-1103

Sponaugle S, Cowen RK, Shanks A, Morgan SG, Leis JM, Pineda JS, Boehlert GW, Kingsford MJ, Lindeman KC, Grimes C, Munro JL (2002) Predicting selfrecruitment in marine populations: Biophysical correlates and mechanisms. Bulletin of Marine Science 70:341-375

Stanton BR, Goring DG, Bell RG (2001) Observed and modelled tidal currents in the New Zealand region. New Zealand Journal of Marine and Freshwater Research 35:397-415

Swearer SE, Caselle JE, Lea DW, Warner RR (1999) Larval retention and recruitment in an island population of a coral-reef fish. Nature 402:799-802 Swearer SE, Shima JS, Hellberg ME, Thorrold SR, Jones GP, Robertson DR, Morgan SG, Selkoe KA, Ruiz GM, Warner RR (2002) Evidence of self- 
recruitment in demersal marine populations. Bulletin of Marine Science 70:251-271

Taylor MS, Hellberg ME (2003) Genetic evidence for local retention of pelagic larvae in a Caribbean reef fish. Science 299:107-109

Thiel M, Gutow L (2005) The ecology of rafting in the marine environment. II. The rafting organisms and community. In: Oceanography and Marine Biology an Annual Review, Vol 43, Vol 43, p 279-418

Thorrold SR, Jones GP, Hellberg ME, Burton RS, Swearer SE, Neigel JE, Morgan SG, Warner RR (2002) Quantifying larval retention and connectivity in marine populations with artificial and natural markers. Bulletin of Marine Science 70:291-308

Tioho H, Tokeshi M, Nojima S (2001) Experimental analysis of recruitment in a scleractinian coral at high latitude. Marine Ecology-Progress Series 213:7986

Tomascik T (1991) Settlement-Patterns of Caribbean Scleractinian Corals on Artificial Substrata Along a Eutrophication Gradient, Barbados, West-Indies. Marine Ecology-Progress Series 77:261-269

Tomascik T, Sander F (1985) Effects of Eutrophication on Reef-Building Corals .1. Growth-Rate of the Reef-Building Coral Montastrea-Annularis. Marine Biology 87:143-155

Tomascik T, Sander F (1987a) Effects of Eutrophication on Reef-Building Corals .2. Structure of Scleractinian Coral Communities on Fringing Reefs, Barbados, West-Indies. Marine Biology 94:53-75 
Tomascik T, Sander F (1987b) Effects of Eutrophication on Reef-Building Corals .3. Reproduction of the Reef-Building Coral Porites-Porites. Marine Biology $94: 77-94$

Tomascik T, vanWoesik R, Mah AJ (1996) Rapid coral colonization of a recent lava flow following a volcanic eruption, Banda Islands, Indonesia. Coral Reefs $15: 169-175$

Turak E (2003) Coral diversity and distribution in the Wakatobi National Marine Park. Chapter In Rapid Ecological Assessment Wakatobi National Park (PetSoede and Erdmann, 2003) WWF and TNC Joint Publication Underwood JN, Smith LD, Van Oppen MJH, Gilmour JP (2007) Multiple scales of genetic connectivity in a brooding coral on isolated reefs following catastrophic bleaching. Molecular Ecology 16:771-784

Underwood JN, Smith LD, van Oppen MJH, Gilmour JP (2009) Ecologically relevant dispersal of corals on isolated reefs: implications for managing resilience. Ecological Applications 19:18-29

Van Oosterhout C, Hutchinson WF, Wills DPM, Shipley P (2004) MICRO-

CHECKER: software for identifying and correcting genotyping errors in microsatellite data. Molecular Ecology Notes 4:535-538

van Oppen MJH, Lutz A, De'ath G, Peplow L, Kininmonth S (2008) Genetic Traces of Recent Long-Distance Dispersal in a Predominantly Self-Recruiting Coral. Plos One 3

Vander Veur J (2010) The behavior and ecology of Austrolittorina antipodum and Austrolittorina cincta: models for marine reserve connectivity studies. Msc Thesis. Victoria University of Welligton, New Zealand. 
Wagner LD, Ross JV, Possingham HP (2007) Catastrophe management and interreserve distance for marine reserve networks. Ecological Modelling 201:8288

Warner RR, Cowen RK (2002) Local retention of production in marine populations: Evidence, mechanisms, and consequences. Bulletin of Marine Science $70: 245-249$

Waters JM, McCulloch GA, Eason JA (2007) Marine biogeographical structure in two highly dispersive gastropods: implications for trans-Tasman dispersal. Journal of Biogeography 34:678-687

Waters JM, Roy MS (2004) Phylogeography of a high-dispersal New Zealand seastar: does upwelling block gene-flow? Molecular Ecology 13:2797-2806

Weng KC, Boustany AM, Pyle P, Anderson SD, Brown A, Block BA (2007) Migration and habitat of white sharks (Carcharodon carcharias) in the eastern Pacific Ocean. Marine Biology 152:877-894

Willis TJ, Millar RB, Babcock RC (2003) Protection of exploited fish in temperate regions: high density and biomass of snapper Pagrus auratus (Sparidae) in northern New Zealand marine reserves. Journal of Applied Ecology 40:214227

Winnepenninckx B, Backeljau T (1998) Isolation and characterization of microsatellite markers in the periwinkle Littorina striata King \& Broderip, 1832 (Mollusca, Gastropoda, Prosobranchia). Molecular Ecology 7:12531254

Wood AR, Gardner JPA (2007) Small spatial scale population genetic structure in two limpet species endemic to the Kermadec Islands, New Zealand. Marine Ecology-Progress Series 349:159-170 
Zhan AB, Hu JJ, Hu XL, Lu W, Wang ML, Peng W, Hui M, Bao ZM (2008) Fast identification of scallop adductor muscles using species-specific microsatellite markers. European Food Research and Technology 227:353359

Zouros E, Foltz DW (1984) Possible Explanations of Heterozygote Deficiency in Bivalve Mollusks. Malacologia 25:583-591 